\title{
ESTUdO TOPOGRÁFICO DA DOR DE ORIGEM DENTÁRIA
}

Tese apresentada ao Programa de Pósgraduação do Departamento de Fisiologia e Biofísica do Instituto de Ciências Biomédicas da Universidade de São Paulo, para obtenção do Título de Doutor em Ciências. 


\section{ESTUDO TOPOGRÁFICO DA DOR DE ORIGEM DENTÁRIA}

Tese apresentada ao Programa de Pósgraduação do Departamento de Fisiologia e Biofísica do Instituto de Ciências Biomédicas da Universidade de São Paulo, para obtenção do Título de Doutor em Ciências.

Área de Concentração: Fisiologia Humana

Orientador: Prof. Dr. Marcus Vinícius Chrysóstomo Baldo

São Paulo

2010 
São Paulo, 03 de junho de 2004

\section{PARECER 585/CEP}

Prezada Senhora,

Atendendo sua solicitação, a Comissão de Ética em Pesquisas com Seres Humanos do ICB, em sua Quadragésima sexta reunião, realizada no dia 02-junho-04, analisou o projeto de sua responsabilidade intitulado: "Estudo topográfico da dor de origem dentária"

Informo que, após análise do projeto, esta comissão resolveu acatar o parecer favorável do Comitê de Ética em Pesquisa da Faculdade de Odontologia, a qual sugere que deixe mais claro no material e métodos o número de sujeitos que estarăo envolvidos na pesquisa.

Esclareço a V.Sa. que dentro de 12 meses, relatório do referido projeto deverá ser encaminhado à Secretaria deste CEP.

Atenciosamente,

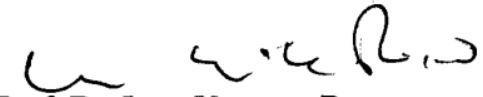

Prof. Dr. LUIZ VICENTE. RIZZO

Coordenador da Comissão de Ética em

Pesquisas com Seres Humanos - ICB /USP

Ilma. Sra.

Milene CaMargo Regatão

Departamento de Fisiologia \& Biofisica

Instituto de Ciências Biomédicas da USP

Comissăo de Ética em Pesquisa com Seres Humanos do Instituto de Clencias Blomédicas / USP Aprovada pela Comissåo Nacional de Ética em Pesquisa - CONEP, em 10 de fevereiro de 1998. 
Aos meus queridos pais, pelo incentivo e apoio durante toda a minha jornada até aqui. Vocês são meus eternos e verdadeiros mestres por toda minha vida.

\begin{abstract}
A minhas queridas irmãs, amigas eternas, que me acompanharam e motivaram, nas conversas de curtas e longas distâncias, em mais uma etapa vencida.
\end{abstract}

Ao querido Cyrille, sempre ao meu lado nos momentos mais difíceis e importantes do meu doutorado, me assistindo com muito carinho, amor e paciência. 


\section{Agradecimentos}

Primeiramente gostaria de agradecer ao meu orientador e amigo Prof. Dr. Marcus Vinícius C. Baldo. Pela coragem e disposição de percorrer novos caminhos no mundo da pesquisa comigo. Obrigada por sua acolhida, paciência, dedicação e amizade. Você contribuiu muito com minha formação. Do pouco que sei, devo muito a você!

Ao querido "tio" José Roque Aguilar in memorian, por acreditar e confiar em mim e por todo apoio que me deu. Seus ensinamentos profissionais e humanos serão sempre uma referência para mim.

Ao Prof. Celso Luis Caldeira que iniciou este trabalho comigo ainda na graduação, fazendo despertar um grande interesse sobre o tema, e por toda a contribuição a minha pesquisa.

A todas as professoras, principalmente a Prof. Dra. Maria Aparecida Borsatti, e funcionárias do Serviço de Urgência da Faculdade de Odontologia da USP, pela oportunidade de desenvolver meu projeto de pesquisa neste Serviço e por serem sempre atenciosas e prestativas durante minha coleta de dados.

Ao Prof. Dr. Peter Claessens, pelo imprescindível auxílio estatístico, sempre com muita dedicação, paciência e boa vontade.

Aos meus grandes amigos do laboratório: Carol, André, Hamilton, Amanda, Kelly, Léo e Camila, pela pronta ajuda no que fosse necessário, pelos enriquecedores papos na hora do café ou as longas discussões nas mesas dos bares... Sem vocês esses anos não seriam tão especiais.

Aos meus familiares e amigos: Mauro, Eduardo, tio Fernando (in memorian) tio João, tia Angela, Stefania, Janaína, Bianchi, Claudia, Joe, Eunice, Emily, Daniela, Filippo, Manuel, Michèle, Michel, Florence e Bruno, eternos incentivadores, com os quais puder compartilhar um pouco da minha jornada. Em especial, agradeço minha amiga Prof. Dra. Andreia Traina, pelo companheirismo e amizade de todos os momentos. 
A todos os voluntários, amigos e desconhecidos, que se propuseram a participar da minha pesquisa. Sem vocês nada disso seria possível.

Aos sempre atenciosos funcionários do ICB.

Ao importante apoio financeiro da CAPES e CNPq. 
"La peau humaine separe le monde em deux espaces. Côté couleur, côté douleur." Paul Valéry 


\section{REGATÃO, M.C. Estudo Topográfico da Dor Referida de Origem Dentária. 2010. 116 p. [Tese] São Paulo: Instituto de Ciências Biomédicas da Universidade de São Paulo, 2010.}

A dor é um fenômeno complexo, resultado de um processamento elaborado da estimulação nociceptiva e que possui um componente afetivo-comportamental, podendo ser modulada por vários fatores. Ela ainda possui, como outras modalidades sensoriais, um conjunto de características tais como: duração, localização, intensidade. Um aspecto particularmente associado à localização da dor se denomina dor referida, e refere-se à sensação de dor que não está localizada na região da injúria, mas em outra área adjacente ou distante. A maioria dos pacientes que têm alguma alteração de origem dentária pulpar ou periapical tem dor referida, e algumas das características da dor parecem influenciar este fenômeno. Por meio do preenchimento de fichas clínicas, contendo informações sobre as características da sensibilidade dolorosa e de outras submodalidades somestésicas, investigamos, em 60 voluntários humanos, a distribuição topográfica de áreas de dor referida de origem dentária na região de cabeça e pescoço. Por meio de métodos psicofísicos, também comparamos a resolução espacial da dor com a resolução espacial de outras modalidades somestésicas (mecânica e térmica). Nossos resultados indicam que a intensidade da dor favorece o aparecimento do fenômeno da dor referida dental e ainda interfere na sua dispersão topográfica. A duração contínua da dor favorece a intensificação da mesma, podendo assim amplificar a área dolorosa. Dentes algógenos com polpa viva influenciam um maior espalhamento da dor, quando comparada com o diagnóstico de polpa mortificada, pelo fato de apresentarem maior vascularização, densidade de nociceptores e maior concentração de mediadores químicos. Estes fatos podem ser explicados por mecanismos básicos de integração neuronal, como a somação temporal, que por sua vez, tenderia a aumentar o número áreas de dor referida e sua dispersão sobre os diversos ramos trigeminais. A localização do dente algógeno não interfere no aparecimento e dispersão da dor referida. Além disso, observamos que a resolução espacial na localização da estimulação dolorosa é maior que a resolução espacial da localização de outros estímulos somestésicos nos elementos dentários.

Palavra chave: dor, diagnóstico, dor dental referida, sistema trigeminal. 


\section{Regatão, M.C. Study of Referred Pain of Dental Origin. São Paulo.}

Instituto de Ciências Biomédicas da Universidade de São Paulo, 2010.

The majority of patients who suffer from toothache report referred pain to other sites in the head and neck. Thus, the aim of this study was to investigate the clinical and psychophysical characteristics of referred pain in the orofacial region and how factors such as intensity, duration and nature of odontogenic pain might modulate them. We employed psychophysical and clinical methods to correlate pain perception with the anatomy and physiology of the trigeminal system. Sixty patients reporting primary toothache were investigated as to the clinical and psychophysical aspects of their pain's symptoms and signals (intensity, duration, location and state of the pulp inflammatory process). Pain intensity and state of irreversible pulp inflammation were found to significantly affect facilitate the incidence of referred pain and its spread across vertical laminations. Considering these results, we proposed a physiological model based on both neuronal integration (spatial and temporal summation) and the topographic organization of the trigeminal system, which is able to explain the observed characteristics of referred dental pain.

Key words: Pain. Endodontic diagnostic. Toothache. Referred pain. Trigeminal system. 


\section{Sumário}

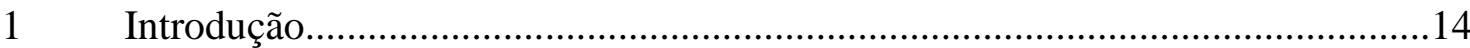

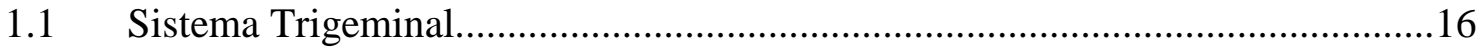

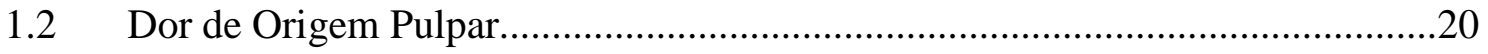

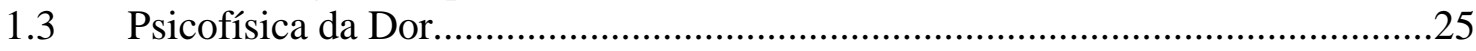

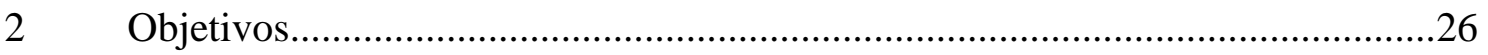

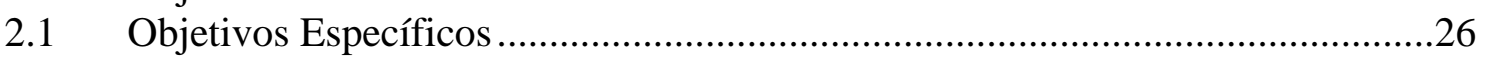

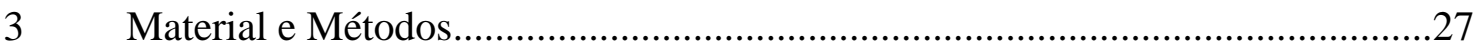

3.1 Resolução Espacial Mecânica e Térmica............................................................28

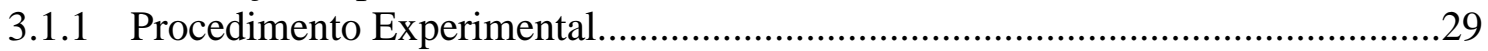

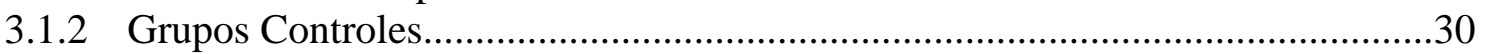

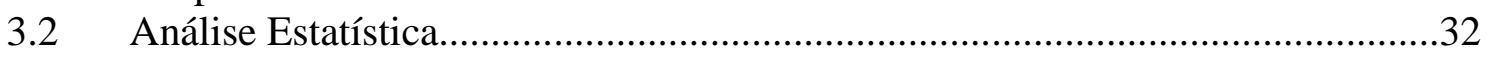

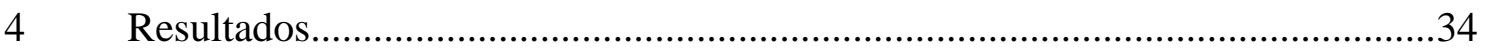

4.1 Mensuração da Dor: Comparação das Escalas de Dor.............................................36

4.2 Distribuição Topográfica da Dor Referida..............................................................37

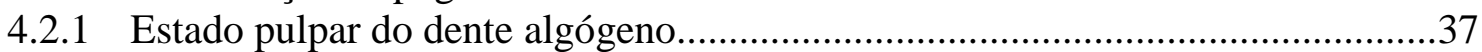

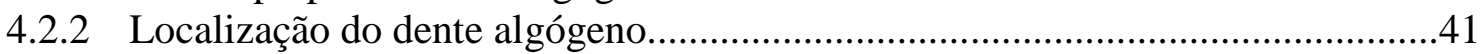

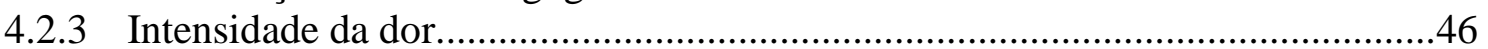

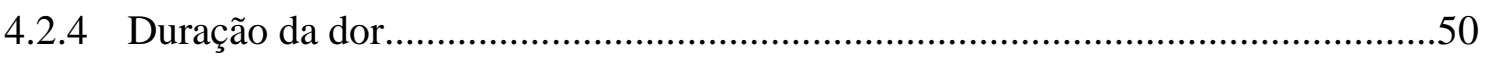

4.2.5 Padrão de Dispersão da Dor Referida...................................................................53

4.3 Inter-relações das Características Fisiopatológicas do Dente Algógeno...............59

4.3.1 Estado pulpar vs Intensidade da dor................................................................6

4.3.2 Estado pulpar vs Duração da dor.......................................................................61

4.3.3 Localização do dente algógeno vs Intensidade da dor.........................................62

4.3.4 Localização do dente algógeno vs Duração da dor ……………………………....64

4.3.5 Intensidade da dor vs Duração da dor..............................................................65

4.4 Resolução Espacial de Estímulos Somestésicos....................................................66

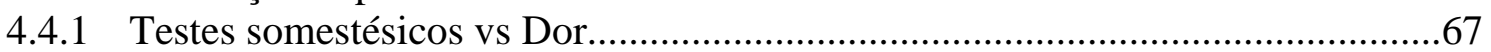

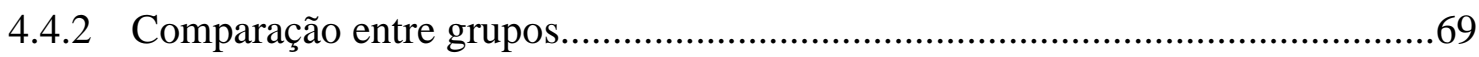

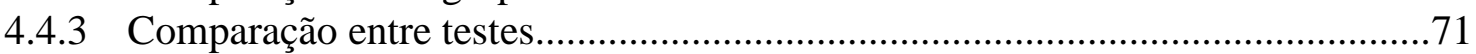

4.4.4 Comparação entre grupos dentais.....................................................................72

4.4.5 Dispersão dos erros cometidos nos testes somestésicos.........................................74

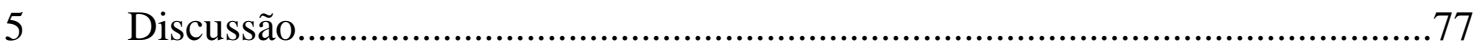

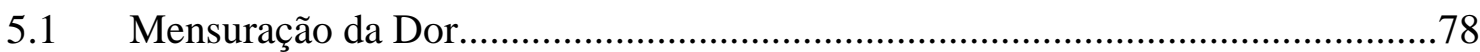

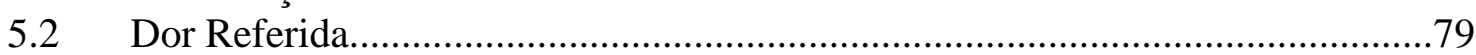

5.3 Resolução Espacial de Estímulos Somestésicos..................................................86

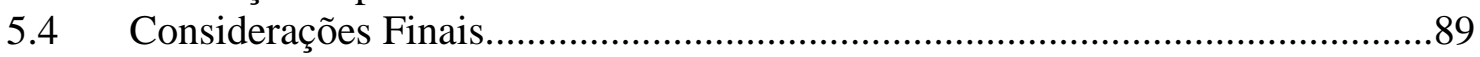

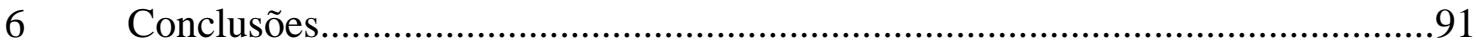

6.1 Mensuração da Dor.......................................................................................

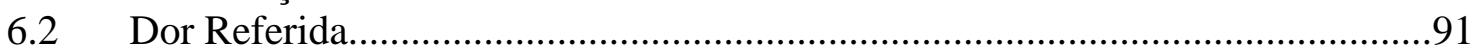

6.3 Resolução Espacial de Estímulos Somestésicos....................................................92

Referências Bibliográficas...........................................................................................93

ANEXO 


\section{Introdução}

A dor foi tratada de diferentes formas desde os séculos passados. O significado da dor era freqüentemente associado às emoções, e palavras como tristeza, angústia, sofrimento eram usadas como sinônimos de dor (OKESON, 2006). É uma experiência individual de todos os povos em todos os tempos, mas que não ocupa um lugar idêntico nas diferentes sociedades e épocas. Exceto por suas particularidades anatômicas e fisiológicas, a dor parece ser uma reconstrução cultural e social (REY, 2000).

Atualmente, a dor é definida como "uma experiência sensorial e emocional desagradável, associada com um dano tecidual potencial ou real, ou descrita em termos de lesões teciduais" (MERSKEY e BOGDUK, 1994). É um fenômeno complexo, resultado de um processamento elaborado da estimulação nociceptiva e que possui um componente afetivo-comportamental, podendo ser modulado por vários fatores, como por exemplo, as experiências anteriores do indivíduo e seu estado emocional (GRAFF-RADFORD, 2003). É um sintoma da existência de anormalidade significando certo benefício em favor da conservação do próprio organismo (LE BRETTON, 2006).

A dor é a primeira razão das consultas médicas. Diariamente, pacientes buscam cuidados para a redução ou eliminação da dor em serviços de saúde no mundo todo (TORTAMANO et al., 2007; LE BRETTON, 2006; HARGREAVES e SELTZER, 2002; BELL,1991). Uma das fases mais importantes de qualquer tratamento é o diagnóstico e a dor é um instrumento a serviço do diagnóstico, dando ao profissional a oportunidade de descobrir qual a harmonia perdida. (INGLE et al, 1979a). O diagnóstico é a arte de identificar os sinais e sintomas no contexto de cada caso clínico usando conhecimento científico para determinar e eliminar a causa do problema, não confundindo as diferentes patologias que podem se assemelhar clinicamente. Para isso, é necessário o uso de uma semiotécnica bem elaborada e o conhecimento da fisiologia da dor para alcançar o diagnóstico correto (ABD-ELMEGUID e YU, 2009; INGLE et al, 1979b).

"Infeliz do dentista que trilha sua carreira profissional com uma importuna incerteza sobre os problemas mais fáceis da dor" (INGLE et al, 1979b). O diagnóstico dental ainda não possui muitos recursos tecnológicos avançados, contando com a capacidade individual e com experiências pessoais do profissional que o realiza. Muitos problemas de diagnóstico 
esgotarão a paciência e testarão a habilidade profissional mais sofisticada. Só um profissional bem treinado terá sucesso completo no diagnóstico dos casos mais difíceis (CHAMBERS, 1982).

A dor possui uma série de características tais como: tipo da dor, localização, intensidade, início e evolução temporal, fatores de melhora e piora, e estas informações sobre a dor darão subsídios para o diagnóstico e posterior tratamento da queixa dolorosa. Um aspecto particularmente associado à localização da dor se denomina dor referida. Este termo, primeiramente descrito por Martyn em 1864, refere-se à sensação de dor que não está localizada na região da injúria, mas em outra área adjacente ou distante.

O mecanismo de dor referida pode ser explicado por uma ampla ramificação axonal inervando diferentes estruturas e a grande convergência dos aferentes primários sensoriais da cabeça e pescoço para neurônios de projeção (HARGREAVES, 2002). Por exemplo, um único neurônio de projeção no subnúcleo caudal recebe informações sensoriais advindas de diversas polpas dentárias, da córnea, e da pele (SESSLE, 1987), e quando há aumento na frequiência de disparos ocasionados pela dor, gera uma maior dificuldade para o sistema nervoso central localizar um determinado estímulo.

A dor somática profunda e a dor facial caracterizam-se por serem difusas e de localização pobre, propiciando o fenômeno da dor referida (SESSLE, 1987; BELL, 1991). Utilizaremos aqui a denominação usual dos trabalhos científicos desta área que empregam o termo dor referida para toda dor que é sentida em outro local, próximo ou distante, do foco doloroso. Dentro desta complexidade, o estudo da dor (seus mecanismos e características) e o conhecimento dos critérios de diagnóstico diferencial das odontalgias contribuirão para o diagnóstico preciso e posterior sucesso do tratamento dentário, visto que de seu conhecimento e determinação depende toda a terapia dentária a ser instituída. Neste contexto, o estudo do sistema trigeminal é essencial para compreensão do mecanismo de dor orofacial. 


\subsection{Sistema Trigeminal}

O nervo trigêmeo, $\mathrm{V}$ par craniano, é responsável pela condução da maior parte das informações somestésicas da face, conjuntiva ocular e dura-máter, cavidade oral (mucosa oral, polpa dentária, periodonto, gengiva circundante, dois terços anteriores da língua) além da inervação motora de musculatura mastigatória (WAITE,2004). Ele está dividido em três ramos: oftálmico, maxilar e mandibular (Figura 1).

Os corpos celulares da maioria das fibras trigeminais sensitivas encontram-se em um gânglio, localizado em uma depressão do crânio, ventralmente à ponte, e denominado gânglio trigeminal, semilunar, ou de Gasser. Como exceção importante, os neurônios trigeminais que conduzem informação proprioceptiva estão localizados no sistema nervoso central (SNC), constituindo um núcleo denominado núcleo mesencefálico do trigêmeo. $\mathrm{O}$ complexo trigeminal é composto por quatro núcleos: o principal, mesencefálico e espinal que são responsáveis pelo processamento de informações somestésicas e proprioceptivas, enquanto o núcleo motor do trigêmeo é responsável pela inervação motora da musculatura mastigatória. (WAITE,2004; USUNOFF, MARANI, e SCHOEN, 1997; BRODAL, 1981).

$\mathrm{O}$ núcleo principal do trigêmeo recebe projeções de mecanoceptores da face e cavidade oral, sendo considerado o análogo trigeminal dos núcleos da coluna dorsal. Essas projeções conduzem informações tácteis epicríticas da face ao núcleo principal ipsilateral, dando origem também a uma ramificação descendente que alcança o núcleo espinal do trigêmeo ipsilateral, mas com uma projeção para o núcleo espinal trigeminal contralateral (USUNOFF, MARANI e SCHOEN, 1997). Esta projeção conduz a sensibilidade térmica e dolorosa. O núcleo espinal recebe ainda projeções de outros nervos cranianos (glossofaríngeo, vago) também responsáveis pela inervação da face, dos nervos cervicais superiores, além de fibras corticais inibitórias e excitatórias (SI e SII, córtex frontal e parietal, principalmente). A divisão caudal deste núcleo apresenta uma organização laminar similar ao corno dorsal da medula espinal. Os aferentes primários mecanorreceptivos de limiar baixo terminam nas laminas III e IV e em regiões mais rostrais deste núcleo; já os aferentes primários nociceptivos terminam principalmente na lamina I, II e V, onde estão concentrados os neurônios de amplitude dinâmica ampla e neurônios nociceptivos específicos (WAITE, 2004; SESSLE, 2003; USUNOFF, MARANI, e SCHOEN, 1997). No entanto, recentes pesquisas indicam que também existem grupos de neurônios nociceptivos 
também na divisão oral do núcleo espinal do trigêmeo (WODA, 2003; CHIANG et al., 2002).

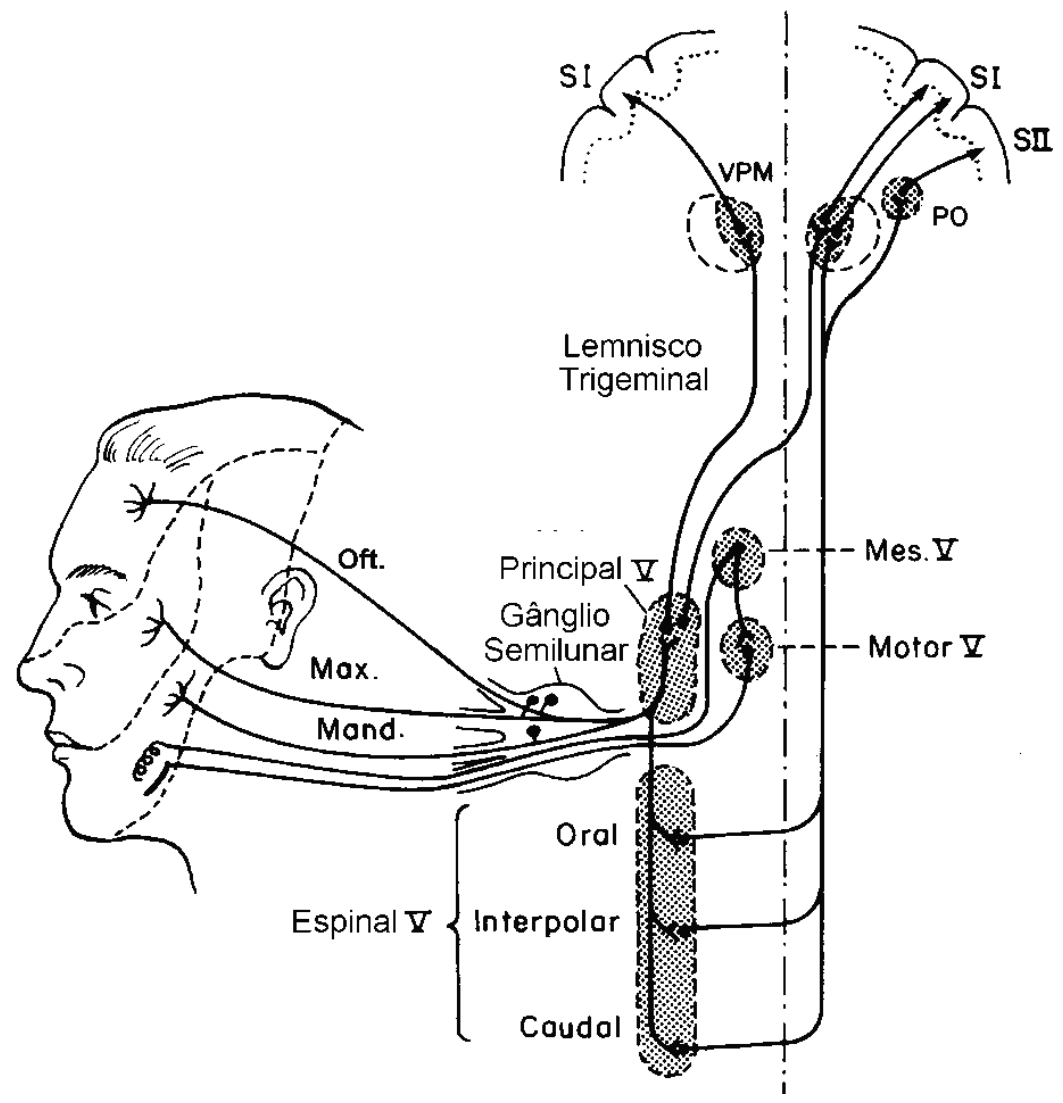

Figura 1: Organização do sistema trigeminal. Os ramos trigeminais: oftálmico (Oft.), maxilar (Max.) e mandibular (Mad.). Os quatro núcleos do nervo trigêmio: principal, espinal, mesencefálico e motor. PO: núcleos posteriores do tálamo. VPM: núcleo ventro-póstero-medial do tálamo. Áreas somatossensoriais primárias (SI), secundárias (SII) do córtex cerebral.

Estudos anatômicos (WAITE, 2004; USUNOFF, MARANI, e SCHOEN, 1997; SHIGENAGA et al., 1986a; BRODAL, 1981) indicam a existência de um padrão conhecido como "casca de cebola" indicando que axônios que inervam a região facial próxima à linha média (região perioral) fazem sinapses rostralmente no núcleo caudal do trigêmeo, enquanto axônios que inervam regiões sucessivamente posteriores, fariam sinapses primárias consecutivamente nas partes mais caudais deste núcleo. Portanto, as áreas de referência de dor se distribuiriam de acordo com o arranjo das fibras aferentes no núcleo espinal do trigêmeo, porção caudal (Figura 2B) e não de acordo com a inervação dos 
diferentes ramos trigeminais (Figura 2A). Entretanto, clinicamente, observa-se extensa superposição destas áreas (FALACE et al., 1996; BRODAL, 1981; INGLE, 1979b).

$\mathbf{A}$

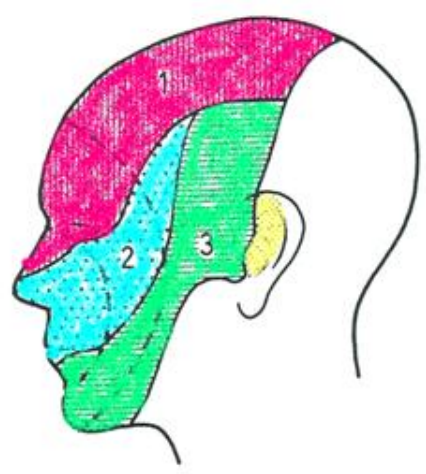

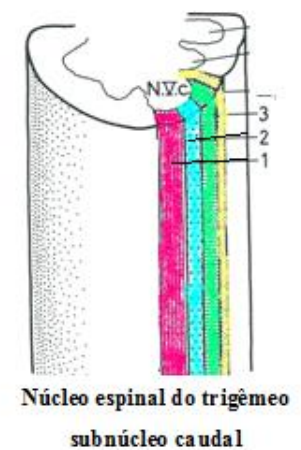

B

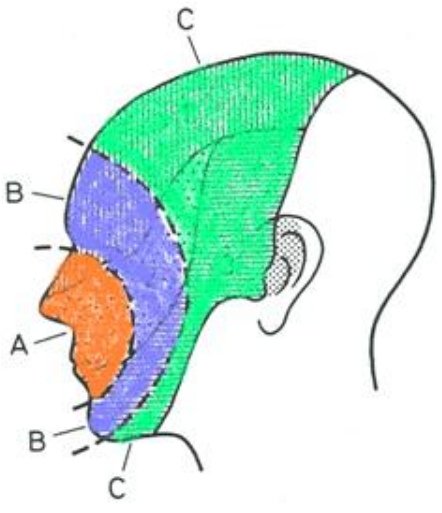

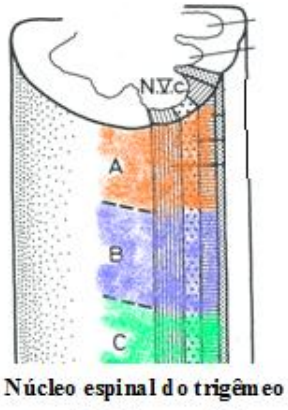

sub nú cleo caudal

Figura 2: Organização Hodológica do Núcleo Espinal do Trigêmeo, porção caudal (em "casca de cebola) A- Representação das áreas inervadas pelos ramos trigeminais e sua organização topográfica no núcleo espinal do trigêmeo, sendo 1: ramo oftálmico; 2: ramo maxilar; 3: ramo mandibular. B- Axônios que inervam a região facial próxima à linha média fazem sinapses rostralmente no núcleo espinal do trigêmeo, enquanto axônios que inervam regiões sucessivamente posteriores, fazem sinapses consecutivamente nas partes mais caudais deste núcleo.

Dos núcleos trigeminais parte da informação sensorial alcança o tálamo por meio do lemnisco trigeminal, projetando-se ao núcleo ventro-póstero-medial e núcleos talâmicos posteriores. As projeções talâmicas são retransmitidas ao córtex somatossensorial (KANDEL et al, 2000; PARENT, 1996) (Figura 1), e estão envolvidas nas respostas perceptivas, cognitivas e emocionais dos estímulos orofaciais. Existem, porém, projeções para outras regiões, como cerebelo, substância cinzenta periaquedutal, formação reticular do tronco cerebral, subnúcleo oral, onde parte da informação será retransmitida para centros cerebrais superiores e a outra parte participará da modulação da transmissão somatossensorial (SESSLE, 2003).

As informações proprioceptivas que partem da musculatura mastigatória, e as mecanoceptivas originadas no periodonto, projetam-se ao núcleo mesencefálico do trigêmeo. No periodonto podemos encontrar fibras mielínicas de maior calibre, que estão relacionadas à sensação de tato e pressão, e fibras mielínicas finas e amielínicas, que estão relacionadas à dor (LINDEN, 1990). Metade dos mecanorreceptores periodontais inerva 
mais de um dente, porém um dos dentes que ela inerva ativa-a preferencialmente. Além disto, os mecanorreceptores periodontais parecem responder melhor à estimulação em uma determinada direção. A distribuição destes receptores nos elementos dentários não é equânime: os dentes anteriores, superiores e inferiores recebem uma maior inervação que os dentes posteriores (TRULSSON, 2006).

Essas fibras aferentes primárias projetam-se ao núcleo motor do trigêmeo estabelecendo uma via que permite a realização de um reflexo monosináptico similar ao reflexo de estiramento (SESSLE, 2006). Esse reflexo trigeminal constitui-se na contração da musculatura elevadora da mandíbula em resposta à pressão nos dentes mandibulares ou abaixamento da mandíbula. As fibras proprioceptivas que inervam os processos alveolares e periodonto também participam do controle da força de mordida (TRULSSON, 2006; LINDEN, 1990). Quando um indivíduo perde todos ou a maior parte dos seus dentes, ele perde capacidade de percepção do meio bucal em aproximadamente 30\% (JACOBS, VAN STEENBERGHE, e BOU SERHAL, 1997). A cavidade oral é densamente inervada, com aferentes sensoriais responsáveis pela gustação e também somestesia, como nociceptores, receptores térmicos, corpúsculos de Meissner, Ruffini e disco de Merkel (JACOBS et al., 2002). A informação veiculada por estes receptores chega ao tálamo e daí segue para o córtex somestésico primário, onde regiões que são mais inervadas estão melhor representadas no mapa somatotópico (Figura 3). Podemos observar como a face, cavidade oral e os dentes estão representados no mapa somatotópico indicando o importante refinamento sensorial destas regiões (MIYAMOTO et al., 2006; JACOBS, et al., 2002; DASILVA et al., 2002). 


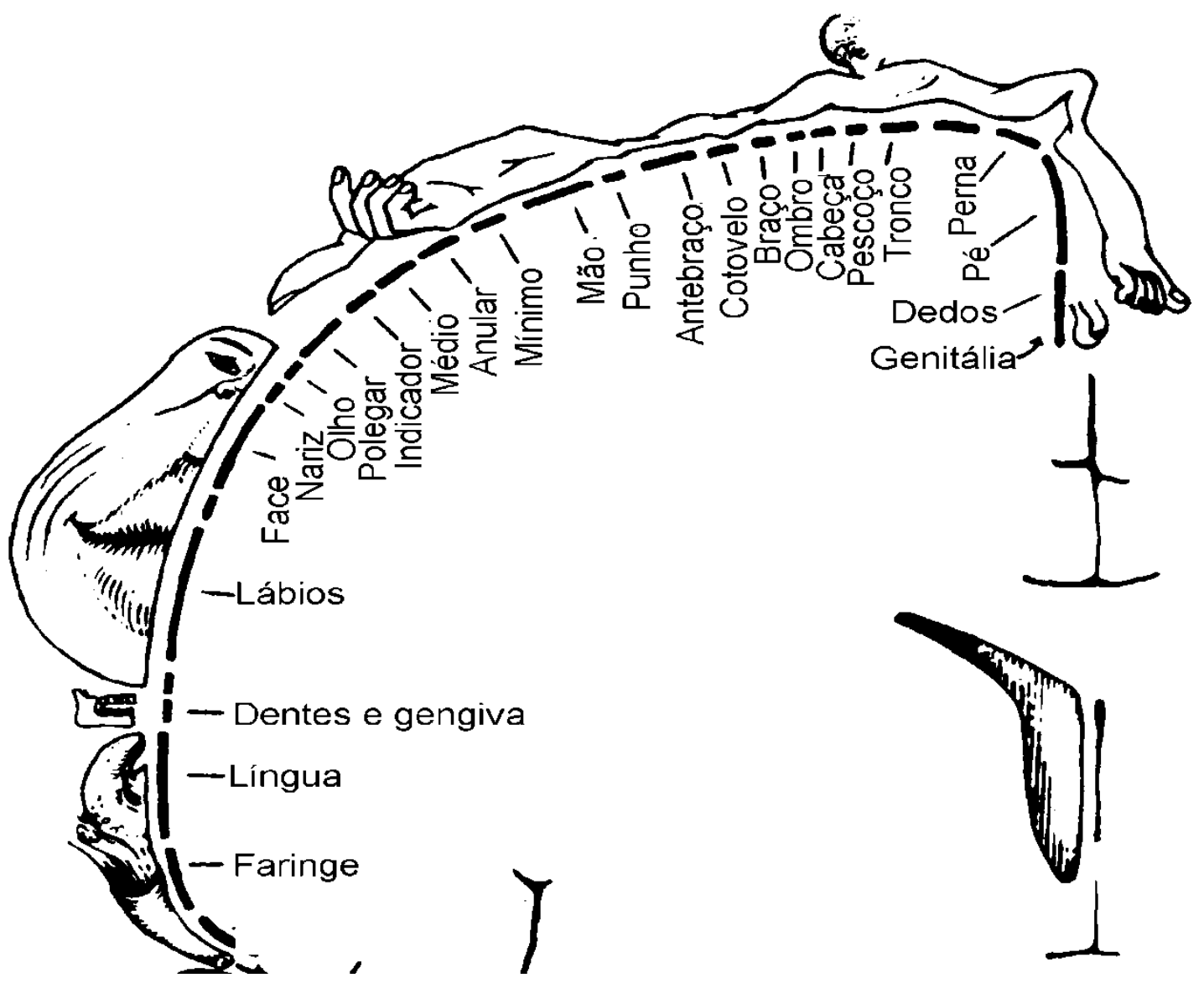

Figura 3: Mapa somatotópico, também conhecido como "homúnculo de Penfield", da superfície corpórea no córtex somatossensorial primário. O tamanho relativo do córtex dedicado a cada parte do corpo está relacionado com $s$ densidade de aferencias sensoriais provenientes daquela região, indicando a importância sensorial da região.

As informações somestésicas trigeminais, assim como as oriundas dos demais seguimentos do corpo, seguem distintas vias, processamentos e modulações ao longo do seu trajeto, que serão interpretadas como diferentes sensações (as variadas submodalidades somestésicas) dependendo da natureza do estímulo e do tipo de receptor sensorial ativado.

\subsection{Dor de Origem Pulpar}

O complexo dentina-polpa está entre os tecidos mais densamente inervados do corpo, porém raramente percebemos sensações advindas desta estrutura, a menos que ela seja a sede de algum processo patológico (BYERS e NÄRHI, 2002). Um estudo sobre dor 
na população brasileira mostrou uma alta prevalência de dores dentárias, um percentual de 38,4\% (SIQUEIRA, 2001).

Os dentes são inervados por axônios principalmente das divisões maxilar e mandibular do trigêmeo. Esses axônios penetram no dente pelo forame apical ramificandose na polpa dentária. A polpa dentária é um órgão sensorial refinado, constituído por tecido conjuntivo frouxo especializado, possuindo essencialmente vasos, fibras autônomicas que modulam a microcirculação e, majoritariamente, fibras nervosas aferentes de dois tipos: Adelta e C, dentro das paredes rígidas do dente (PASHLEY, 2002) - Figura 4. As terminações nervosas livres destas fibras são responsáveis pela inervação sensorial do dente e, como são essencialmente nociceptores, quando estimulados, causam predominantemente a sensação de dor (LYNN e PERL, 1996). No entanto, outros estudos têm mostrado que pode haver uma variedade de sensações, além da dor, dependendo do tipo e número de fibras ativadas e também da quantidade e intensidade do estímulo aplicado (NÄRHI, 1985).

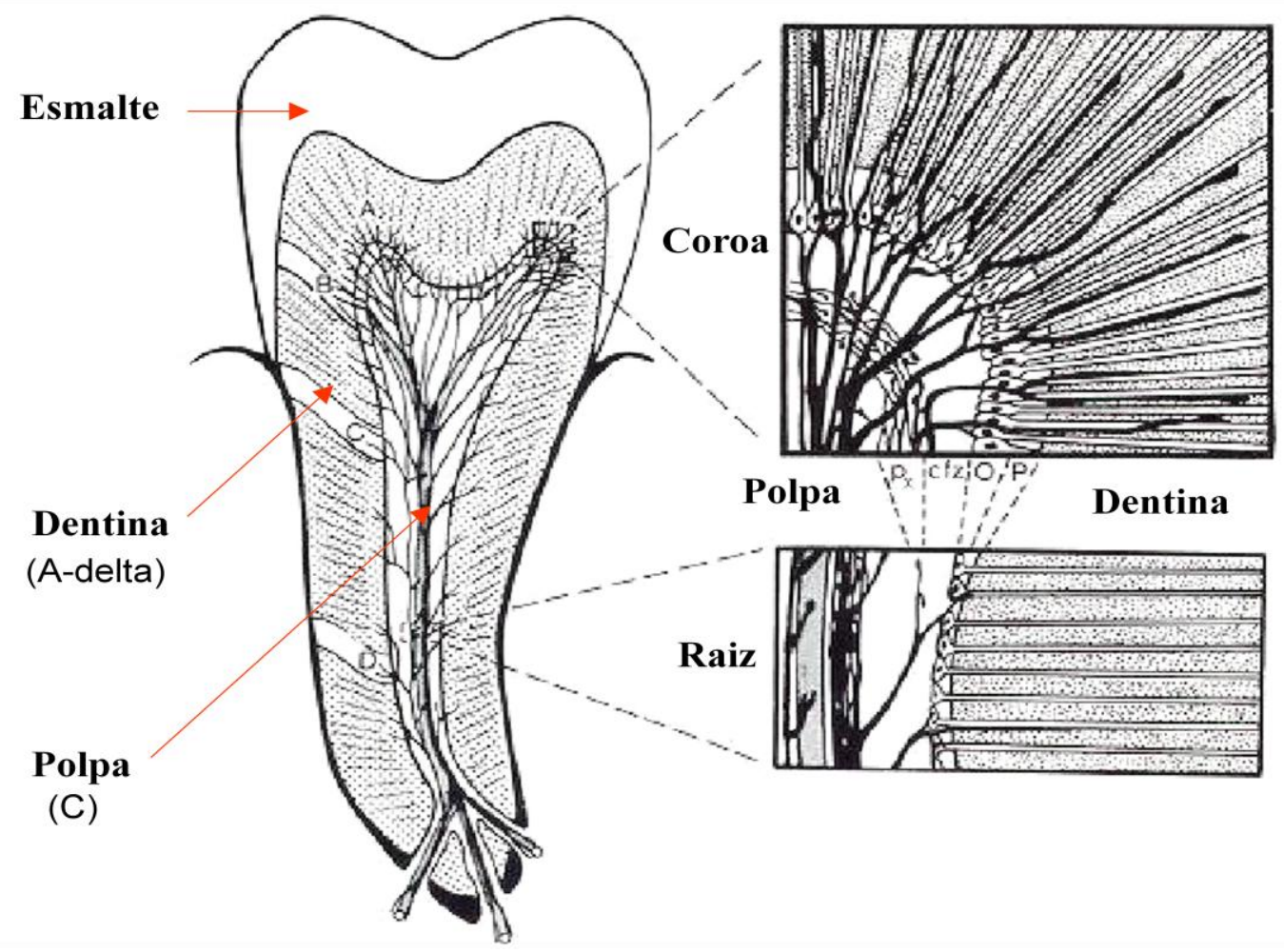

Figura 4: Esquema de um dente em corte longitudinal, mostrando as estruturas que o compoe: esmalte, dentina e polpa. No detalhe a direita, temos um maior aumento do limite da dentina com a polpa, onde podemos visualizar os túbulos dentinários, os odontoblastos e os prolongamentos nervosos que penetram nos túbulos dentinários na região da dentina (acima) e na região radicular. 
Nociceptores são terminações nervosas livres das fibras $C$ não-mielínicas e A $\delta$ mielinizadas responsáveis pela transdução de estímulos mecânicos, térmicos e químicos nocivos aos tecidos e que podem desencadear a experiência da dor. Estas terminações possuem diferentes tipos de receptores (que respondem a estímulos de natureza diversas) em sua membrana, pertencentes à superfamília dos receptores de potencial transiente (transient receptor potential -TRP), e, como são receptores inotrópicos, são responsáveis pela hipopolarização das células na presença de estímulos potencialmente lesivos (HAGENACKER, LEDWIG e BÜSSELBERG, 2008; JULIUS e BASBAUM, 2001). Cabe lembrar que nocicepção e dor não são sinônimos: pode existir dor sem nocicepção (dor neuropática, por exemplo) (CHAPMAN e STILLMAN, 1996) e nocicepção sem dor, por exemplo, uma pessoa em grande perigo e muito ferida não sente dor porque há atuação maciça do mecanismo modulatório da dor (supressão da dor) (FIELDS, 2004; FIELDS, 2000; GEBHART, 2004).

Há várias teorias que buscam explicar a sensibilidade dolorosa do elemento dentário, porém a mais aceita é teoria hidrodinâmica da dor dentária, proposta por Brännström. Como o esmalte e o cemento são estruturas desprovidas de inervação, a estimulação da dentina ou diretamente da polpa são responsáveis pela sensibilidade dentária (ARANA-CHAVEZ, 2001; NÄRHI, 1985; INGLE et al, 1979b). Estímulos aplicados sobre o dente induzem uma movimentação dos fluidos intra-tubulares, que por sua vez causam uma distorção no tecido peritubular e conseqüente ativação das terminações nervosas que estão nos túbulos dentinários e na região pulpar pré-dentina (NÄRHI, 1985, BENDER, 2000, BRÄNNSTRÖM e ÅSTRÖM, 1972). Variações de temperatura também podem provocar dor por induzir à contração térmica do esmalte elevando a pressão transmitida à dentina e a polpa, ativando os nociceptores. O processo inflamatório provoca dor porque pode desencadear uma série de reações que favorecem a ativação de nociceptores: vários mediadores químicos são liberados, aumentando a excitabilidade de nociceptores, ocorrendo vasodilatação de arteríolas que irrigam a polpa, aumentando a pressão hidrostática no interior do dente e comprimindo os vasos que drenam a polpa (ABD-ELMEGUID e YU, 2009; BRADLEY, 1986; NÄRHI, 1985). 
As terminações nervosas das fibras do tipo A-delta penetram nos túbulos dentinários e são responsáveis pela sensação dos estímulos aplicados na superfície dental, podendo provocar uma dor aguda, rápida e bem localizada. As fibras $\mathrm{C}$ estão presentes na polpa dentária, tem um limiar de ativação maior que as fibras A-delta, podendo causar dor persistente, severa e mal localizada (BENDER, 2000; TROWBRIDGE, 1986; OLGART, 1986; NÄRHI, 1985). A diferente localização destas fibras na estrutura dental faz com estes receptores respondam a estímulos distintos: estímulos frios na dentina irão excitar os receptores ligados às fibras A-delta, enquanto mediadores inflamatórios liberados na polpa irão excitar as terminações nervosas livres das fibras C amielínicas (BYERS e NÄRHI, 2002; BENDER, 2000). Porém, o estado de inflamação pulpar pode contribuir para hipersensibilidade dentinária (BYERS e NÄRHI, 2002; OLGART, 1986). As fibras do tipo C são mais resistentes que as fibras do tipo A, podendo sobreviver nos tecidos pulpares em hipoxia, o que explica a sensibilidade de alguns dentes mesmo com a polpa mortificada (BENDER, 2000; OLGART, 1986). A polpa é considerada viva enquanto o suprimento sanguíneo estiver preservado (SUDA e IKEDA, 2002; CHAMBERS, 1982).

As informações nociceptivas são conduzidas por meio das fibras A-delta e C ao núcleo espinal do trigêmeo e para outras regiões, como formação reticular e núcleo do trato solitário (SESSLE, 2000). O núcleo caudal é um local importante de entrada da informação vinda da polpa, porém não é o único: porções rostrais do núcleo espinal trigeminal recebem também aferentes pulpares nociceptivos (SHINENAGA et al., 1986b; DALLEL, 2000). O subnúcleo caudal não é um relê passivo de transmissão dos sinais nociceptivos para centros neurais superiores. Apresentando uma complexa rede de interneurônios e recebendo projeções descendentes, neurônios de projeção e aferentes sensoriais primários, ele atua como um importante local de processamento da dor, podendo haver modulação da dor já na sua entrada no sistema nervoso central (HARGREAVES, 2002). As informações veiculadas pelas fibras A-delta e C seguem vias distintas a partir daí: fibras A-delta seguem para a porção caudal do tálamo ventrobasal e depois para o córtex somestésico; já as fibras C seguem para o núcleo intralaminar do tálamo, córtex e hipotálamo (ABD-ELMEGUID e YU, 2009; BENDER, 2000).

A dor não é resultado da simples condução de informação nociceptiva para o SNC; esta via ascendente pode sofrer modulações (de várias estruturas do SNC, por exemplo: 
córtex, substância cinzenta periaquedutal, tálamo, núcleo magno da rafe) ao longo do seu percurso (TRACEY, 2005; OKESON, 1998, FIELDS, 2004, GEBHART, 2004). Sua modulação está integrada a outros circuitos neurais, particularmente àqueles envolvidos na elaboração de reflexos motores, respostas vegetativas, alerta, atenção e emoções. Esse componente afetivo-comportamental torna complicada a mensuração da dor em seres humanos; no entanto, suas medidas comportamentais são importantes para o seu conhecimento fisiológico e tratamento clínico (BRADLEY, 1986).

A polpa dentária é uma estrutura somática profunda com características viscerais e esta é uma razão que favorece o fenômeno de dor referida às adjacências ou à distância (BELL, 1991). Fenômenos secundários que acompanham a dor, como a hiperalgesia secundária, normalmente ampliam a área dolorosa e dificultam a localização do foco algógeno da dor. Além disso, uma manifestação dolorosa pode ocorrer nos dentes estando, porém, sua origem localizada em outra estrutura do organismo. Já são conhecidas algumas causas deste tipo de dor: problemas psicogênicos (LILLY e LAW, 1997; BATES e STEWART, 1991), enxaquecas, sinusites, alterações cardiovasculares, nevralgias faciais, disfunções de ATM, otite média e outras (CALDEIRA et al., 1999). Muitos trabalhos na literatura relatam que a dor de dente pode ser difusa e de difícil localização, além de propiciar o fenômeno de dor referida, às adjacências ou à distância do local afetado e que características da dor, tais como intensidade, duração e sua etiologia parecem influenciar este fenômeno (WRIGHT, 2000; FALACE, 1996; SESSLE, 1987; INGLE et al, 1979).

A maioria dos pacientes que têm alguma alteração de origem dentária pulpar ou periapical relata dores em outras regiões da cabeça e pescoço, isto é, tem dor referida (FALACE, 1996; REGATÃO, CALDEIRA E BALDO, 2002). Por esta razão, a odontalgia necessita de um estudo mais detalhado da manifestação, etiologia, características e distribuição topográfica da dor referida. Esse estudo, fundamentado na organização anátomo-fisiológica do sistema trigeminal, permitiria uma melhor compreensão da sensibilidade somestésica e particularmente das manifestações dolorosas de origem dentária, possivelmente auxiliando na realização de procedimentos diagnósticos. 


\subsection{Psicofísica da Dor}

A psicofísica é o estudo da relação quantitativa entre as propriedades dos estímulos (dimensão física) e a experiência sensorial (dimensão psicológica) (SCHIFFMAN, 2001) e vem prestando uma grande contribuição no estudo da sensação e percepção da dor ao longo do tempo. A investigação da relação entre o estímulo causador da dor com a sensação produzida por este é fundamental para o esclarecimento do fenômeno doloroso, contribuindo significativamente para o aprimoramento dos métodos de diagnóstico, condutas terapêuticas, testes de novos medicamentos e, por conseqüência, com a melhoria na qualidade de vida dos doentes (GRACELY, 1999).

O estudo do fenômeno doloroso realizado por meio de métodos psicofísicos correlaciona aspectos perceptivos da dor (quanto dói, onde dói, como dói, quando dói, etc.) com o estímulo causador da dor: a lesão real ou potencial, quer induzida experimentalmente por um estímulo controlado, quer originada de uma patologia (SILVA e RIBEIRO-FILHO, 2006). Quando nos preocupamos em relacionar a intensidade de um estímulo doloroso com a sensação gerada por este estímulo, estamos nos remetendo à psicofísica da dor. Portanto, é imprescindível considerarmos tanto os instrumentos de medida da sensibilidade dolorosa, quanto os mecanismos da dor (seus componentes e agentes determinantes). Podemos destacar algumas vantagens na utilização da psicofísica como fornecedora de métodos para avaliação e mensuração da percepção de dor: os procedimentos são simples, rápidos e realizados com baixo custo (GRACELY, e DUBNER, 1981). Podemos, ainda, obter informações valiosas sobre a queixa dolorosa, para fins diagnósticos e de avaliação da terapêutica que será instituída, permitindo uma averiguação posterior de sua eficácia. Apenas temos acesso à percepção da dor pelo relato pessoal do doente, já que a dor é uma experiência subjetiva (SILVA e RIBEIRO-FILHO, 2006). Neste trabalho, a fim de avaliarmos a própria metodologia do estudo da dor, comparamos a mensuração da dor por duas escalas diferentes e que são amplamente utilizadas na clínica e em estudos sobre percepção de dor: a escala ordinal numérica e a escala analógica visual (EAV). 


\section{Objetivos}

Realizar um aprofundamento no estudo da organização funcional da divisão somestésica do sistema trigeminal, por meio de métodos psicofísicos e clínicos em voluntários humanos.

\subsection{Objetivos Específicos}

- Avaliar a distribuição topográfica da dor de origem pulpar ou periapical;

- Investigar a influência da intensidade da dor dental sobre a topografia da dor referida;

- Comparar a resolução espacial de estímulos nociceptivos com a resolução espacial de estímulos mecânicos e térmicos;

- Comparar a mensuração da dor em duas diferentes escalas (numérica e analógica visual). 


\section{Material e Métodos}

Para a realização do estudo clínico e psicofísico dor, avaliamos pacientes que apresentavam dor dental, particularmente aquelas originadas na polpa dentária e suas possíveis referências na região de cabeça e pescoço. Portanto, analisamos pacientes com dor de origem endodôntica por meio do preenchimento de uma ficha clínica (Ficha Clínica 1 - ANEXO 1) com dados referentes às características da dor, tais como: duração, localização, intensidade - medida pela escala analógica visual (EAV) e também pela escala numérica de 0 a 10 (CONTI, et al, 2001; GRACELY e NALIBOFF, 1996) - fatores de melhora e piora, áreas de referência e irradiação da dor e diagnóstico provável. Contamos com as informações relatadas pelos pacientes no procedimento de anamnese e observamos o diagnóstico provável da manifestação dolorosa. Em alguns casos, realizamos tomadas radiográficas do dente sinálgico (dente que o paciente refere à dor) e/ou algógeno (dente que sedia o processo patológico) para um melhor esclarecimento do diagnóstico. A ficha contém uma hemiface (SICHER e JANDLER, 1981), com áreas previamente delimitadas, de acordo com a anatomia do complexo trigeminal, onde pudemos determinar a região ou regiões dolorosas (Figura 5).

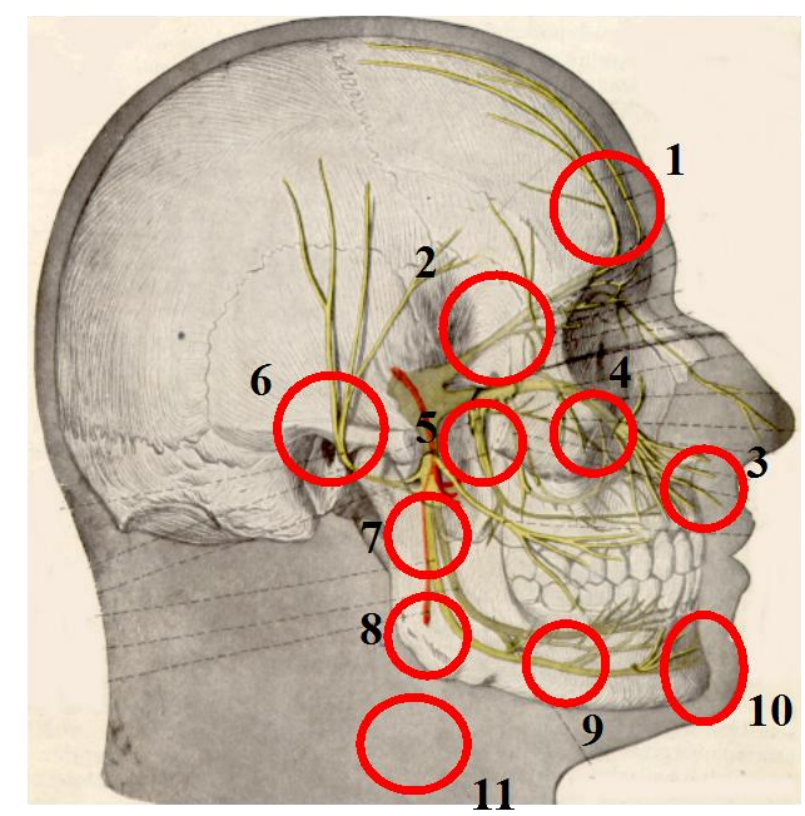

Figura 5: Desenho da hemiface humana da ficha clínica (SICHER e JANDLER, 1981) onde foram anotadas as áreas dolorosas relatadas pelos pacientes. 
Os dados foram colhidos na Clínica Odontológica da Faculdade de Odontologia da USP, Setor de Urgência Odontológica, onde contamos com a infra-estrutura necessária para a realização da pesquisa: o equipo, mocho, carrinho auxiliar, aparelho de raio X; e também material de consumo: algodão, espelho clínico, pinça clínica, máscaras descartáveis, luvas de procedimento, gorro e aventais. O preenchimento da ficha clínica foi realizado sempre pela pós-graduanda para padronização das respostas. Utilizamos as informações que são rotineiramente colhidas no procedimento de anamnese e exame físico anteriormente ao atendimento, sem que houvesse prejuízo de tempo com relação ao alívio da dor. Todos os pacientes foram informados sobre as finalidades e implicações da pesquisa, sempre deixando claro a não obrigatoriedade de seu ingresso. $O$ projeto não interferiu no atendimento que o paciente se submeteu e também não ofereceu o menor risco para os mesmos. Foi solicitada a assinatura de um termo de consentimento aos pacientes ou aos seus responsáveis legais (ANEXO 2).

Consideramos para análise 60 pacientes, sendo 45 do sexo feminino e 15 do masculino, entre 15 e 60 anos, de qualquer etnia ou classe social, que possuíam manifestação dolorosa de origem pulpar (de qualquer natureza). Os fatores de exclusão da amostra foram: pacientes que apresentaram doença periodontal associada ao dente doloroso, múltiplos dentes algógenos e dentes com rizogênese incompleta. Apenas os

pacientes que apresentavam exclusivamente processos patológicos pulpares e que se propuseram a participar da pesquisa foram incluídos na amostra.

\subsection{Resolução Espacial Mecânica e Térmica}

Investigamos, num segundo momento, a capacidade destes pacientes de localizar e distinguir diferentes estímulos - mecânicos e térmicos - em elementos dentários sadios, para analisar a relação entre a resolução espacial somestésica e a distribuição topográfica da dor de origem dentária.

Em cada voluntário, para cada um dos testes experimentais, testamos um mínimo de 4 e um máximo de 6 elementos dentários hígidos, localizados na arcada superior ou inferior, lado direito ou esquerdo, e pertencentes a qualquer dos diferentes grupos dentais (incisivos, caninos, pré-molares e molares). Estes deveriam apresentar coroas íntegras e não 
possuir restaurações extensas. Excluímos dessa amostra dentes com qualquer relato de sintomatologia dolorosa espontanea, história prévia de traumatismo dentário, problemas periodontais ou que apresentassem rizogênese incompleta.

\subsubsection{Procedimento Experimental}

O teste térmico de escolha foi o de baixa temperatura, o gás refrigerante diclorodifluorometano (DDM - temperatura aproximada de $-50^{\circ} \mathrm{C}$ - nome comercial EndoFrost Roeko®), um teste de fácil execução e que não provoca danos ao elemento dentário (RICKOFF et al., 1988), já que o teste térmico realizado com alta temperatura, se aplicado por um longo período de tempo pode provocar danos permanentes aos dentes (EDWALL, 1986). O gás foi aplicado em uma pequena esfera de algodão e, com o auxílio da pinça clínica, o aplicamos no elemento dentário, por aproximadamente 5 segundos. Pedimos para os pacientes se manifestarem verbalmente ao sentirem qualquer tipo de estímulo no elemento dentário. Registramos qual era a sensação e localização do estímulo e, se o estímulo causasse dor, o paciente quantificava a sensação dolorosa em uma escala numérica de 0 a 10. Para a localização do dente, o paciente mostrava com o dedo indicador qual dente havia sido estimulado. Também anotamos a impressão subjetiva do grau de dificuldade em localizar o dente que tinha sido estimulado. Preenchemos uma segunda ficha clínica (Ficha Clínica 2 - Parte A, ANEXO 3) com as informações fornecidas pelo paciente sobre o teste térmico.

O estímulo mecânico provocado pelo contato da esfera de algodão com o elemento dentário pode facilitar a localização do dente que está sendo testado, por isso realizamos um teste basal com a aplicação de uma esfera de algodão no elemento dentário, sem o estímulo térmico, para comparação com os dados do teste térmico (Ficha Clínica 2 - Parte $\mathrm{B}$, ANEXO 4). Para isso, os testes eram realizados exatamente nos mesmos dentes que tinham sido testados com estímulo térmico. Novamente, a tarefa do paciente era se manifestar verbalmente a qualquer sensação que tivesse no elemento dentário. O paciente deveria indicar em qual dente sentiu o estímulo apontando com o dedo indicador sobre o dente. A sensação relatada pelo paciente foi anotada na ficha clínica e a impressão subjetiva da facilidade ou dificuldade em localizar o dente estimulado. 
Outro teste mecânico (aqui denominado pressórico) foi realizado através da percussão vertical, já que este estimula principalmente a região periapical, além de algumas fibras periodontais desta região (CHAMBERS,1982). Utilizamos o cabo do espelho clínico, tomando o cuidado de uniformizar a intensidade (na medida do possível) e freqüência do estímulo sobre os dentes. Este teste não tem capacidade de provocar danos ao elemento dentário. Embora grosseiro, tal teste é rotineiramente utilizado na prática clínica, daí nosso interesse em confrontar seus resultados com aqueles obtidos nos demais procedimentos, padronizados de forma mais rigorosa. Após a percussão vertical, o paciente mostrava com o dedo indicador qual dente havia sido estimulado, o que sentiu com este estímulo e sua impressão sobre a dificuldade em localizar corretamente o dente estimulado. As informações colhidas dos pacientes foram armazenadas na Ficha Clínica 2 - Parte C (ANEXO 5), para posterior comparação com as outras modalidades sometésicas.

A ordem da realização dos testes mecânicos e térmico foi aleatorizada. Foi solicitada a assinatura de um termo de consentimento aos voluntários ou aos seus responsáveis legais (ANEXO 6).

\subsubsection{Grupos Controles}

No intuito de flagrar possíveis interferências que a experiência dolorosa poderia ocasionar na coleta dos testes somestésicos (pacientes submetidos ao estresse causado tanto pelo processo doloroso quanto pela iminência de uma intervenção odontológica), realizamos estes mesmos testes de resolução espacial em grupos de pessoas que não apresentavam dor dental - os grupos controles. Então, os três testes mencionados acima (térmico, mecânico e pressórico) foram realizados também nesses grupos controles na tentativa de revelar se existiriam diferenças nas respostas de pessoas que não apresentam quaisquer queixas de origem dental com as dos pacientes que procuraram o serviço de Urgência Odontológica com dor de origem endodôntica, e quais seriam estas diferenças.

Os grupos controles foram compostos por participantes sem qualquer queixa de dor dental e que se propuseram a tomar parte como voluntários do projeto de pesquisa, sendo tanto do sexo feminino como masculino, entre 18 anos e 50 anos, de qualquer etnia ou classe social. Em todos os voluntários, para cada teste experimental, testamos 4 dentes 
hígidos, sem relato de sintomatologia dolorosa e com coroas íntegras (sem coroas protéticas ou restaurações extensas), que não apresentaram história prévia de traumatismo dentário, problemas periodontais ou rizogênese incompleta.

Utilizamos dois diferentes grupos controles. O primeiro foi composto de voluntários não dentistas submetidos aos mesmos testes que os pacientes, seguindo os mesmos protocolos experimentais relatados acima. Portanto, as respostas desses voluntários (que foi realizada da mesma maneira que nos pacientes) foram assinaladas em novas fichas clínicas que seguem o modelo das fichas utilizadas com os pacientes - ANEXO 3, 4 e 5.

O segundo grupo foi composto por dentistas ou estudantes de odontologia que possuem o conhecimento sobre a anatomia, nomenclatura e notação dental (Figura 6).

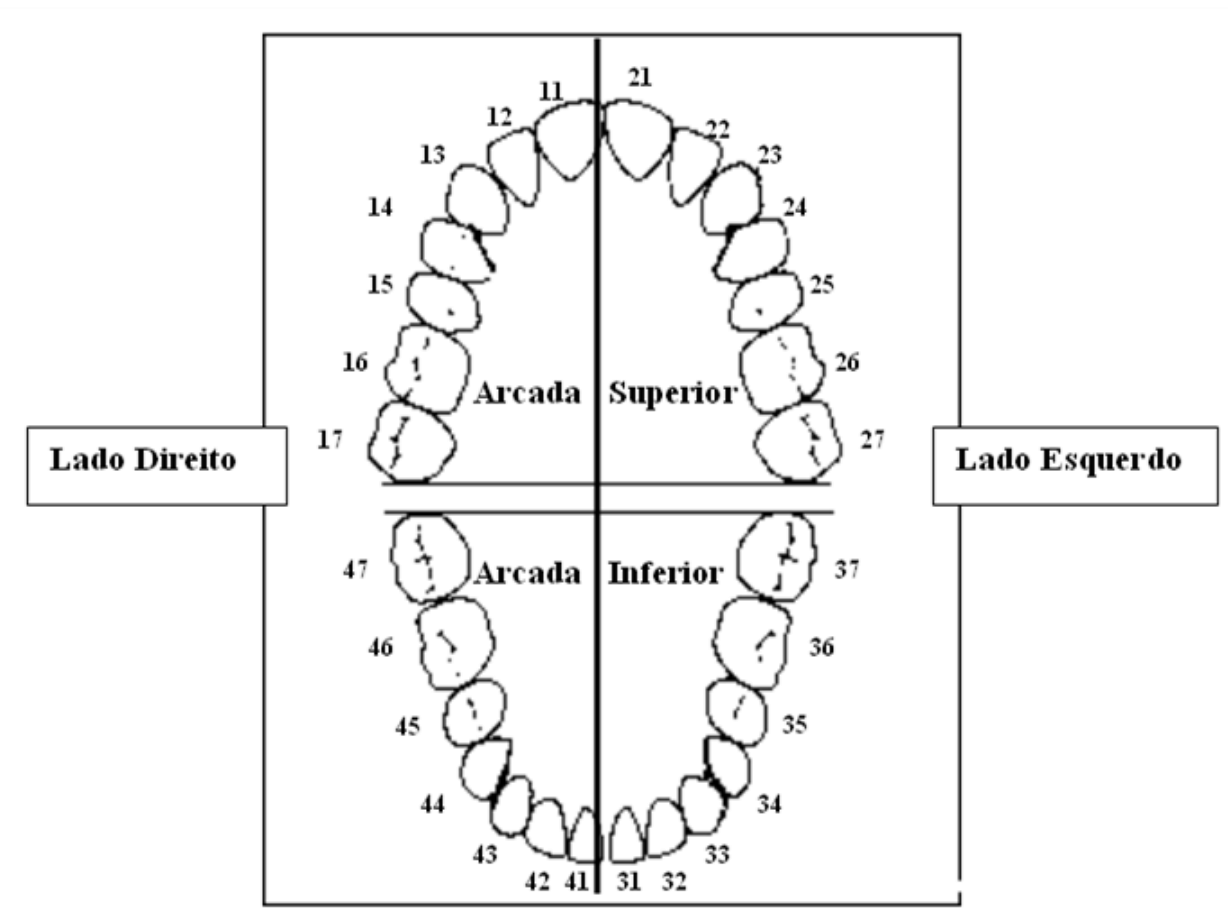

Figura 6: Esquema das arcadas dentárias, superior e inferior, com a notação indicativa de cada elemento dentário e sua localização.

Realizamos os mesmos testes e procedimentos já descritos, porém os voluntários foram instruídos a responder ao teste apenas citando verbalmente qual o elemento dentário que ele acreditava ter sido estimulado, isto é, sem apontar ou tocar no dente como os outros grupos. A inclusão desse grupo teve a intenção de revelar se apontar ou, sobretudo, tocar o elemento dentário poderia facilitar a correta localização do dente estimulado. Portanto, os 
voluntários deste grupo reportaram verbalmente em qual dente foi percebido o estímulo, a partir da comparação da sua representação topográfica dos dentes com os traços mnemônicos da sensação do estímulo. Os dados foram armazenados em fichas clínicas iguais às dos demais grupos (ANEXO 3,4 e 5).

Todos os voluntários foram considerados para análise dos resultados, sendo 60 no total, com 30 voluntários em cada grupo controle: “dentistas" e "não dentistas". Foi solicitada a assinatura de um termo de consentimento aos voluntários ou aos seus responsáveis legais (ANEXO 6).

\subsection{Análise Estatística}

Os resultados foram analisados por meio de métodos estatísticos descritivos e testes de hipóteses utilizando-se métodos não paramétricos, em decorrência da natureza das variáveis coletadas.

$\mathrm{Na}$ análise dos dados referentes à dor, utilizamos o teste exato de Fisher. Quando havia expectativa teórica de uma direção do efeito foi realizado um teste unicaudal, sendo empregados testes bicaudais nos demais. Utilizamos também o teste de correlação de Spearman quando comparadas, entre os pacientes, duas variáveis medidas em escalas ordinais.

Para a análise da segunda parte do projeto, em que foram investigadas as resoluções espaciais mecânica e térmica, utilizamos um teste de máxima verossimilhança (AGRESTI, 2007; HAYS, 1994), onde avaliamos a probabilidade da distribuição da respostas binárias (acerto ou erro na localização do dente estimulado) dadas pelos voluntários. Analisamos, então, o efeito de algumas variáveis independentes (fatores) que poderiam influenciar a correta identificação dos dentes testados, enumeradas a seguir:

1- O grupo de voluntários: pacientes, dentistas e não dentistas;

2- O tipo de teste realizado: teste térmico, teste mecânico e percussão vertical;

3- O grupo dental estudado: incisivos, caninos, pré-molares e molares.

Para corrigir a possível a inflação do erro do tipo I, ajustamos o valor de alfa por meio da correção de Bonferroni: em fatores com 3 níveis (fatores grupo e teste), o alfa 
utilizado foi de 0,02 e naqueles com 4 níveis (fator grupo dental), o alfa utilizado foi de 0,008. O programa estatístico utilizado foi o SAS 9.2.

Para análise da dispersão dos erros cometidos, realizamos um teste de assimetria em torno da mediana, usando adaptação do teste não paramétrico de Wilcoxon (ZAR, 2009, pág. 127). 


\section{Resultados}

Obtivemos uma amostra de 60 pacientes que preenchiam os requisitos de inclusão da pesquisa - pacientes que apresentaram apenas manifestações dolorosas de origem pulpar (de qualquer natureza), sem doença periodontal associada ou com outros dentes apresentando manifestação dolorosa. De acordo com parâmetros pré-estipulados por nós (ANEXO 7), efetuamos a tabulação das informações colhidas (ANEXO 8).

A amostra é composta de 45 mulheres e 15 homens, com idade variável entre 15 e 60 anos (sendo a média de 32,4 anos e 11,4 o desvio padrão). Com esta amostra um tanto quanto heterogênea, poderíamos encontrar diferenças significativas entre as pessoas, dependendo da faixa etária e gênero. Portanto, realizamos uma análise dividindo a amostra por gênero, comparando homens e mulheres (ANEXO 9), e por faixa etária, comparando jovens e adultos (dividindo a amostra pela mediana da idade) - ANEXO 10. Apenas em uma variável encontramos diferenças significativas entre homens e mulheres: a correlação entre intensidade da dor e número de áreas com dor referida, onde obtivemos uma correlação positiva apenas no grupo feminino $(r=0,63$ coeficiente de correlação de Spearman). Independentemente do gênero estudado, os resultados obtidos foram praticamente os mesmos do que quando analisados juntos homens e mulheres. $\mathrm{O}$ mesmo aconteceu para a análise por faixa etária. Apenas obtivemos diferença significativa quando analisamos uma única variável: os adultos apresentaram dentes algógenos com diagnóstico de polpa morta em maior proporção que os jovens (teste exato de Fisher, bicaudal, $\mathrm{p}=0,0061$ ). Os resultados obtidos foram essencialmente os mesmos do que quando analisadas todas as faixas etárias em conjunto. Embora a amostra pareça heterogênea, ela não apresentou grandes diferenças entre os grupos que a compõe. Portanto, analisaremos, durante todo o projeto, toda a amostra colhida como sendo representativa da população, sem diferir significativamente entre seus subgrupos.

Os dentes com patologias pulpares estudados estão localizados tanto na arcada inferior ( 35 dentes) quanto na arcada superior ( 25 dentes), distribuídos por todos os grupos dentais: incisivos, caninos, pré-molares e molares. Observamos que, nesta amostra, em 50\% dos casos, o diagnóstico provável encontrado foi de dentes com polpa viva (com lesões inflamatórias irreversíveis) e 50\% com polpa mortificada (com e sem lesão periapical). 
Todos os pacientes necessitaram de intervenção endodôntica. Observamos dor referida em 90\% dos pacientes estudados; apenas $10 \%$ dos pacientes relataram dor unicamente no elemento dentário. Dos pacientes estudados, 12\% apontaram incorretamente o dente algógeno, sendo que, destes, 5\% apontaram como sinálgico o dente vizinho ao dente algógeno e os $7 \%$ restantes indicaram como dente sinálgico um dente mais distante e que pertencia a um grupo dental diferente do algógeno.

Primeiramente, apresentaremos os resultados relativos à comparação dos dois instrumentos de mensuração da dor utilizados neste trabalho. Em seguida, parte dos resultados que apresentaremos estão resumidos no diagrama abaixo (Figura 7). Analisamos o dente algógeno quanto à sua localização (arco superior e inferior), estado pulpar (polpa viva e mortificada), duração da dor (intermitente ou contínua) e intensidade da dor deste dente, sempre relacionando com aspectos relativos à dor referida: se esta estava presente ou não, a quantidade de áreas dolorosas (Figura 5, Materiais e Métodos) e o número de ramos trigeminais afetados. Depois analisamos o padrão de dispersão da dor referida. Ao final desta seção, analisaremos se as características fisiopatológicas do dente algógeno se correlacionam entre si.

DOR REFERIDA:

Presença vs Ausência

Número de áreas

Número de ramos

Padrão de dispersão

Características

Topográficas

da Dor Referida

Características

Fisiopatológicas

do Dente

Algógeno

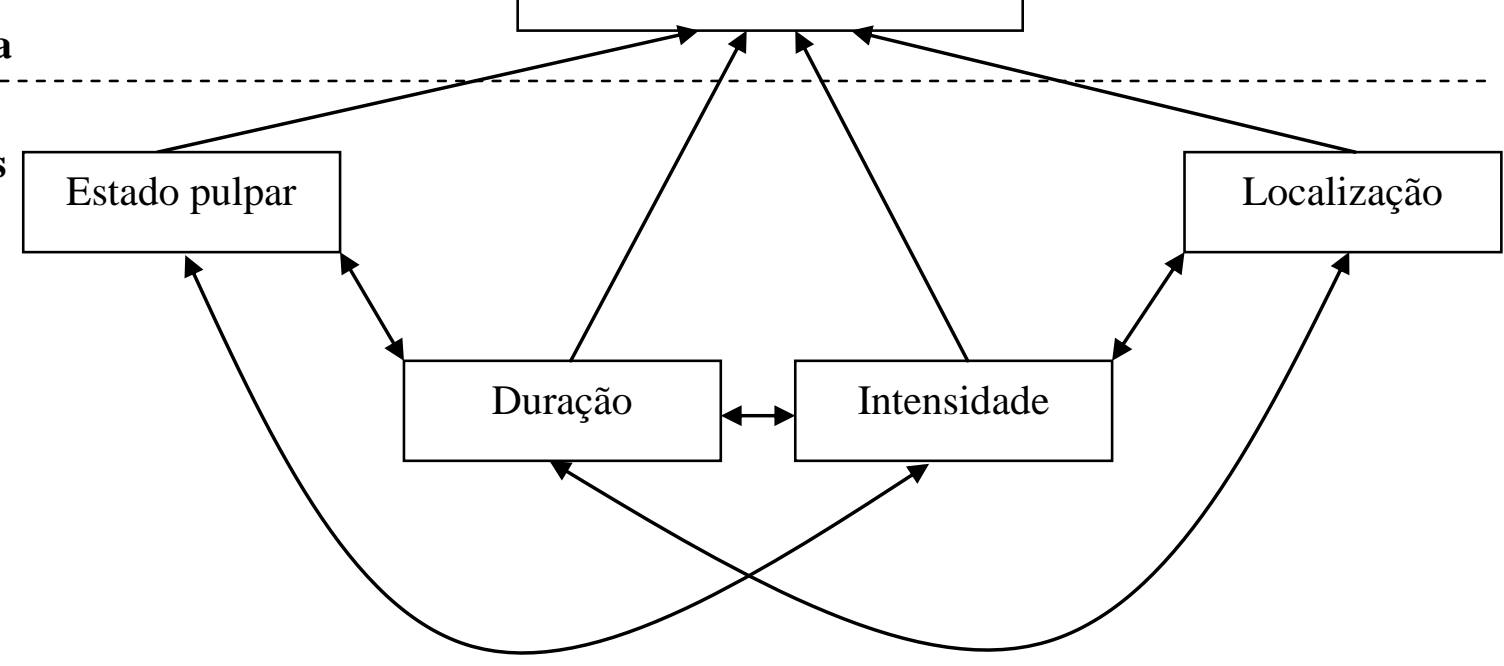

Figura 7: Diagrama dos resultados que serão apresentados a seguir. As flechas indicam as comparações que foram realizadas. 


\subsection{Mensuração da Dor: Comparação das Escalas de Dor}

Comparamos as duas escalas de mensuração da dor que utilizamos na ficha clínica para obtenção dos dados e que são bastante usadas tanto em ambiente de laboratório quanto na prática clínica: a escala ordinal numérica e a escala analógica visual (EAV) - Figura 8.

Realizado teste estatístico destes dados (teste Wilcoxon), observamos que existe uma diferença significativa entre as duas escalas $(\mathrm{p}<0,001)$, indicando que essas escalas diferem entre si quanto à mensuração da dor. $O$ fato pode ser explicado pela talvez não compreensão integral por parte dos sujeitos do procedimento envolvido na EAV (PRICE, e HARKINS, 1992). No entanto, encontramos uma correlação positiva entre estas duas escalas ( $r=0,765 ; \mathrm{p}<0,001$ - coeficiente de correlação de Spearman). Então, mesmo se numericamente estas escalas são diferentes, elas possuem uma correspondência de valores e significado, indicando que elas são instrumentos válidos, e relativamente equivalentes, para mensuração da dor. Sendo assim, utilizaremos a escala numérica para a análise referente à intensidade da dor.

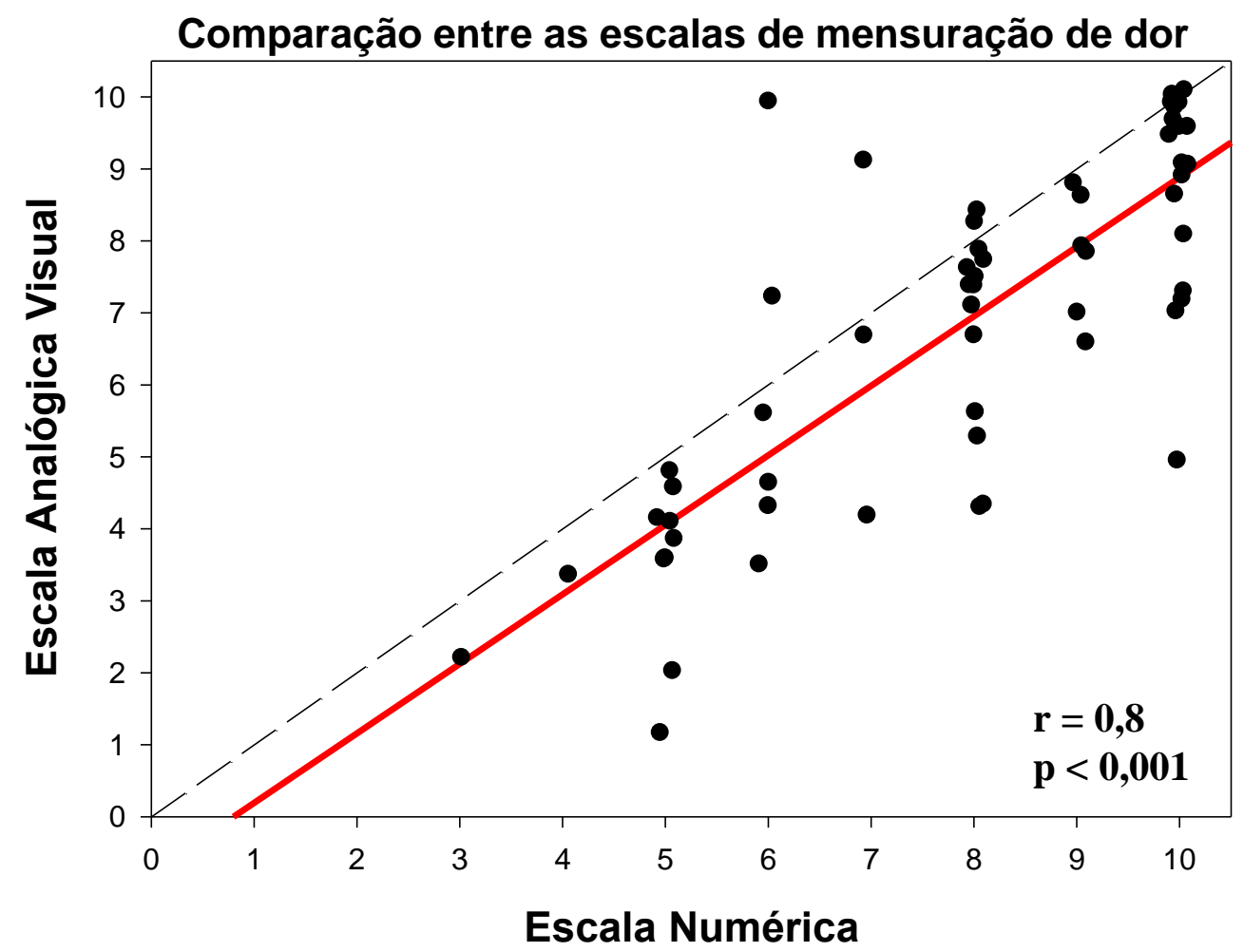

Figura 8: Correlação positiva entre a intensidade da dor medida pela escala ordinal numérica e a escala analógica visual (EAV). 


\subsection{Distribuição Topográfica da Dor Referida}

Apresentaremos aqui os resultados referentes ao estudo da dor referida, realizando as análises previstas no diagrama mostrado no início dos resultados (Figura 7).

\subsubsection{Estado pulpar do dente algógeno}

Na Tabela 1 e Figura 9 temos a distribuição do número de áreas de referência de dor dental apontadas pelos pacientes de acordo com o estado pulpar do dente algógeno.

Tabela 1: Estado pulpar versus quantidade de regiões com referência de dor

\begin{tabular}{c|c|c|c|c|c|c|c|c|c}
\hline \multirow{2}{*}{$\begin{array}{c}\text { Estado } \\
\text { Pulpar }\end{array}$} & \multicolumn{8}{c}{ Número de áreas de referência de dor dental } \\
\cline { 2 - 11 } & $\mathbf{0}$ & $\mathbf{1}$ & $\mathbf{2}$ & $\mathbf{3}$ & $\mathbf{4}$ & $\mathbf{5}$ & $\mathbf{6}$ & $\mathbf{7}$ & $\mathbf{8}$ \\
\hline Polpa Viva & $4(7 \%)$ & $1(2 \%)$ & $5(8 \%)$ & $6(10 \%)$ & $2(3 \%)$ & $6(10 \%)$ & $3(5 \%)$ & $2(3 \%)$ & $1(2 \%)$ \\
\hline Polpa Morta & $2(3 \%)$ & $6(10 \%)$ & $9(15 \%)$ & $5(8 \%)$ & $5(8 \%)$ & $3(5 \%)$ & $0(0 \%)$ & $0(0 \%)$ & $0(0 \%)$ \\
\hline Total: & $6(10 \%)$ & $7(12 \%)$ & $14(23 \%)$ & $11(18 \%)$ & $7(12 \%)$ & $9(15 \%)$ & $3(5 \%)$ & $2(3 \%)$ & $1(2 \%)$ \\
\hline
\end{tabular}

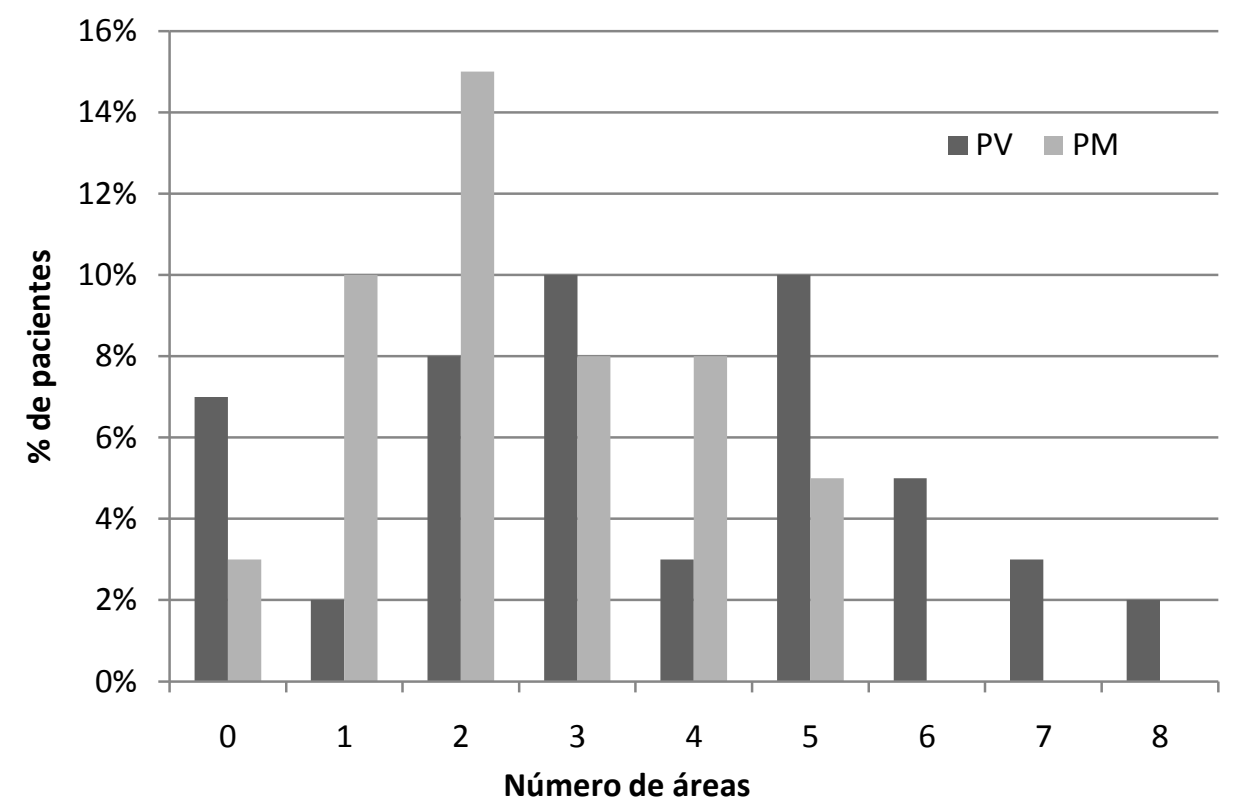

Figura 9: Distribuição dos pacientes (em porcentagem) que apresentaram dente com polpa viva (PV) e polpa morta (PM) pelo número de áreas de dor referida reportada. 
A Tabela 2 é produto da Tabela 1. Zero, na Tabela 1, indica que os pacientes não tiveram dor referida (sem DR) e o restante dos pacientes, com poucas ou muitas áreas, apresentou dor referida (com DR). O estado pulpar polpa viva e morta têm basicamente a mesma proporção de áreas com e sem dor referida (teste exato de Fisher, bicaudal, $\mathrm{p}=0,6707)$.

Tabela 2: Estado pulpar encontrado dividido em dois grupos com relação a existência ou não de dor referida (DR), com DR ou sem DR, respectivamente.

\begin{tabular}{c|c|c}
\hline & Sem DR & Com DR \\
\hline Polpa Viva & $4(7 \%)$ & $26(43 \%)$ \\
\hline Polpa Morta & $2(3 \%)$ & $28(47 \%)$ \\
\hline Total: & $6(10 \%)$ & $54(90 \%)$
\end{tabular}

Analisando os casos que apresentaram dor referida, temos uma divisão dos dados acima em dois grupos: os que referiram poucas áreas de dor (de 1 a 4 áreas) e outro, com um maior número de áreas dolorosas (5 ou mais áreas de referência de dor dental) - Tabela 3 e Figura 10.

Tabela 3: Diagnóstico encontrado dividido em dois grupos com relação ao número de áreas de referência de dor dental: poucas áreas (de 1 a 4 áreas) e muitas áreas (de 5 a 8 áreas).

\begin{tabular}{c|c|c}
\cline { 2 - 3 } & $1-4$ & $5-8$ \\
\hline Polpa Viva & $14(23 \%)$ & $12(20 \%)$ \\
\hline Polpa Morta & $25(42 \%)$ & $3(5 \%)$ \\
\hline Total: & $39(65 \%)$ & $15(25 \%)$
\end{tabular}




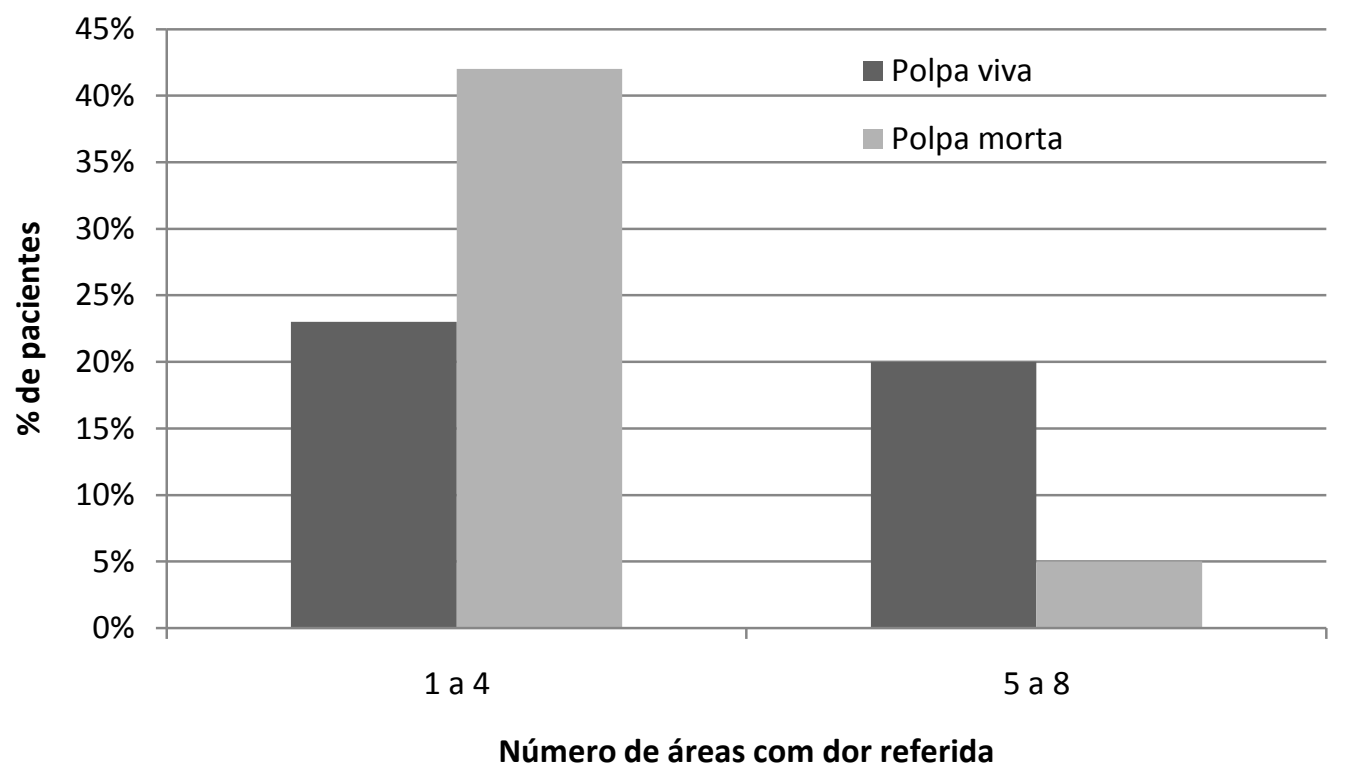

Figura 10: Número de áreas com referência de dor dividida em: poucas áreas (de 1 a 4 áreas) e muitas áreas (de 5 a 8 áreas) versus o estado pulpar encontrado: polpa viva e polpa morta .

Aplicando o teste estatístico exato de Fisher (bicaudal) aos dados da Tabela 3, observamos que, com relação ao número de áreas de referência de dor dental, os dentes com polpa viva têm significativamente mais áreas com dor referida do que os dentes com polpa mortificada $(\mathrm{p}=0,0057)$.

Analisamos a relação do estado pulpar (polpa viva ou morta) do dente algógeno com os ramos trigeminais afetados pela dor referida: oftálmico, maxilar e mandibular e também região cervical (Tabela 4 e Figura 11). Cabe ressaltar que a delimitação das áreas trigeminais (Figura 5) é apenas uma aproximação, pois existe uma superposição da inervação dos ramos trigeminais em determinadas áreas da face. A classificação realizada aqui é bastante simplificada e leva em consideração a predominância provável de inervação de um dentre os três ramos trigeminais. 
Tabela 4: Distribuição das áreas de referência de dor dos dentes algógenos nos ramos trigeminais com relação ao estado pulpar encontrado, polpa viva (PV) ou polpa morta (PM).

\begin{tabular}{c|c|c}
\hline \multirow{2}{*}{} & \multicolumn{2}{c}{ Diagnóstico } \\
\cline { 1 - 3 } Áreas Trigeminais & PV & PM \\
\cline { 1 - 3 } Of & - & 1 \\
\hline Mx & - & 3 \\
\hline Md & 5 & 8 \\
\hline Of, Mx & - & 4 \\
\hline Of, Md & 4 & 5 \\
\hline Mx, Md & 6 & 2 \\
\hline Of, Mx, Md & 6 & 2 \\
\hline Md, Cerv & 2 & 2 \\
\hline Of, Md, Cerv & 1 & - \\
\hline Of, Mx, Cerv & - & 1 \\
\hline Of, Mx, Md, Cerv & 2 & - \\
\hline 0 & 4 & 2 \\
\hline TOTAL & 30 & 30 \\
\hline
\end{tabular}

\begin{tabular}{l|c|c}
\cline { 2 - 3 } \multicolumn{1}{c|}{} & PM & PV \\
\hline Of & $\mathbf{1 3}$ & $\mathbf{1 3}$ \\
\hline Mx & $\mathbf{1 2}$ & $\mathbf{1 4}$ \\
\hline Md & $\mathbf{1 9}$ & $\mathbf{2 6}$ \\
\hline Cerv & 3 & 5 \\
\hline
\end{tabular}

Áreas Trigeminais: ramos do nervo trigêmeo Of: ramo oftálmico

Mx: ramo maxilar Md: ramo mandibular Cerv: região cervical

À esquerda, na Tabela 4, temos as regiões trigeminais dolorosas em relação ao estado pulpar do dente algógeno. À direita, um resumo desta tabela, apontando numericamente as áreas afetadas pelo dente algógeno, as queixas dolorosas, que foram originadas por dentes algógenos com diagnóstico de polpa viva e morta na proporção de $50 \%$ polpa viva e $50 \%$ polpa morta. Observamos que, tanto na tabela da esquerda quanto da direita, não há uma diferença importante quando comparamos os dentes com polpa mortificada e com polpa viva. Portanto, dentes com polpa viva ou morta podem apresentar dor referida equanimente em todos os ramos do trigêmeo. 


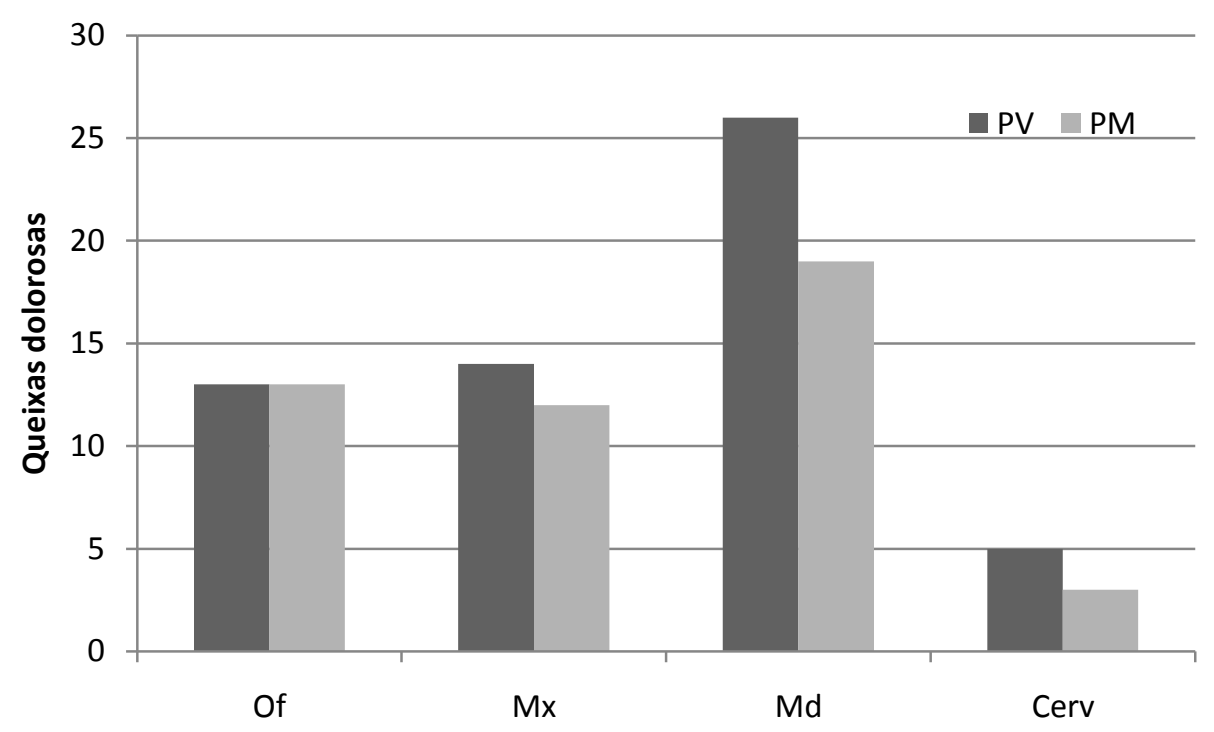

Figura 11: Relação do estado pulpar do dente algógeno, polpa viva (PV) e polpa morta (PM), com o ramo trigeminal $(\mathrm{Of}=$ of tálmico; $\mathrm{Mx}=$ maxilar; $\mathrm{Md}=$ mandibular $)$ e região cervical (Cerv) com referência de dor.

\subsubsection{Localização do dente algógeno}

Na Tabela 5 e Figura 12 temos a distribuição dos pacientes divididos pelo número de áreas com dor referida com relação a localização do dente algógeno: dentes superiores e inferiores.

Tabela 5: Localização da dor versus quantidade de regiões com referência de dor

\begin{tabular}{c|c|c|c|c|c|c|c|c|c}
\cline { 3 - 10 } & \multicolumn{7}{c}{ Número de áreas de referência de dor dental } \\
\cline { 2 - 10 } & $\mathbf{0}$ & $\mathbf{1}$ & $\mathbf{2}$ & $\mathbf{3}$ & $\mathbf{4}$ & $\mathbf{5}$ & $\mathbf{6}$ & $\mathbf{7}$ & $\mathbf{8}$ \\
\hline Dentes Superiores & $3(5 \%)$ & $2(3 \%)$ & $5(8 \%)$ & $7(12 \%)$ & $3(5 \%)$ & $2(3 \%)$ & $2(3 \%)$ & $0(0 \%)$ & $1(2 \%)$ \\
\hline Dentes Inferiores & $3(5 \%)$ & $5(8 \%)$ & $9(15 \%)$ & $4(7 \%)$ & $4(7 \%)$ & $7(12 \%)$ & $1(2 \%)$ & $2(3 \%)$ & $0(0 \%)$ \\
\hline Total: & $6(10 \%)$ & $7(12 \%)$ & $14(23 \%)$ & $11(18 \%)$ & $7(12 \%)$ & $9(15 \%)$ & $3(5 \%)$ & $2(3 \%)$ & $1(2 \%)$ \\
\hline
\end{tabular}




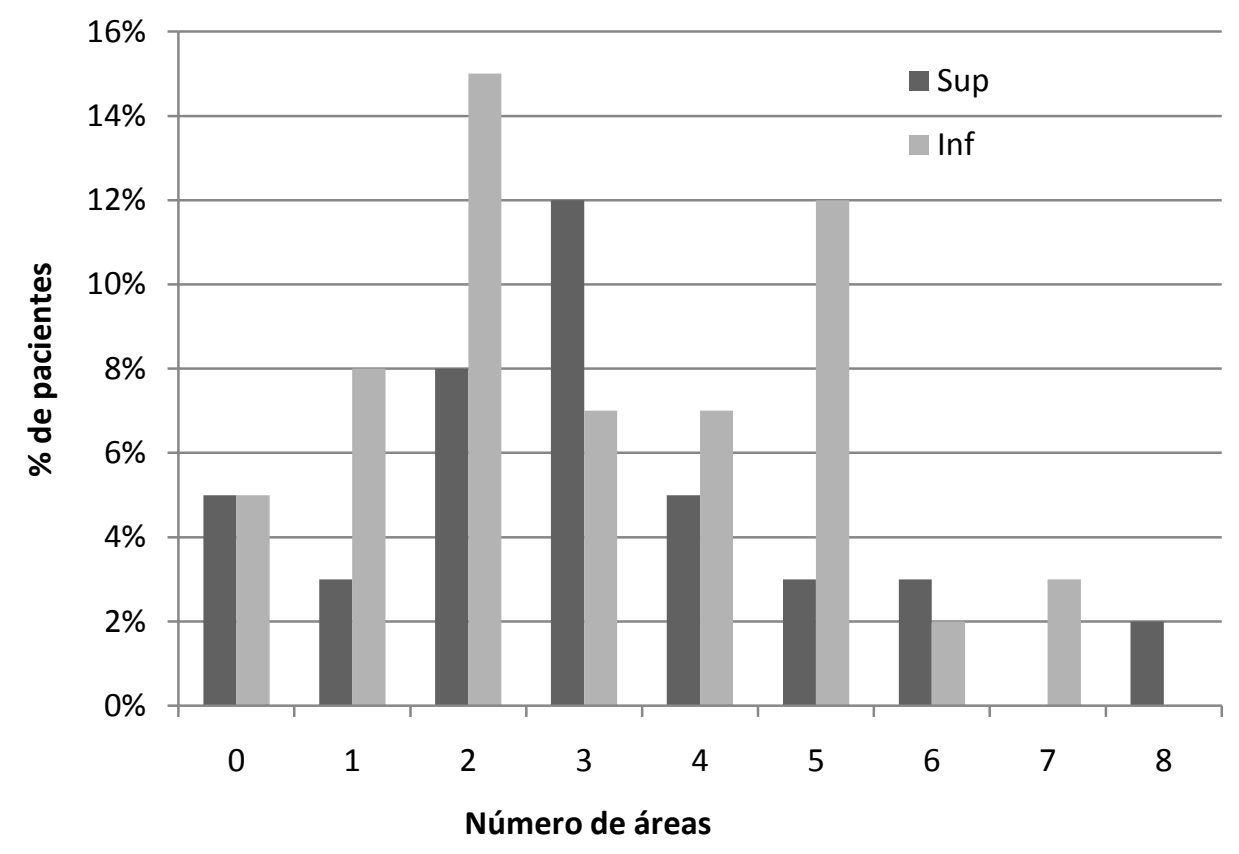

Figura 12: Distribuição dos pacientes (em porcentagem) que apresentaram dentes algógenos superiores (Sup) ou inferiores (Inf) pelo número de áreas de dor referida reportada.

A Tabela 6 é produto da Tabela 5. Zero área de dor referida indica que os pacientes não tiveram dor referida (sem DR) e o restante dos pacientes, com poucas ou muitas áreas, tem dor referida (com DR). Fazendo uma simplificação da Tabela 5 para análise dos pacientes que tiveram dor referida, dividimos os dados em dois grupos: com baixo número de áreas de dor referida (de 1 a 4 áreas) e com mais áreas de dor (5 ou mais áreas de referência de dor dental), como mostrado na Tabela 7 e Figura 13. 
Tabela 6: Localização do dente algógeno, arco superior ou inferior, com relação a existência ou não de dor referida (DR), com DR ou sem DR, respectivamente.

\begin{tabular}{c|c|c}
\cline { 2 - 3 } & Sem DR & Com DR \\
\hline Superior & $3(5 \%)$ & $22(37 \%)$ \\
\hline Inferior & $3(5 \%)$ & $32(53 \%)$ \\
\hline Total: & $6(10 \%)$ & $54(90 \%)$ \\
\hline
\end{tabular}

Tabela 7: Localização do dente algógeno dividido em dois grupos com relação ao número de áreas de referência de dor dental: poucas áreas (de 1 a 4 áreas) e muitas áreas (de 5 a 8 áreas).

\begin{tabular}{c|c|c}
\cline { 2 - 3 } & $1-4$ & $5-8$ \\
\hline Superior & $17(28 \%)$ & $5(8 \%)$ \\
\hline Inferior & $22(37 \%)$ & $10(17 \%)$ \\
\hline Total: & $39(65 \%)$ & $15(25 \%)$ \\
\hline
\end{tabular}

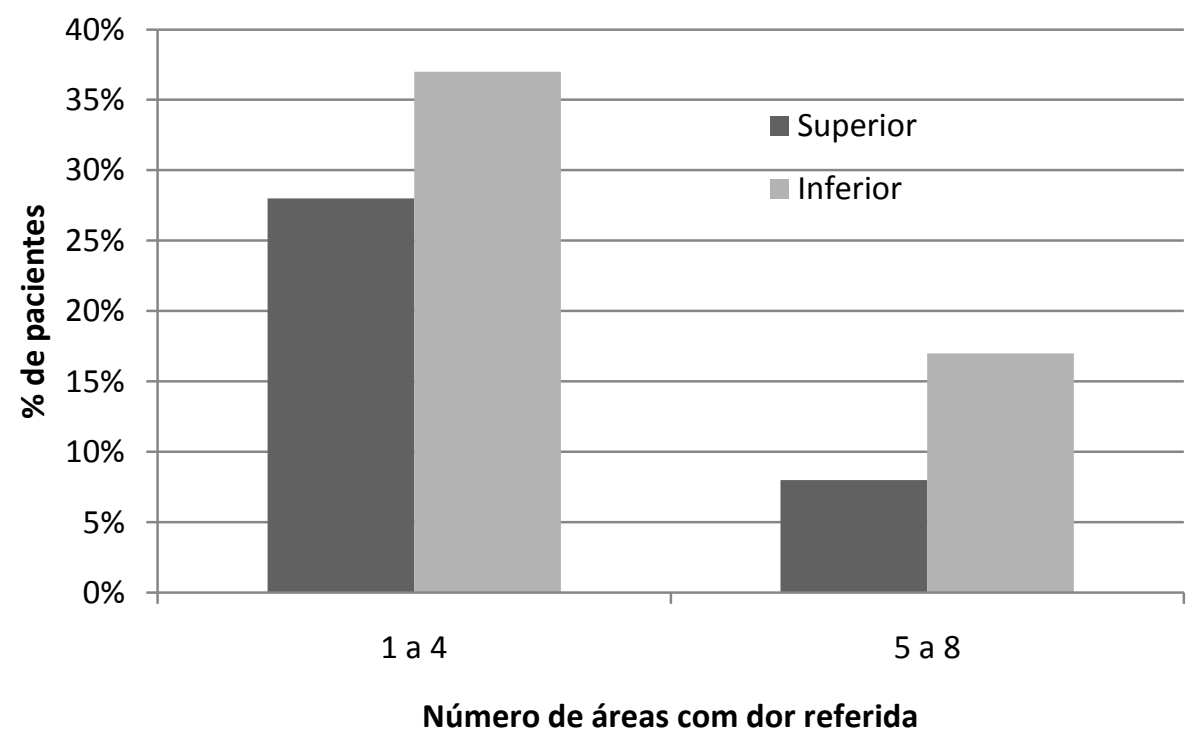

Figura 13: Número de áreas com referência de dor dividido em: poucas áreas (de 1 a 4 áreas) e muitas áreas (de 5 a 8 áreas) versus a localização do dente algógeno: superior ou inferior. 
Não foi encontrada diferença significativa nos dados da Tabela 6 e da Tabela 7 (teste estatístico exato de Fisher, bicaudal, $\mathrm{p}=0,6862$ e $\mathrm{p}=0,5509$, respectivamente). Isto indica que o arco superior e o inferior não diferem em apresentar ou não dor referida e no número de áreas acometidas pela dor referida. Portanto, o número de áreas com dor referida parece depender do diagnóstico provável (polpa viva versus polpa morta), mas não da sua localização, arco superior ou inferior.

Analisamos a relação da localização do dente algógeno (arcada superior ou inferior) com suas áreas de referência de dor na face com relação aos ramos trigeminais: oftálmico, maxilar e mandibular e também região cervical (Tabela 8).

Tabela 8: Distribuição das áreas de referência de dor dos dentes algógenos nos ramos trigeminais de acordo com sua localização, superior ou inferior.

田

\begin{tabular}{c|c|c}
\multirow{2}{*}{} & \multicolumn{2}{|c}{ Dente Algógeno } \\
\cline { 1 - 3 } Áreas Trigeminais & Superior & Inferior \\
\hline Of & - & 1 \\
\hline Mx & 3 & - \\
\hline Md & - & 13 \\
\hline Of, Mx & 4 & - \\
\hline Of, Md & 1 & 8 \\
\hline Mx, Md & 7 & 1 \\
\hline Of, Mx, Md & 5 & 3 \\
\hline Md, Cerv & - & 4 \\
\hline Of, Md, Cerv & - & 1 \\
\hline Of, Mx, Cerv & 1 & - \\
\hline Of, Mx, Md, Cerv & 1 & 1 \\
\hline 0 & 3 & 3 \\
\hline TOTAL & 25 & 35 \\
\hline
\end{tabular}

\begin{tabular}{c|c|c}
\cline { 2 - 3 } & Superior & Inferior \\
\hline Of & 12 & 14 \\
\hline$M x$ & 21 & 5 \\
\hline Md & 14 & 31 \\
\hline Cerv & 2 & 6
\end{tabular}

Legenda

Área trigeminal: ramos do nervo trigêmeo Of: ramo oftálmico Mx: ramo maxilar Md: ramo mandibular Cerv: região cervical

À esquerda, na Tabela 8 , temos as regiões trigeminais dolorosas em relação ao dente, superior ou inferior, causador da dor. À direita, um resumo desta tabela, apontando numericamente as áreas afetadas pelo dente algógeno (as queixas dolorosas). Estas queixas de dor referida (105 ao todo) foram originadas por dentes algógenos superiores e inferiores 
na proporção de 25 superiores e 35 inferiores. A partir desta tabela obtivemos a Figura 14, que mostra a relação da manifestação dolorosa do dente algógeno, superior e inferior, com os ramos trigeminais e região cervical.

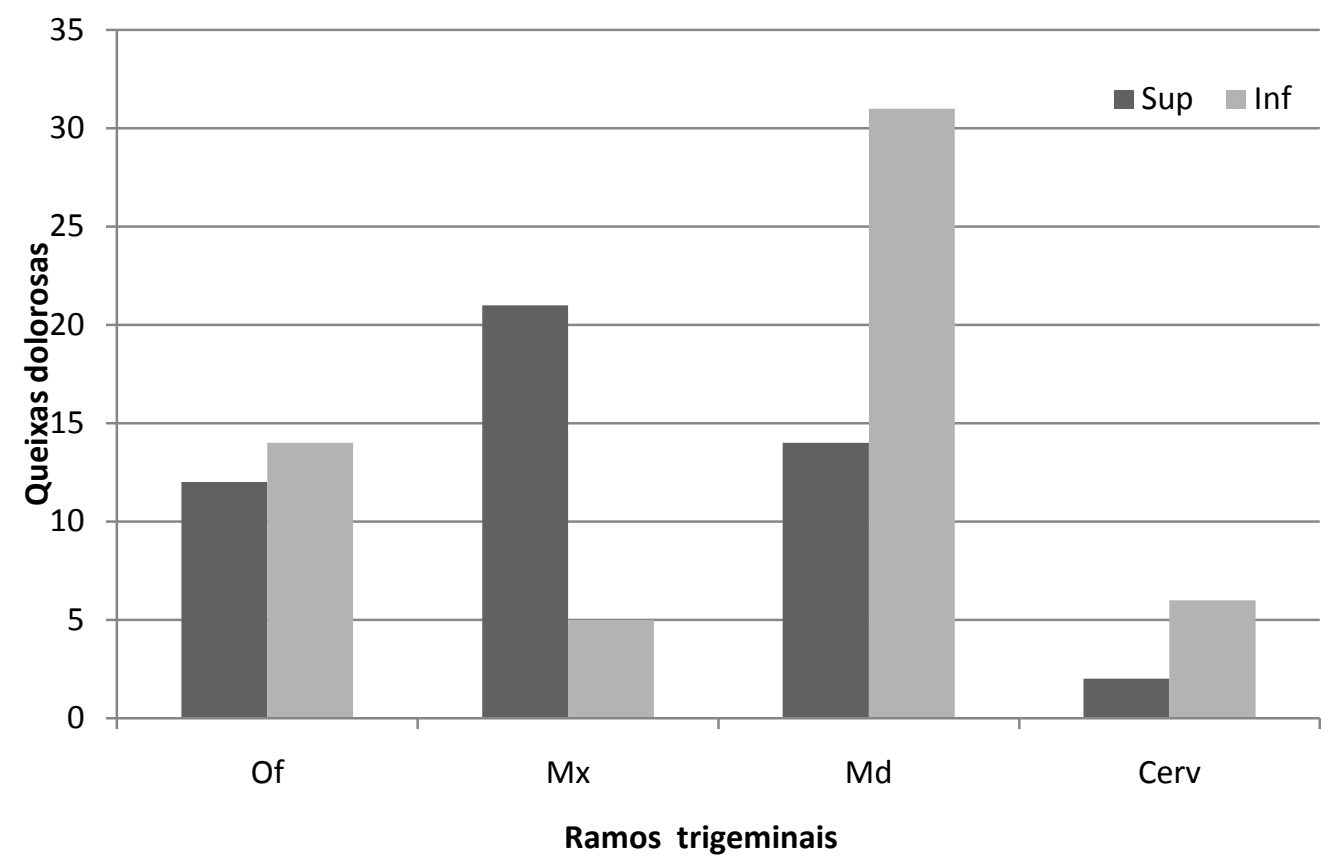

Figura 14: Relação da localização do dente algógeno, superior (Sup) e inferior (Inf), com ramo trigeminal $(\mathrm{Of}=$ oftálmico; $M x=$ maxilar; $M d=$ mandibular $)$ e região cervical (Cerv) com referência de dor.

Observando a Figura 14, percebemos que pode haver manifestação dolorosa em todas as regiões da face para dentes algógenos superiores e inferiores. Porém, notamos uma clara tendência dos superiores terem mais áreas dolorosas no ramo maxilar e poucas áreas nos ramos mandibular e oftálmico, e região cervical. Os dentes inferiores apresentam um maior número de áreas de referência de dor no ramo mandibular e menor nos ramos maxilar e oftálmico, e região cervical.

Esta relação da localização do dente algógeno com a topografia da dor referida merece maior atenção, pois parece existir um padrão de referência de dor dependente da organização das fibras aferentes no núcleo espinal do trigêmeo (PARENT, 1996; BRODAL, 1981), em um padrão conhecido como “casca de cebola”. A análise foi realizada e será apresentada posteriormente. 


\subsubsection{Intensidade da dor}

Analisamos a influência da intensidade nos diversos aspectos da dor, já que a intensidade parece influenciar o fenômeno da dor referida (HARGREAVES, 2002; BENDER, 2000; FALACE, 1996; REGATÃO, CALDEIRA E BALDO, 2002). Os valores estudados se referem sempre à intensidade da dor medida pela escala numérica, já que encontramos uma correlação positiva e significativa entre as duas escalas (vide mensuração da dor - comparação das escalas) - Tabela 9 e Figura 15.

Tabela 9: Número de pacientes que reportaram ou não dor referida versus intensidade da dor.

\begin{tabular}{c|c|c|c|c|c|c|c|c|c|c} 
& \multicolumn{1}{|l}{ Intensidade da Dor } \\
\cline { 2 - 10 } & $\mathbf{1}$ & $\mathbf{2}$ & $\mathbf{3}$ & $\mathbf{4}$ & $\mathbf{5}$ & $\mathbf{6}$ & $\mathbf{7}$ & $\mathbf{8}$ & $\mathbf{9}$ & $\mathbf{1 0}$ \\
\hline $\begin{array}{l}\text { sem dor } \\
\text { referida }\end{array}$ & 0 & 0 & 0 & 0 & $\begin{array}{c}3 \\
(5 \%)\end{array}$ & $\begin{array}{c}1 \\
(2 \%)\end{array}$ & 0 & $\begin{array}{c}1 \\
(2 \%)\end{array}$ & $\begin{array}{c}1 \\
(2 \%)\end{array}$ & 0 \\
\hline $\begin{array}{l}\text { com dor } \\
\text { referida }\end{array}$ & 0 & 0 & $\begin{array}{c}1 \\
(2 \%)\end{array}$ & $\begin{array}{c}1 \\
(2 \%)\end{array}$ & $\begin{array}{c}6 \\
(10 \%)\end{array}$ & $\begin{array}{c}5 \\
(8 \%)\end{array}$ & $\begin{array}{c}3 \\
(5 \%)\end{array}$ & $\begin{array}{c}13 \\
(22 \%)\end{array}$ & $\begin{array}{c}5 \\
(8 \%)\end{array}$ & $\begin{array}{c}20 \\
(33 \%)\end{array}$ \\
\hline
\end{tabular}

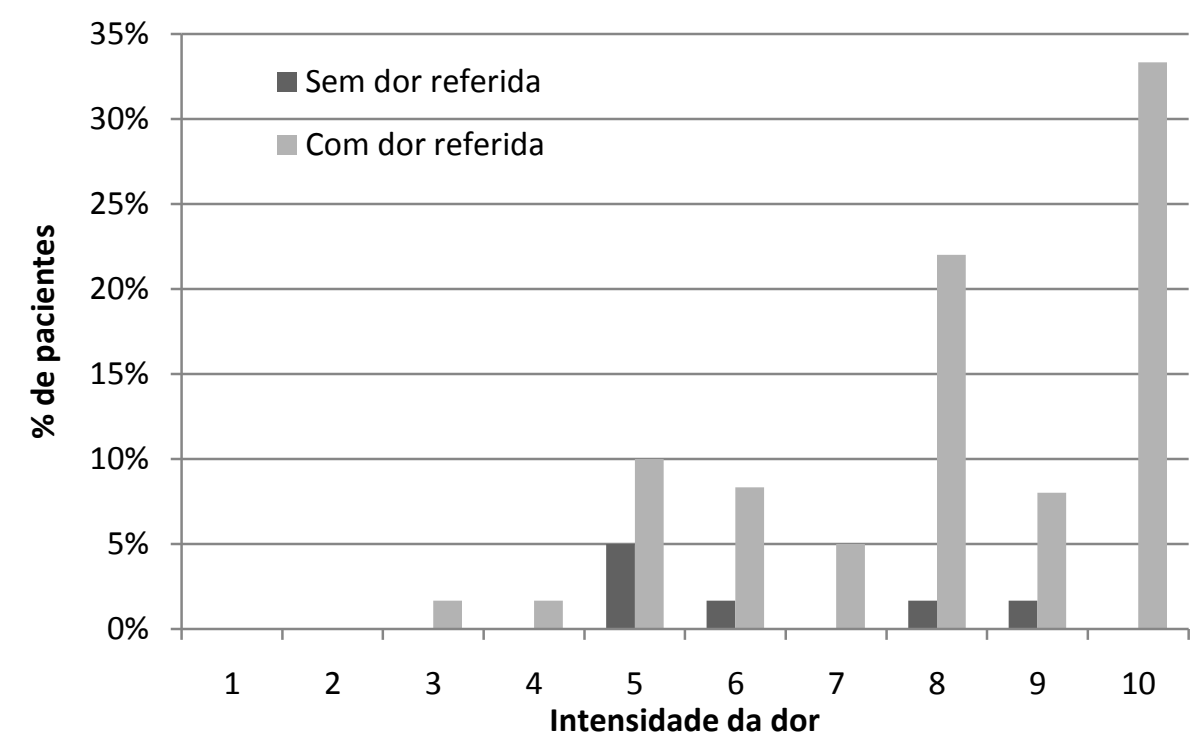

Figura 15: Distribuição dos pacientes com ou sem dor referida pela intensidade da dor reportada medida pela escala ordinal numérica. 
Para análise, separamos estes pacientes que tiveram ou não dor referida em dois grupos de acordo com a intensidade da dor reportada por eles: dor fraca a moderada (de 1 a 5 na escala numérica de dor), dor moderada a intensa (de 6 a 10 na escala numérica de dor), Tabela 10 e Figura 16.

Tabela 10: Pacientes com ou sem dor referida divididos em relação a intensidade da dor: de fraca a moderada ( 1 a 5 na escala numérica); de moderada a intensa (6 a 10 na escala numérica).

\begin{tabular}{c|c|c}
\cline { 2 - 3 } Intensidade da dor & Sem DR & Com DR \\
\hline 1 a 5 & $3(5 \%)$ & $8(13 \%)$ \\
\hline 6 a 10 & $3(5 \%)$ & $46(77 \%)$ \\
\hline Total: & $6(10 \%)$ & $54(90 \%)$ \\
\hline
\end{tabular}

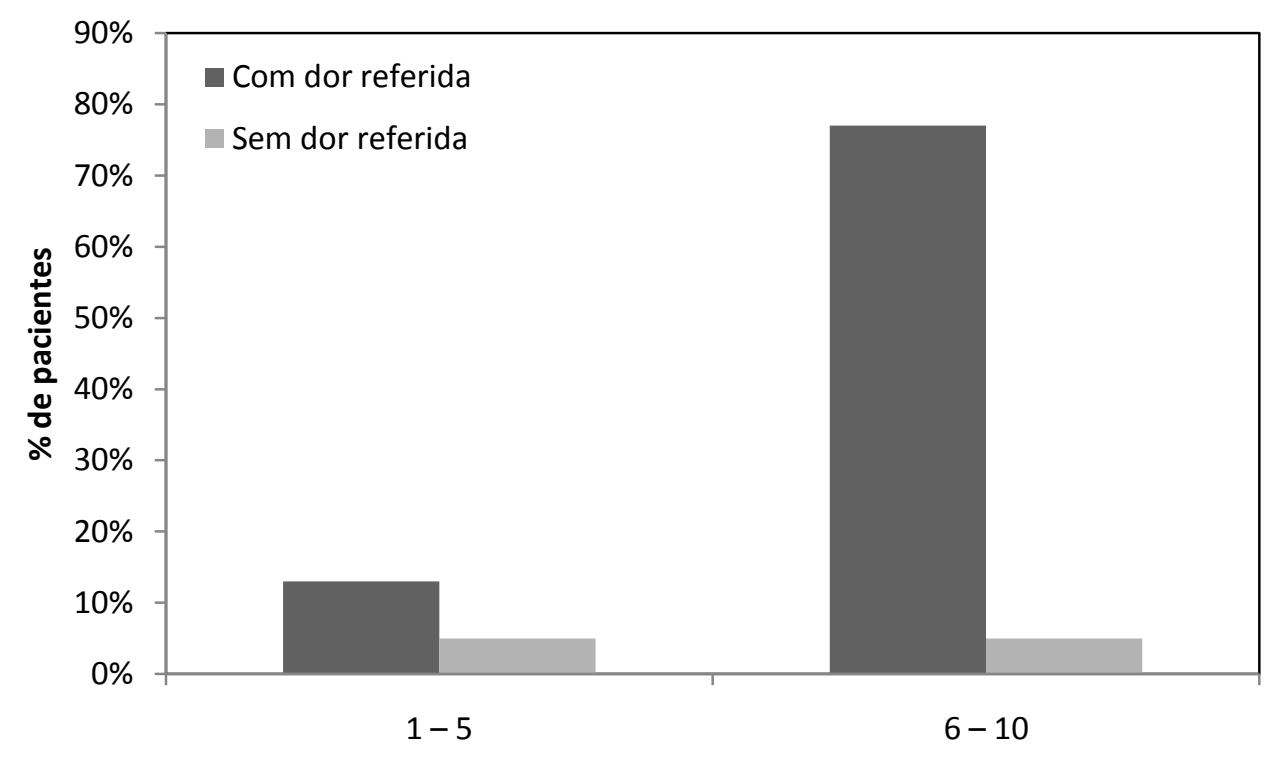

Figura 16: Distribuição dos pacientes (em porcentagem) com ou sem dor referida pela intensidade da dor dividida em dois grupos: com dor de fraca a moderada (1 a 5 na escala numérica) e moderada a intensa (6 a 10 na escala numérica).

A intensidade parece influenciar o fenômeno da dor dental referida (Figuras 15 e 16), visto que encontramos uma diferença significativa entre a intensidade da dor reportada pelos pacientes com o fato do paciente reportar ou não áreas de dor referida na face (teste exato de Fisher, unicaudal, $\mathrm{p}=0,0689)$. Os pacientes com maior intensidade da dor 
normalmente reportam dor referida. Observamos uma clara interação dos fatores "intensidade da dor" e "presença de dor referida": a probabilidade de um paciente apresentar dor referida depende do nível de intensidade da dor (fraca a moderada ou moderada a intensa).

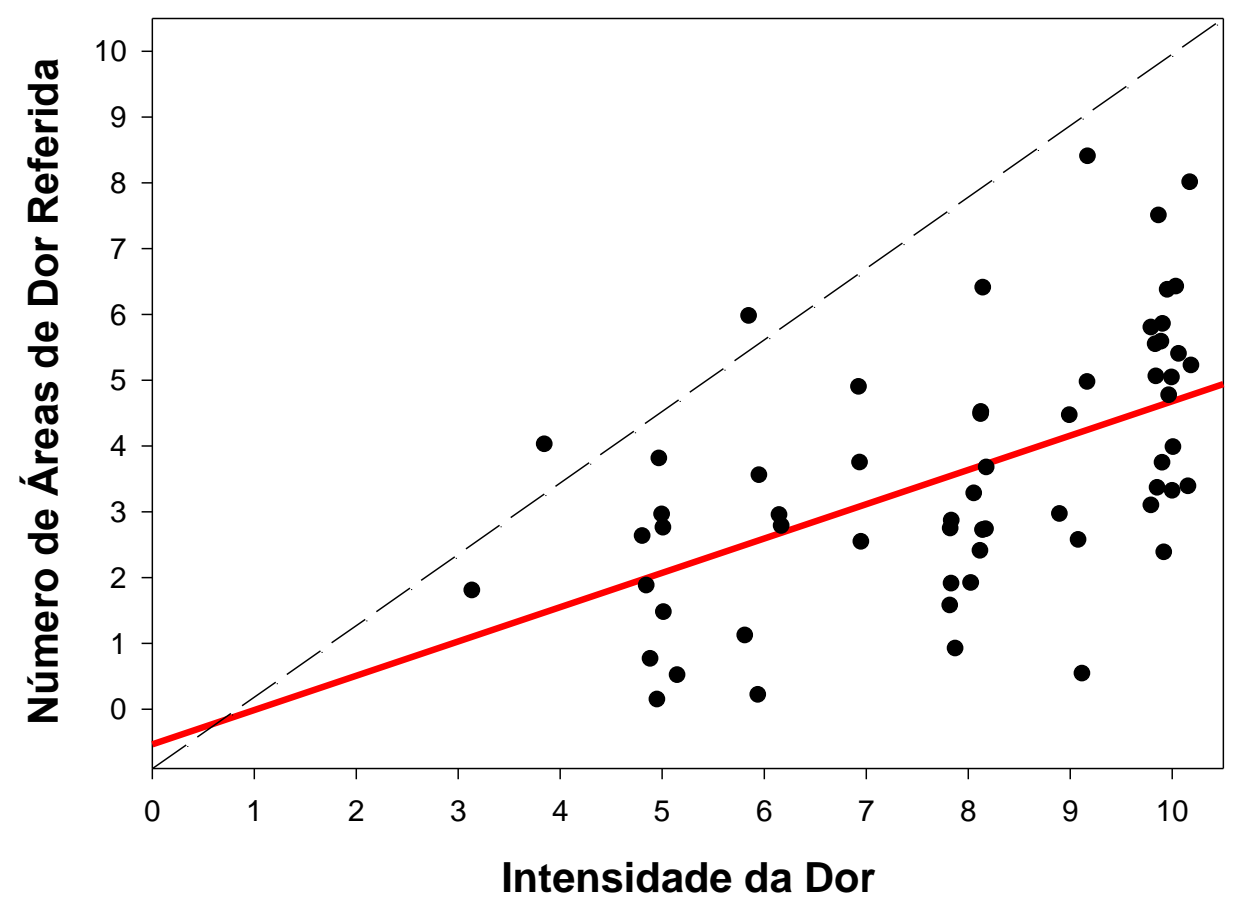

Figura 17: Correlação positiva entre a intensidade da dor medida pela escala ordinal numérica com o número de áreas com dor referida reportada pelos pacientes.

Encontramos uma correlação positiva entre o número de áreas com dor referida e a intensidade da dor $(r=0,60 ; \mathrm{p}<0,001$ - coeficiente de correlação de Spearman)- Figura 17. Quanto maior a intensidade da dor, um maior número de áreas de dor referida era reportado pelos pacientes.

Outro fator estudado foi o número de ramos trigeminais afetados pela dor referida relacionado com a intensidade da dor reportada pelos pacientes. Para análise, dividimos a intensidade da dor em ' fraca a moderada' e 'moderada a intensa'- Tabela 11 e Figura 18. 
Tabela 11: Número de ramos trigeminais que apresentaram dor referida divididos em 2 grupos: até um ramo e mais de 1 ramos versus intensidade da dor dividida em dois grupos: com dor de fraca a moderada ( 1 a 5 na escala numérica) e moderada a intensa (6 a 10 na escala numérica)

\begin{tabular}{c|c|c}
\multicolumn{1}{c}{} & \multicolumn{2}{c}{ Intensidade da dor } \\
\cline { 3 - 3 } $\begin{array}{c}\text { Ramos trigeminais com } \\
\text { Dor Referida }\end{array}$ & $\mathbf{1}$ a 5 & $\mathbf{6}$ a 10 \\
\hline Até 1 & $10(16 \%)$ & $17(28 \%)$ \\
\hline Mais de 1 & $1(2 \%)$ & $32(54 \%)$ \\
\hline Total & $\mathbf{1 1 ( 1 8 \% )}$ & $\mathbf{4 9}(\mathbf{8 2 \%})$ \\
\hline
\end{tabular}

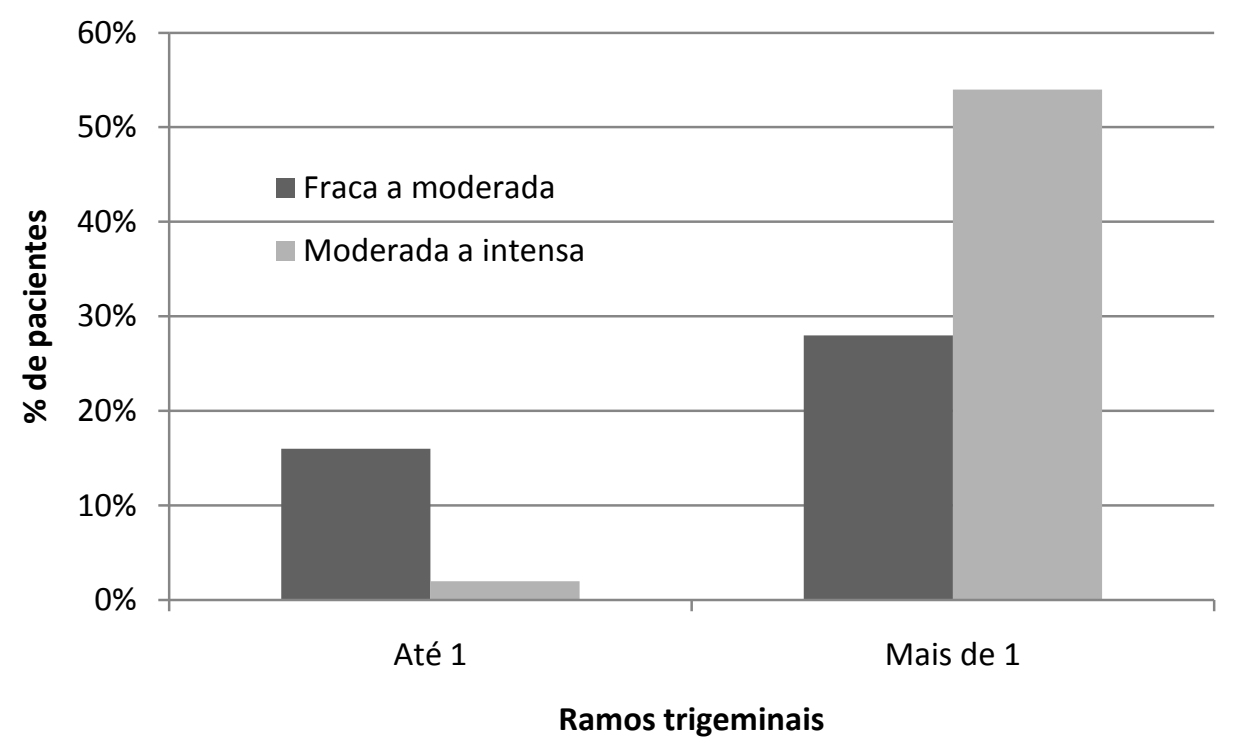

Figura 18: Distribuição dos pacientes pelo número de ramos trigeminais afetados pela dor, divididos em até 1 ramos e mais de 1, quando analisamos a intensidade da dor em dois grupos: com dor de fraca a moderada e moderada a intensa.

Os pacientes que apresentaram dor de moderada a intensa têm uma tendência significativa de relatar dor em um maior número de ramos do trigêmeo do que os pacientes com dor fraca a moderada (teste exato de Fisher, unicaudal, $\mathrm{p}=0,0009$ ).

Os resultados obtidos até aqui referentes à intensidade da dor são convergentes e complementares, isto é, quanto maior a intensidade da dor, maior é a probabilidade do paciente ter áreas de dor referida e, além disso, maior é a chance dele reportar mais áreas dolorosas em um maior número de ramos trigeminais. 


\subsubsection{Duração da dor}

Durante a anamnese, perguntamos ao paciente qual era a duração da dor que ele estava sentido e observamos que a maioria dos pacientes relatava que a dor era contínua (75\%). Os outros $15 \%$ relatavam que a dor iniciava e perdurava por alguns minutos. Separamos a amostra em dois grupos para análise: os que relatavam que a dor era intermitente (durava até meia hora) e os que relatavam que a dor era contínua. Analisamos a influência da duração da dor sobre a existência da dor referida (Tabela 12 e Figura 19).

Tabela 12: Pacientes com ou sem dor referida (DR) divididos em relação a duração da dor: intermitente (até meia hora) ou contínua.

\begin{tabular}{c|c|c}
\cline { 2 - 3 } Duração da dor & Sem DR & Com DR \\
\hline Intermitente & $3(5 \%)$ & $12(20 \%)$ \\
\hline Contínua & $3(5 \%)$ & $42(70 \%)$ \\
\hline Total: & $6(18 \%)$ & $54(90 \%)$ \\
\hline
\end{tabular}

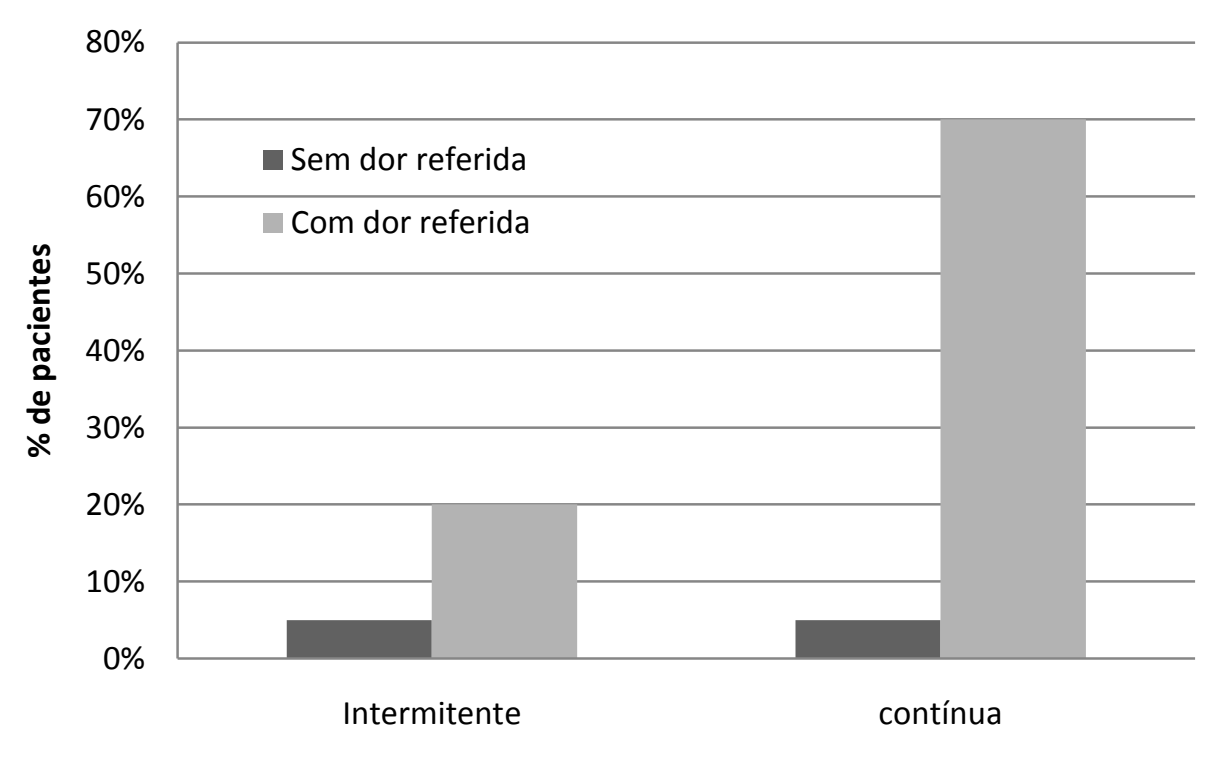

Figura 19: Distribuição dos pacientes (em porcentagem) com ou sem dor referida pela duração da dor dividida em dois grupos: dor intermitente e contínua. 
Apesar da grande diferença na proporção dos pacientes que relataram dor referida quando esta era contínua em relação aos que não apresentaram dor referida, não flagramos uma diferença significativa na duração da dor de dente com a probabilidade de apresentar ou não dor referida em outras regiões da cabeça e pescoço (teste exato de Fisher, bicaudal, $\mathrm{p}=0,1588)$.

Na Tabela 13 e Figura 20 temos a relação da duração da dor com o número de áreas afetadas pela dor referida.

Tabela 13: Duração da dor com relação ao número de áreas de referência de dor dental: poucas áreas (de 1 a 4 áreas) e muitas áreas (de 5 a 8 áreas).

\begin{tabular}{c|c|c}
\cline { 2 - 3 } & $1-4$ & $5-8$ \\
\hline Intermitente & $10(18 \%)$ & $2(4 \%)$ \\
\hline Contínua & $29(54 \%)$ & $13(24 \%)$ \\
\hline Total: & $39(72 \%)$ & $15(28 \%)$ \\
\hline
\end{tabular}

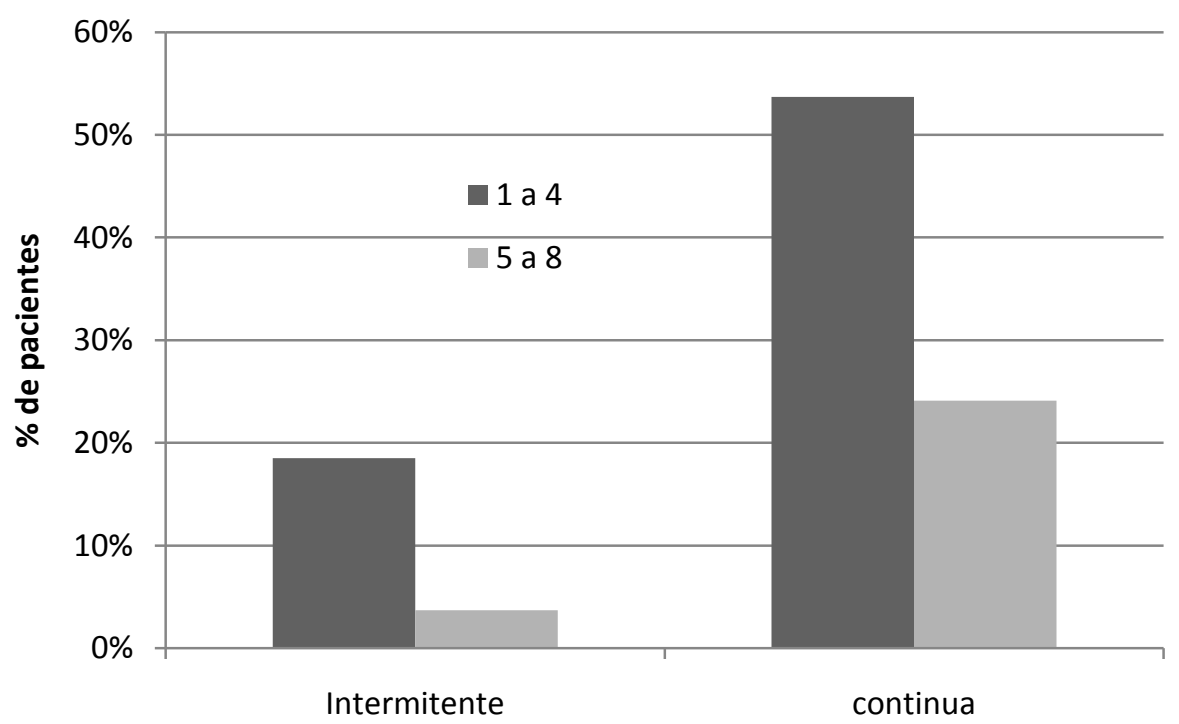

Figura 20: Número de áreas com referência de dor dividido em: poucas áreas (de 1 a 4 áreas) e muitas áreas (de 5 a 8 áreas) versus a duração da dor do dente algógeno. 
A duração da dor de dente, se intermitente ou contínua, parece não influenciar o número de áreas afetadas pela dor referida (teste exato de Fisher, bicaudal, p=0,4741).

Na Tabela 14 e Figura 21 abaixo temos número de ramos trigeminais afetados pela dor referida divididos pela duração da dor.

Tabela 14: Número de ramos trigeminais que apresentaram dor referida divididos em 2 grupos: até um ramo e mais de 1 ramos versus duração da dor dividida em dois grupos: intermitente e dor contínua.

\begin{tabular}{c|c|c}
\multicolumn{1}{c}{} & \multicolumn{2}{c}{ Duração da dor } \\
\cline { 2 - 3 } & & \\
\cline { 2 - 3 } $\begin{array}{c}\text { Ramos trigeminais } \\
\text { com Dor Referida }\end{array}$ & Intermitente & Contínua \\
\hline Até 1 & $12(20 \%)$ & $3(5 \%)$ \\
\hline Mais de 1 & $15(25 \%)$ & $30(50 \%)$ \\
\hline Total & $\mathbf{2 7}(\mathbf{4 5 \%})$ & $\mathbf{3 3 ( 5 5 \% )}$ \\
\hline
\end{tabular}

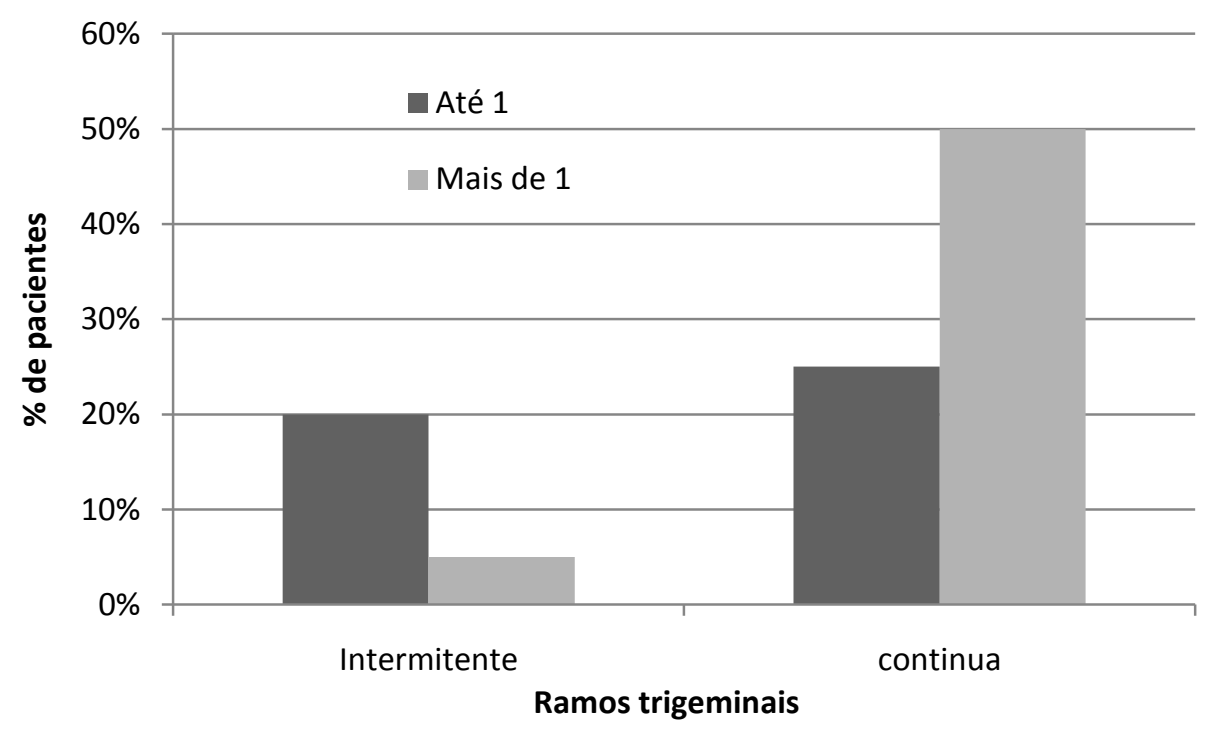

Figura 21: Distribuição dos pacientes pelo número de ramos trigeminais afetados pela dor, dividios em até 1 ramos e mais de 1, quando analisamos a duração da dor em dois grupos: dor intermitente e contínua.

Observamos que a duração da dor influencia o espalhamento da dor referida em um maior número de ramos trigeminais (teste exato de Fisher, bicaudal, p=0,0024). 


\subsubsection{Padrão de Dispersão da Dor Referida}

Realizamos uma análise das áreas de dor referida conforme esta organização topográfica das fibras trigeminais em sua primeira sinapse no núcleo espinal do trigêmeo, subnúcleo caudal. Os neurônios de $2^{\mathrm{a}}$ ordem distribuídos ao longo da direção rostro-caudal da subdivisão caudal do núcleo espinal do trigêmeo possuem campos receptivos que se coalescem, de forma topograficamente organizada, também em uma direção ânteroposterior na face, produzindo áreas que se dispõem verticalmente no segmento cefálico. Observamos se existe uma maior tendência da dor referida se espalhar de acordo com estes campos receptivos, m, no sentido vertical na face humana (Figura 22, à direita). A partir das áreas pré-determinadas por nós na ficha clínica, determinamos quais áreas corresponderiam a esta dispersão vertical e horizontal na hemi face humana, como mostrado na figura abaixo. Cabe lembrar que aqui analisaremos apenas os pacientes que reportaram dor referida, isto é, indicaram que além do dente, mais áreas foram afetadas pela dor. Em nossa amostra, a maioria dos pacientes relatou dor referida: 54 pacientes $(90 \%$ do total) e apenas estes serão analisados a seguir.
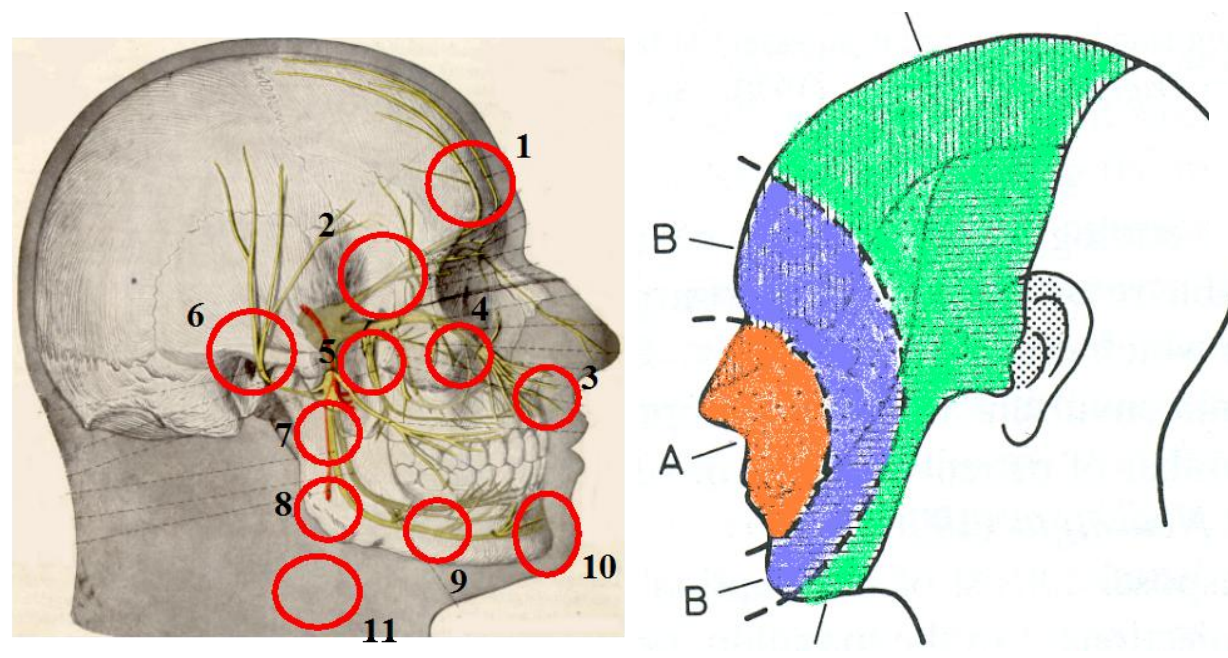

\begin{tabular}{|c|c|}
\hline Área A: & $\mathbf{3 , 4 , 1 0}$ \\
\hline Área B: & $\mathbf{1 , 2 , 4 , 5 , 9 , 1 0}$ \\
\hline Área C: & $\mathbf{5 , 6 , 7 , 8 , 9}$ \\
\hline
\end{tabular}

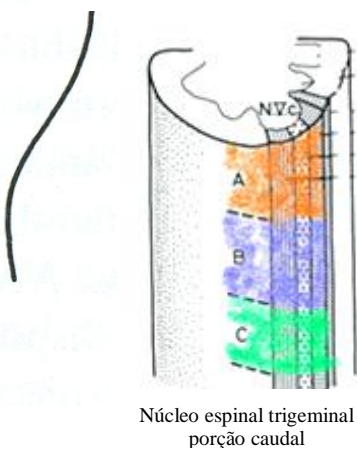

Figura 22: À esquerda: representaçao da hemi face humana utilizada por nós na obtenção dos dados referentes as áreas com dor referida; à direita, representação da hemi face humana delimitada com as áreas onde é mais provével a dispersão da dor referida. A tabela ao lado mostra quais áreas (delimitada por nós na figura da esquerda) foram consideradas para a análise do padrão de referência de dor em "casca de cebola". 
Observamos uma maior dispersão vertical (61\%), indicando que a as áreas de referência de dor se distribuem, preferencialmente, de acordo com o arranjo das fibras aferentes no núcleo espinal do trigêmeo. Entretanto, obtivemos um padrão de dispersão horizontal da dor referida nos $39 \%$ restantes da amostra. A seguir, analisaremos este padrão de dispersão da dor em relação as características fisiopatológicas do dente algógeno.

Os dentes com polpa viva apresentaram uma maior proporção de dispersão horizontal da dor referida, enquanto nos casos de polpa morta, há maior dispersão no sentido vertical (teste exato de Fisher, bicaudal, p=0,0018) - Tabela 15 e Figura 23.

Tabela 15: Dispersão da dor no sentido vertical ou horizontal versus seu estado pulpar: polpa mortificada (PM) ou polpa viva (PV).

\begin{tabular}{c|c|c}
\cline { 2 - 3 } & PM & PV \\
\hline Dispersão Vertical da Dor Referida & $23(43 \%)$ & $10(18 \%)$ \\
\hline Dispersão Horizontal da Dor Referida & $5(9 \%)$ & $16(30 \%)$ \\
\hline Total: & $28(52 \%)$ & $26(48 \%)$ \\
\hline
\end{tabular}

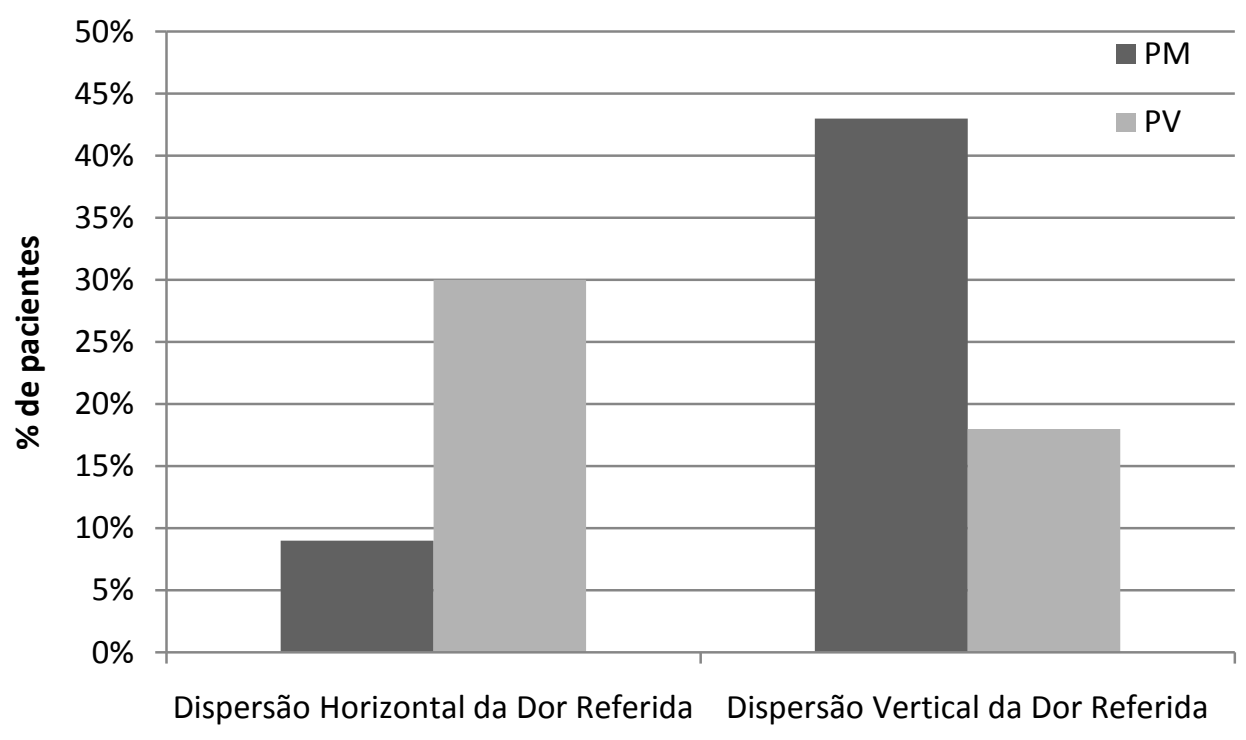

Figura 23: Dispersão da dor referida quando analisado o padrão "casca de cebola" de referencia de dor para os casos de polpa morta(PM) e polpa viva (PV). 
A localização do dente algógeno, se superior ou inferior, parece não influenciar um sentido preferencial de dispersão da dor referida (teste exato de Fisher, bicaudal, p=0,0872) - Tabela 16 e Figura 24.

Realizamos também uma análise mostrando a relação da localização do dente algógeno com a região com que a dor foi sentida e sua incidência. Os resultados estão apresentados nas Figuras 25 e 26, separadas pelos diferentes grupos dentais. Não consideramos na análise os incisivos e caninos, por apresentarem um número muito baixo de dor em nossa amostra. Podemos observar a região onde preferencialmente a dor se refere e o grande espalhamento que esta dor pode apresentar nos sentidos vertical e horizontal.

Tabela 16: Dispersão da dor no sentido vertical ou horizontal versus localização do dente algógeno, superior ou inferior.

\begin{tabular}{c|c|c}
\cline { 2 - 3 } & Superior & Inferior \\
\hline Dispersão Vertical da Dor Referida & $10(18 \%)$ & $23(43 \%)$ \\
\hline Dispersão Horizontal da Dor Referida & $12(22 \%)$ & $9(17 \%)$ \\
\hline Total: & $22(40 \%)$ & $32(60 \%)$ \\
\hline
\end{tabular}

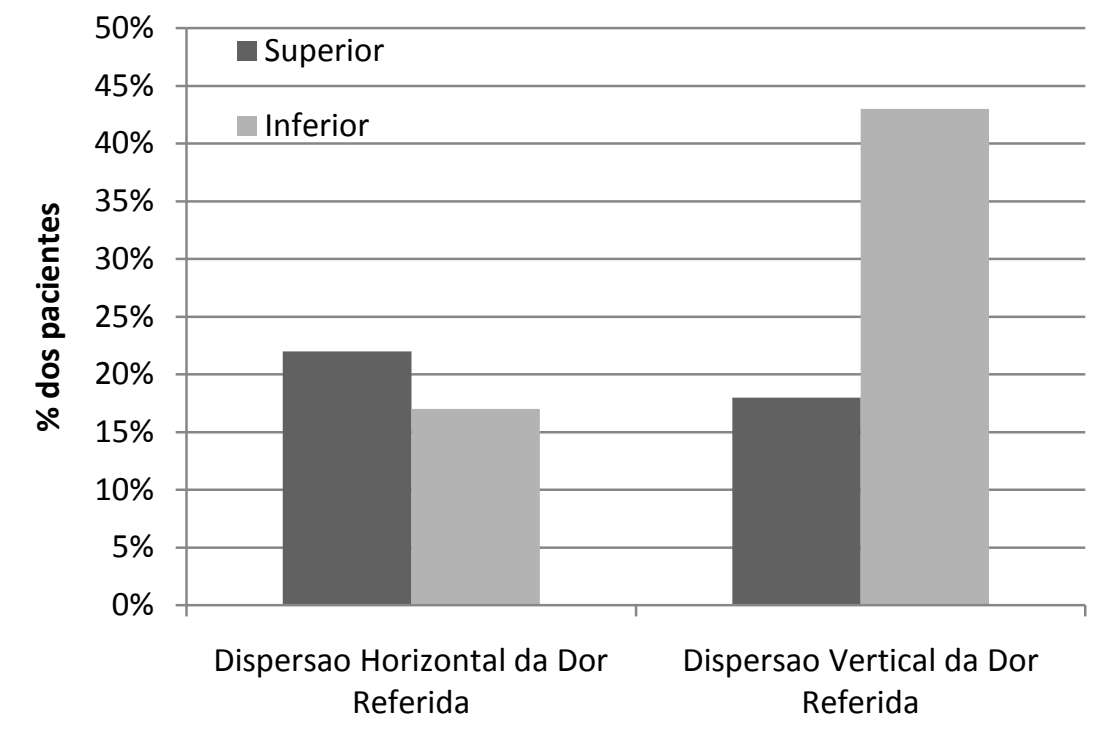

Figura 24: Dispersão da dor referida quando analisado o padrão "casca de cebola" de referencia de dor para dentes algógenos superiores e inferiores. 

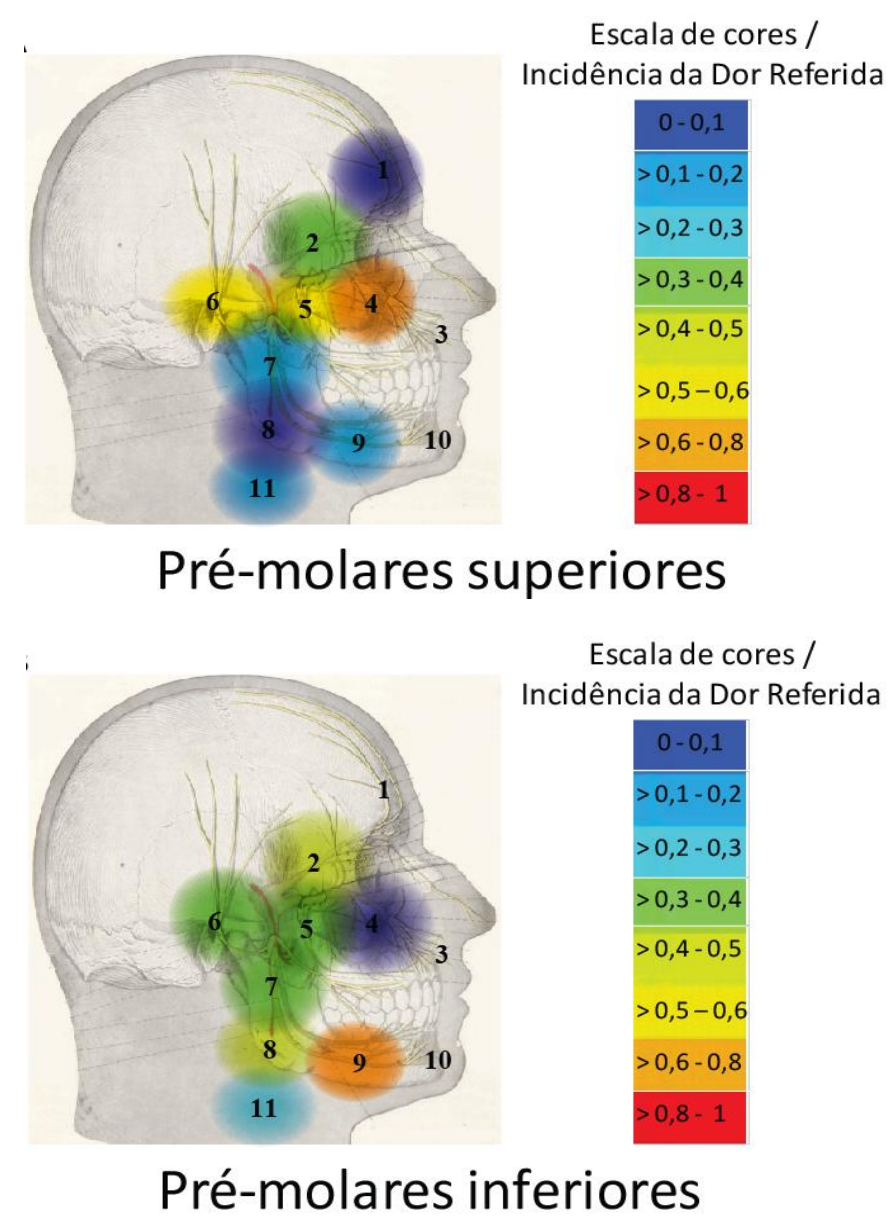

B

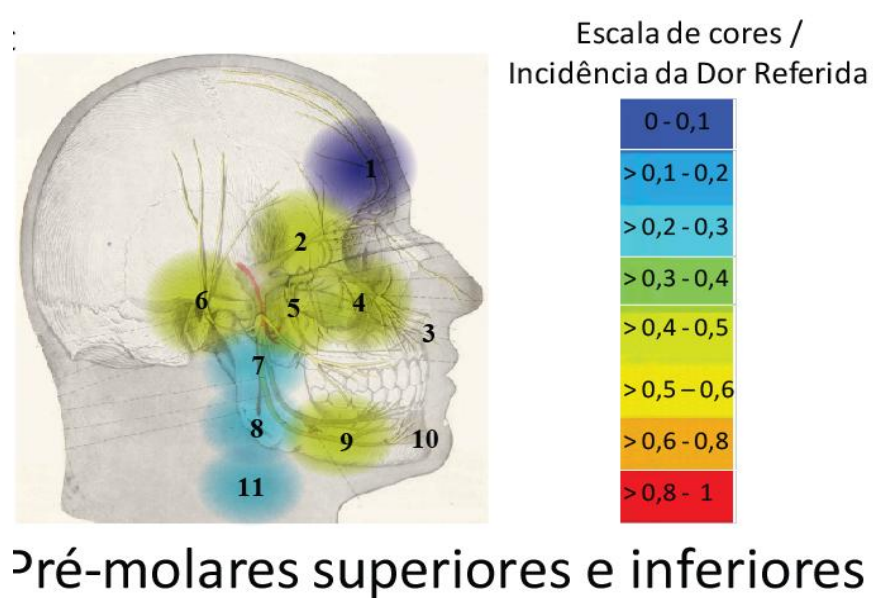

Figura 25: Dispersão da dor referida nos pré-molares. Cada cor da escala ao lado da figura representa um intervalo numérico, expressando a incidência da dor na área demarcada normalizada, isto é, a incidência da dor naquela área dividido pelo número de pacientes com dor nos pré-molares. A: dispersão da dor mais provável em pré-molares superiores $(n=10)$; B: dispersão da dor mais provável para prémolares inferiores $(n=8)$; $C$ : soma de $A$ e $B$, representado as regiões mais prováveis do espalhamento da dor para este grupo dental $(n=18)$. 

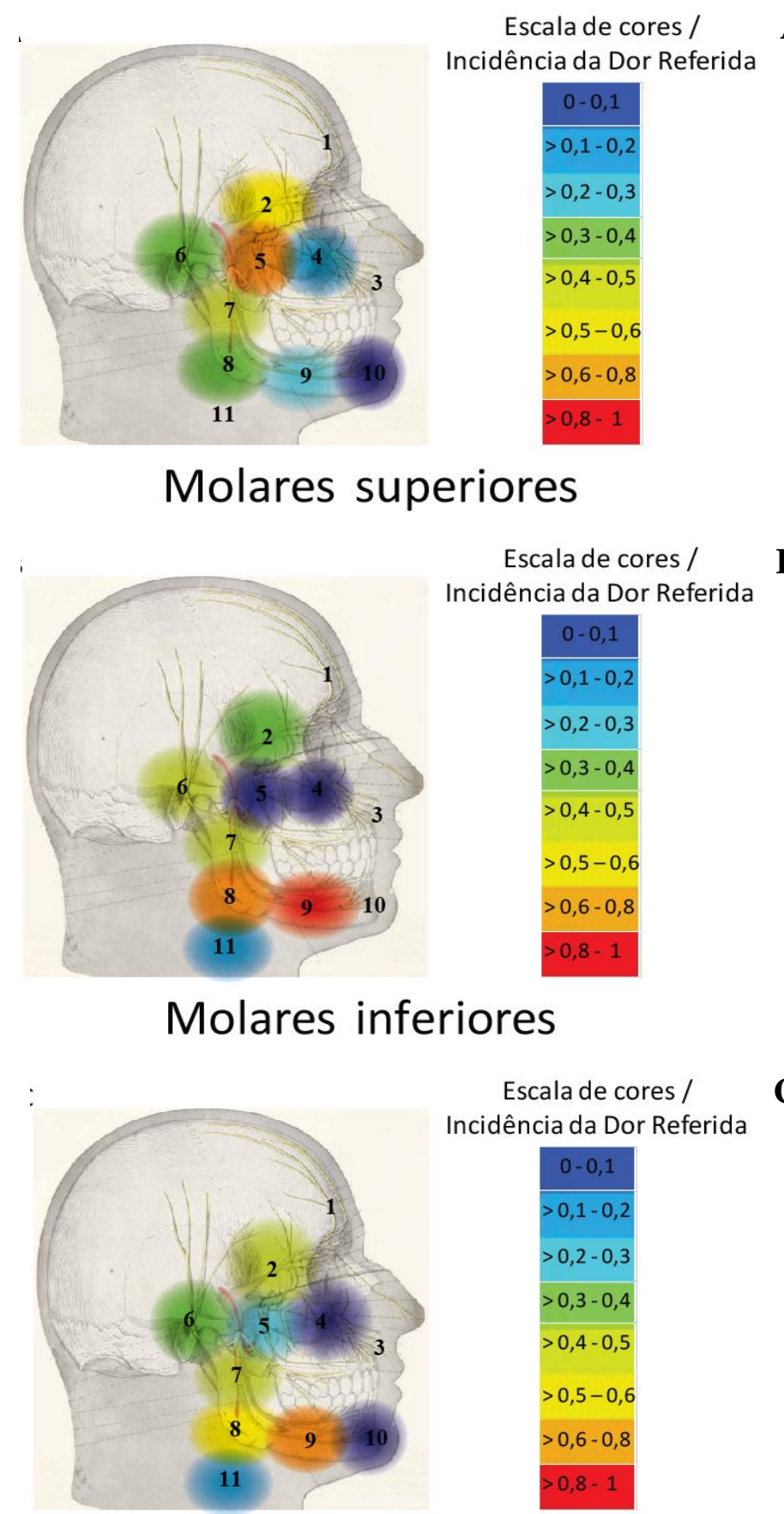

Molares superiores e inferiores

Figura 26: Dispersão da dor referida nos molares. Cada cor da escala ao lado da figura representa um intervalo numérico, expressando a incidência da dor na área demarcada normalizada, isto é, a incidência da dor naquela área dividido pelo número de pacientes com dor nos molares. A: dispersão da dor mais provável em molares superiores $(n=13)$; B: dispersão da dor mais provável para molares inferiores (n=26); C: soma de A e B, representado as regiões mais prováveis do espalhamento da dor para este grupo dental $(n=39)$. 
Nos casos de dor com maior intensidade, obtivemos uma maior proporção de dispersão horizontal da dor referida (teste exato de Fisher, unicaudal, $p=0,0621$ ) - Tabela 17 e Figura 27. Quando a dor é de menor intensidade, há maior dispersão no sentido vertical.

Tabela 17: Dispersão da dor no sentido vertical ou horizontal versus sua intensidade, dividida em: de fraca a moderada (1 a 5 na escala numérica); de moderada a intensa (6 a 10 na escala numérica).

\begin{tabular}{c|c|c}
\cline { 2 - 3 } & $1-5$ & $6-10$ \\
\hline Dispersão Vertical da Dor Referida & $8(15 \%)$ & $25(37 \%)$ \\
\hline Dispersão Horizontal da Dor Referida & $1(2 \%)$ & $20(46 \%)$ \\
\hline Total: & $9(17 \%)$ & $45(83 \%)$ \\
\hline
\end{tabular}

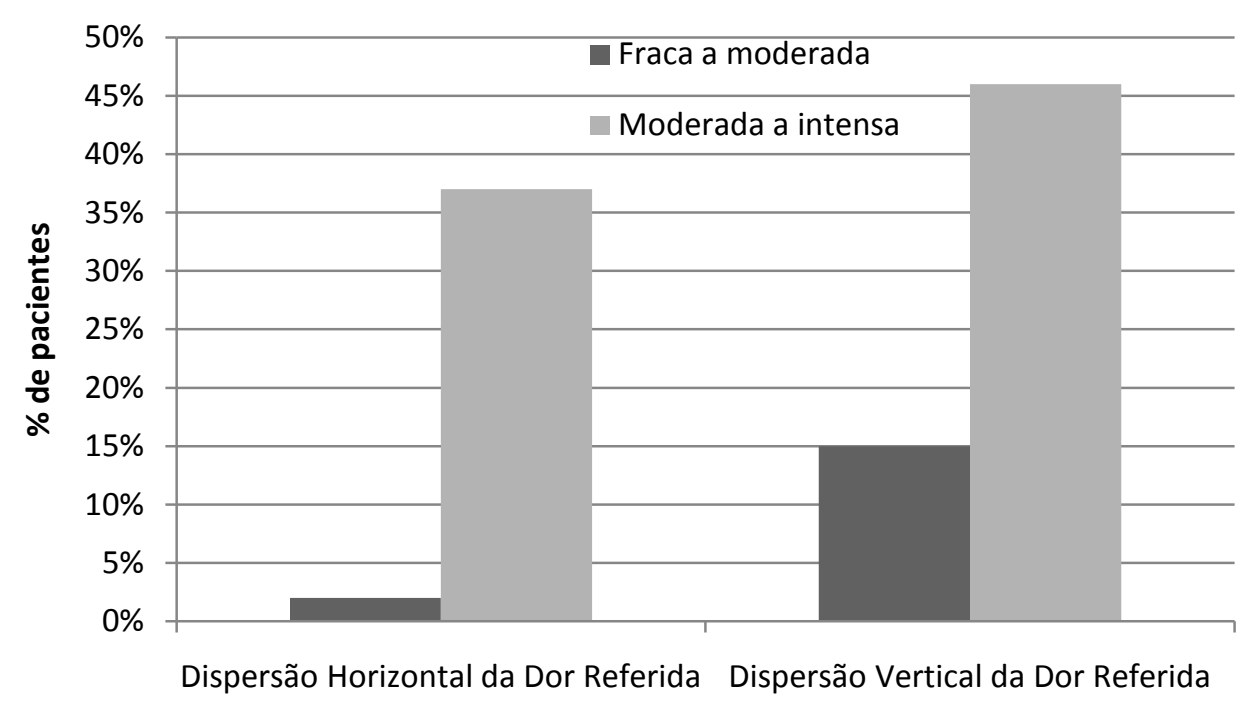

Figura 27: Dispersão da dor referida quando analisado o padrão "casca de cebola" de referencia para dores de menores e maiores intensidades.

Quando a dor era intermitente havia uma maior probabilidade de um espalhamento da dor referida apenas no sentido vertical (teste exato de Fisher, bicaudal, p=0,0181), região esta pertencente ao mesmo correspondente do dermátomo facial que o dente algógeno (Tabela 18 e Figura 28). 
Tabela 18: Dispersão da dor no sentido vertical ou horizontal versus sua duração, dividida em: intermitente (dor durava até meia hora) ou contínua.

\begin{tabular}{c|c|c}
\cline { 2 - 3 } & Intermitente & Contínua \\
\hline Dispersão Vertical da Dor Referida & $11(20 \%)$ & $22(41 \%)$ \\
\hline Dispersão Horizontal da Dor Referida & $1(2 \%)$ & $20(37 \%)$ \\
\hline Total: & $12(22 \%)$ & $42(78 \%)$ \\
\hline
\end{tabular}

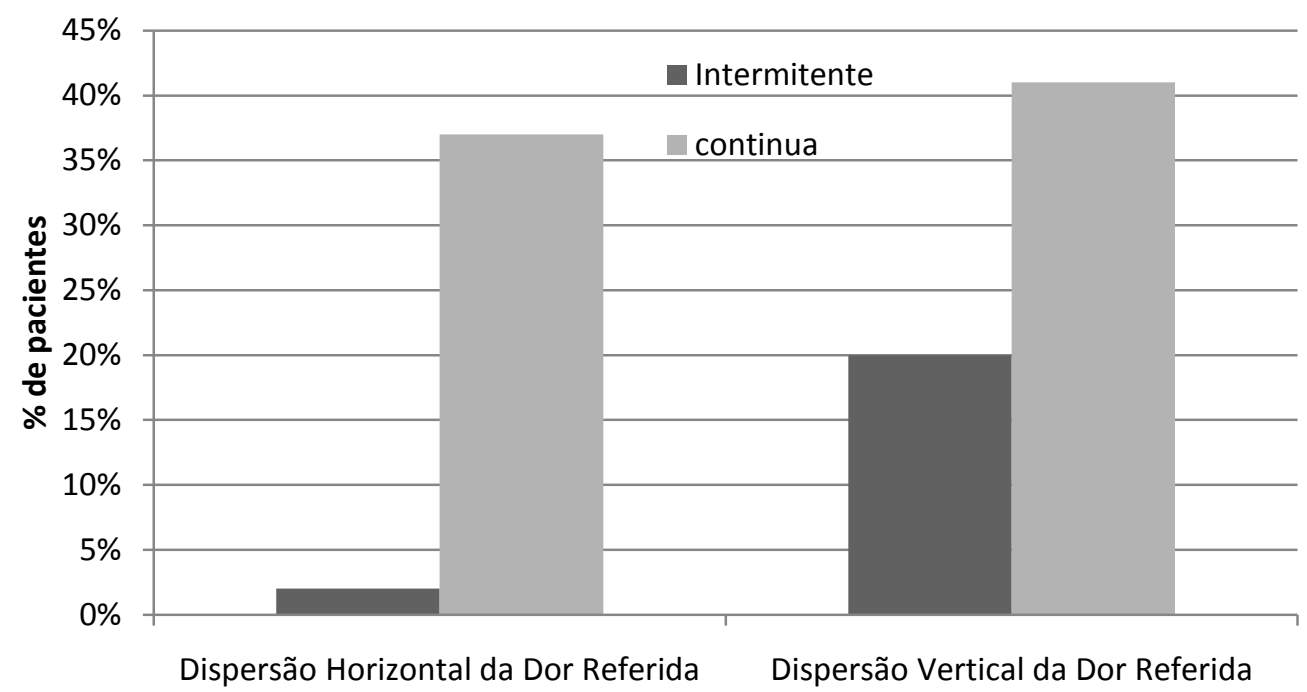

Figura 28: Dispersão da dor referida quando analisado o padrão "casca de cebola" de referencia para dores intermitente e contínua.

\subsection{Inter-relações das Características Fisiopatológicas do Dente Algógeno}

Analisaremos a seguir, como as características fisiopatológicas do dente algógeno se correlacionam entre si. 


\subsubsection{Estado pulpar vs Intensidade da dor}

Correlacionando o estado pulpar, polpa viva ou mortificada, do dente algógeno e a intensidade da dor reportada pelos pacientes temos (Tabelas 19 e 20 e Figura 29):

Tabela 19: Intensidade da dor versus Estado pulpar

\begin{tabular}{c|c|c|c|c|c|c|c|c|c|c}
\cline { 2 - 10 } & \multicolumn{10}{c}{ Intensidade da dor } \\
\cline { 2 - 9 } & $\mathbf{1}$ & $\mathbf{2}$ & $\mathbf{3}$ & $\mathbf{4}$ & $\mathbf{5}$ & $\mathbf{6}$ & $\mathbf{7}$ & $\mathbf{8}$ & $\mathbf{9}$ & $\mathbf{1 0}$ \\
\hline Polpa Viva & 0 & 0 & 0 & 0 & $5(8 \%)$ & $2(3 \%)$ & $1(2 \%)$ & $6(10 \%)$ & $2(3 \%)$ & $14(23 \%)$ \\
\hline Polpa Morta & 0 & 0 & $1(2 \%)$ & $1(2 \%)$ & $4(7 \%)$ & $4(7 \%)$ & $2(3 \%)$ & $8(13 \%)$ & $4(7 \%)$ & $6(10 \%)$ \\
\hline
\end{tabular}

Tabela 20: Estado pulpar, polpa viva (PV) ou polpa morta (PM) versus intensidade da dor dividida em dois grupos: com dor de fraca a moderada (1 a 5 na escala numérica) e moderada a intensa (6 a 10 na escala numérica).

\begin{tabular}{c|c|c} 
& \multicolumn{2}{c}{ Intensidade da dor } \\
Diagnóstico & $\mathbf{1} 5$ & $\mathbf{6}$ a 10 \\
\hline PV & $5(8 \%)$ & $25(42 \%)$ \\
\hline PM & $6(10 \%)$ & $24(40 \%)$ \\
\hline Total & $\mathbf{1 1 ( 1 8 \% )}$ & $\mathbf{4 9 ( 8 2 \% )}$
\end{tabular}

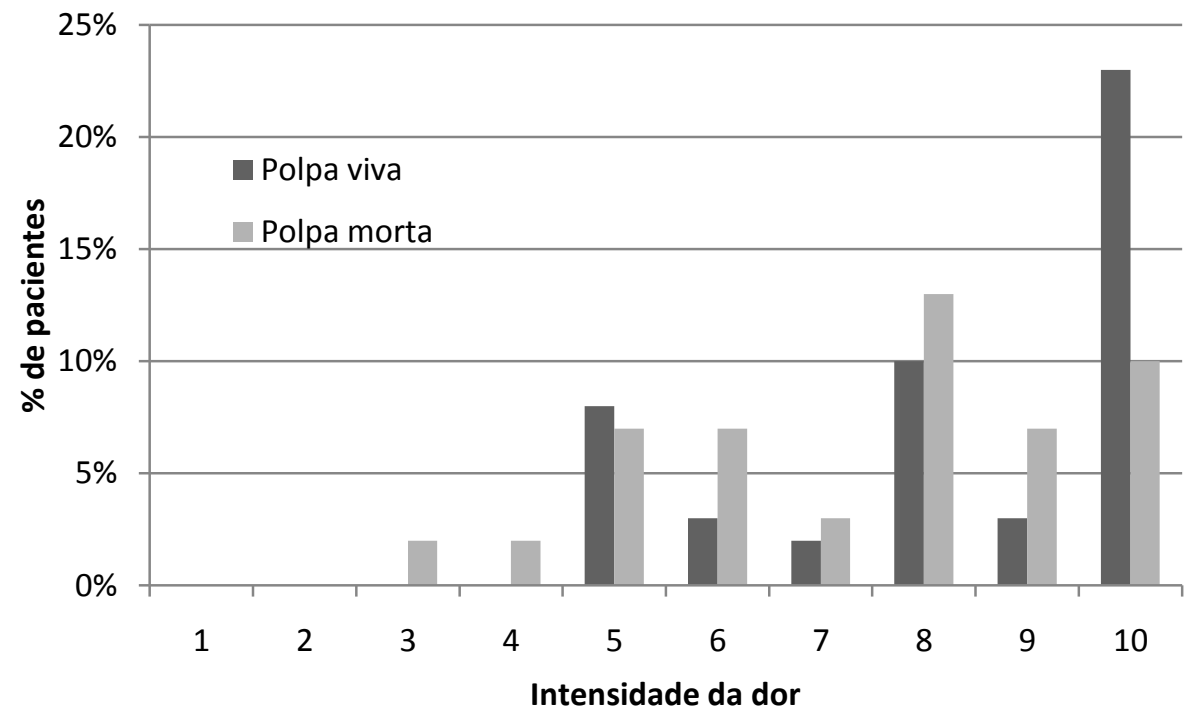

Figura 29: Distribuição dos pacientes com o diagnóstico de polpa viva (PV) e polpa morta (PM) pela intensidade da dor medida pela escala ordinal numérica. 
Quando agruparmos as intensidades em dois grupos (fraca a moderada e moderada a intensa), não encontramos diferença significativa (teste exato de Fisher, unicaudal, p=0,50) entre o diagnóstico polpa viva ou morta (Tabela 20), apesar de existir uma grande diferença entre estes dois diagnósticos na dor de maior intensidade (intensidade 10).

\subsubsection{Estado pulpar vs Duração da dor}

Na correlação do estado pulpar com a duração da dor, temos (Tabela 21 e Figura 30):

Tabela 21: Estado pulpar do dente algógeno, polpa viva (PV) ou polpa morta (PM) versus duração da dor dividida em dois grupos: dor intermitente e contínua.

\begin{tabular}{c|c|c}
\cline { 2 - 3 } & PV & PM \\
\hline Intermitente & $7(12 \%)$ & $\mathbf{8}(13 \%)$ \\
\hline Contínua & $\mathbf{2 3}(38 \%)$ & $22(37 \%)$ \\
\hline Total: & $30(50 \%)$ & $30(50 \%)$ \\
\hline
\end{tabular}

Não encontramos diferença significativa (teste exato de Fisher, bicaudal, $\mathrm{p}=1,00$ ) quando comparamos a duração da dor de dente para os diagnósticos de polpa viva ou morta. 


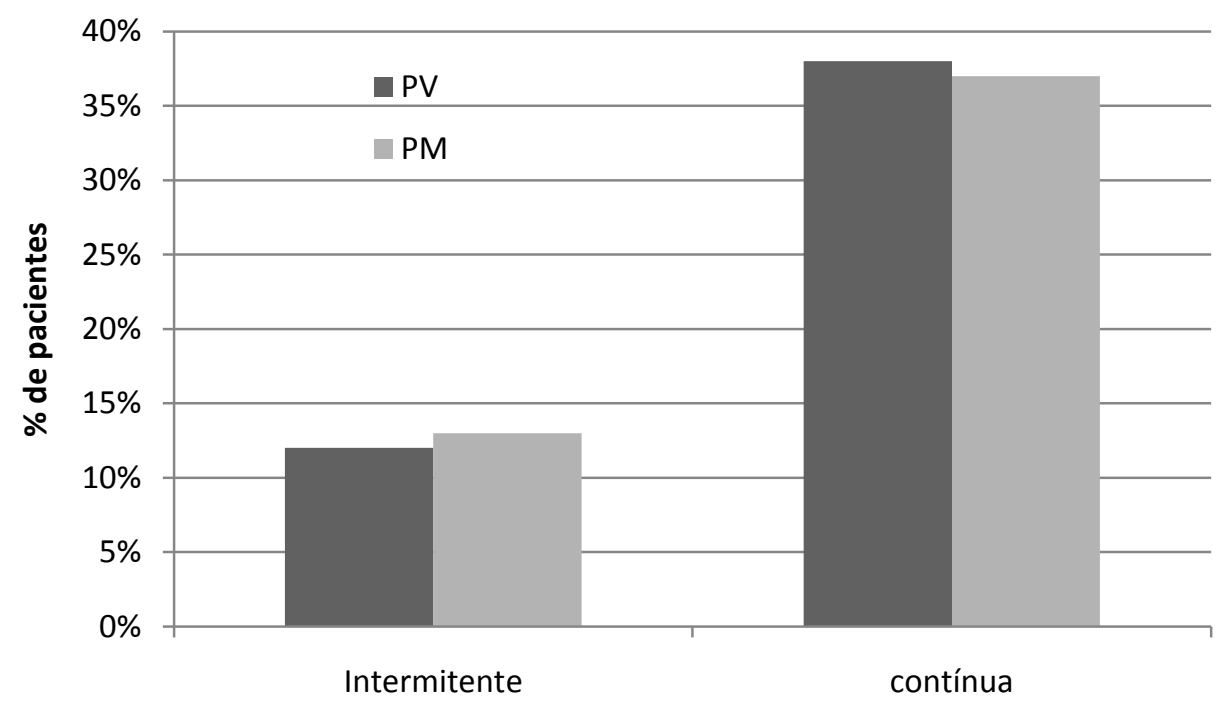

Figura 30: Gráfico do diagnóstico de polpa viva (PV) e polpa mortificada (PM) divididos pela duração da dor em dois grupos: dor intermitente e contínua.

\subsubsection{Localização do dente algógeno vs Intensidade da dor}

A Tabela 22 e Figura 31 mostram a distribuição dos dentes algógenos superiores e inferiores com relação à intensidade da dor.

Tabela 22: Localização do dente algógeno (superior ou inferior) versus Intensidade da dor.

\begin{tabular}{c|c|c|c|c|c|c|c|c|c|c}
\cline { 2 - 10 } & \multicolumn{10}{c}{ Intensidade da dor } \\
\cline { 2 - 11 } & $\mathbf{1}$ & $\mathbf{2}$ & $\mathbf{3}$ & $\mathbf{4}$ & $\mathbf{5}$ & $\mathbf{6}$ & $\mathbf{7}$ & $\mathbf{8}$ & $\mathbf{9}$ & $\mathbf{1 0}$ \\
\hline Dentes sup. & 0 & 0 & 0 & $1(2 \%)$ & $3(5 \%)$ & $3(5 \%)$ & $2(3 \%)$ & $4(7 \%)$ & $4(7 \%)$ & $8(13 \%)$ \\
\hline Dentes inf. & 0 & 0 & $1(2 \%)$ & 0 & $6(10 \%)$ & $3(5 \%)$ & $1(2 \%)$ & $10(16 \%)$ & $2(3 \%)$ & $12(20 \%)$ \\
\hline
\end{tabular}




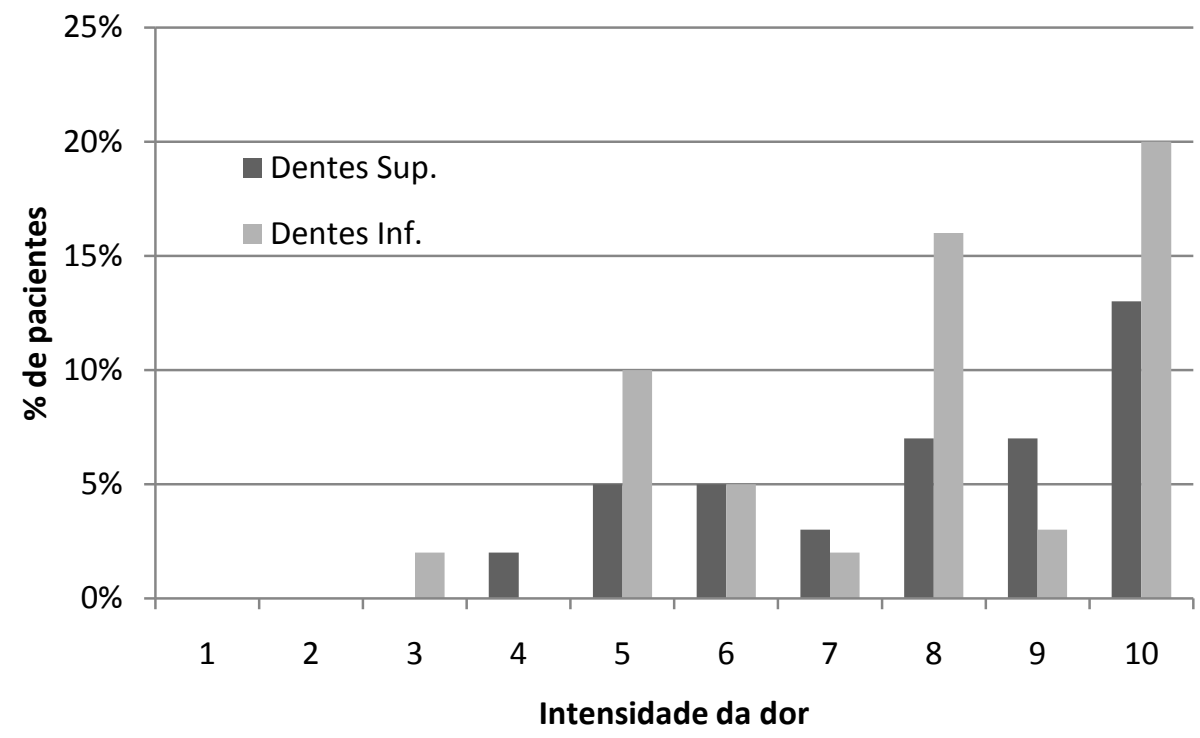

Figura 31: Distribuição dos pacientes pela intensidade da dor reportada por meio da escala numérica, quando a localização do dente algógeno era superior (Sup) ou inferior (Inf).

Abaixo, Tabela 23 e Figura 32, encontram-se os dentes algógenos divididos em superiores e inferiores, quando consideramos dor de fraca a moderada intensidade e de moderada a intensa, para posterior análise.

Tabela 23: Localização do dente algógeno dividido em relação a intensidade da dor: de fraca a moderada (1 a 5 na escala numérica); de moderada a intensa (6 a 10 na escala numérica).

\begin{tabular}{c|c|c}
\cline { 2 - 3 } & $1-5$ & $6-10$ \\
\hline Superior & $4(7 \%)$ & $21(35 \%)$ \\
\hline Inferior & $7(11 \%)$ & $28(47 \%)$ \\
\hline Total: & $11(18 \%)$ & $49(82 \%)$ \\
\hline
\end{tabular}




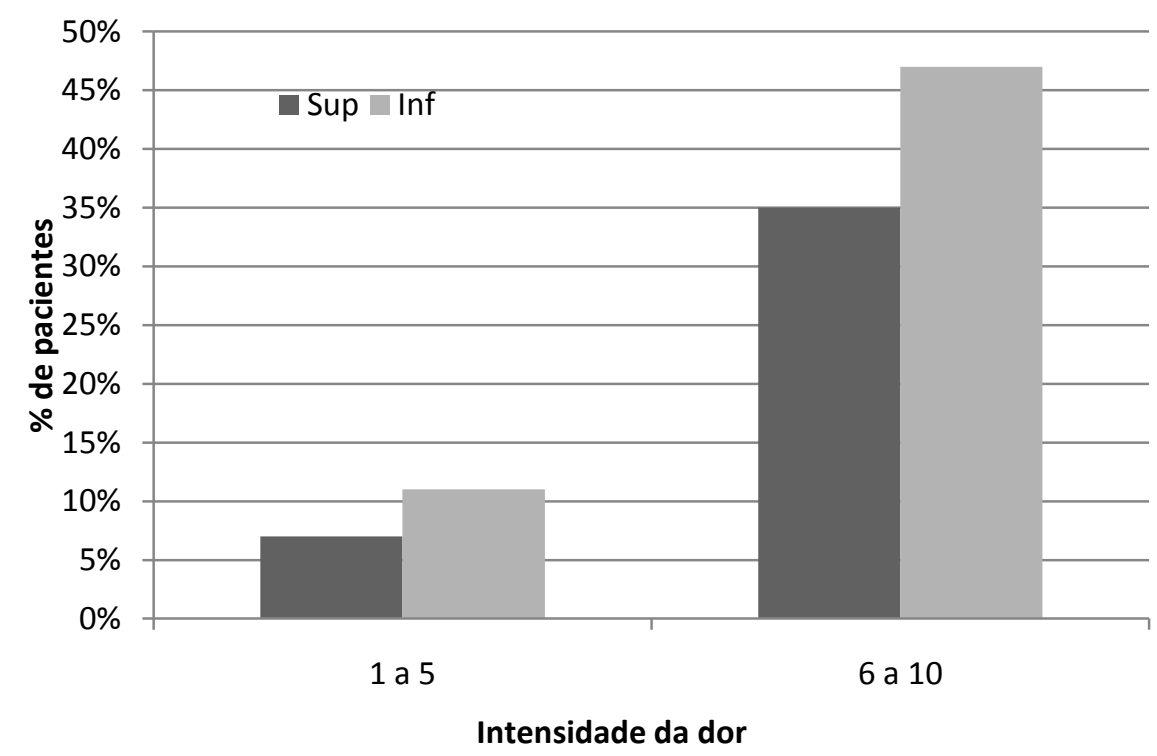

Figura 32: Distribuição dos pacientes quando o dente algógeno era superior (Sup) e inferior (Inf) pela intensidade da dor dividida em dois grupos: com dor de fraca a moderada (1 a 5 na escala numérica) e moderada a intensa (6 a 10 na escala numérica).

Não encontramos diferença significativa entre a intensidade reportada pelos pacientes quando o dente algógeno estava localizado na arcada superior ou inferior (teste exato de Fisher, bicaudal, p=0,7484). Assim, a localização da origem da dor (dente algógeno superior ou inferior) parece não influenciar a intensidade da dor.

\subsubsection{Localização do dente algógeno vs Duração da dor}

Na correlação da localização, superior ou inferior, do dente algógeno com a duração da dor, intermitente ou contínua, temos (Tabela 24 e Figura 33):

Tabela 24: Localização do dente algógeno, superior (sup.) ou inferior (inf.) dividido em relação à duração da dor: dor intermitente e contínua.

\begin{tabular}{c|c|c}
\cline { 2 - 3 } & Sup. & Inf. \\
\hline Intermitente & $5(8 \%)$ & $10(17 \%)$ \\
\hline Contínua & $20(33 \%)$ & $25(42 \%)$ \\
\hline Total: & $25(41 \%)$ & $35(59 \%)$ \\
\hline
\end{tabular}


Não encontramos diferença significativa entre a duração da dor reportada pelos pacientes quando o dente algógeno estava localizado na arcada superior ou inferior (teste exato de Fisher, bicaudal, $\mathrm{p}=0,5522$ ).

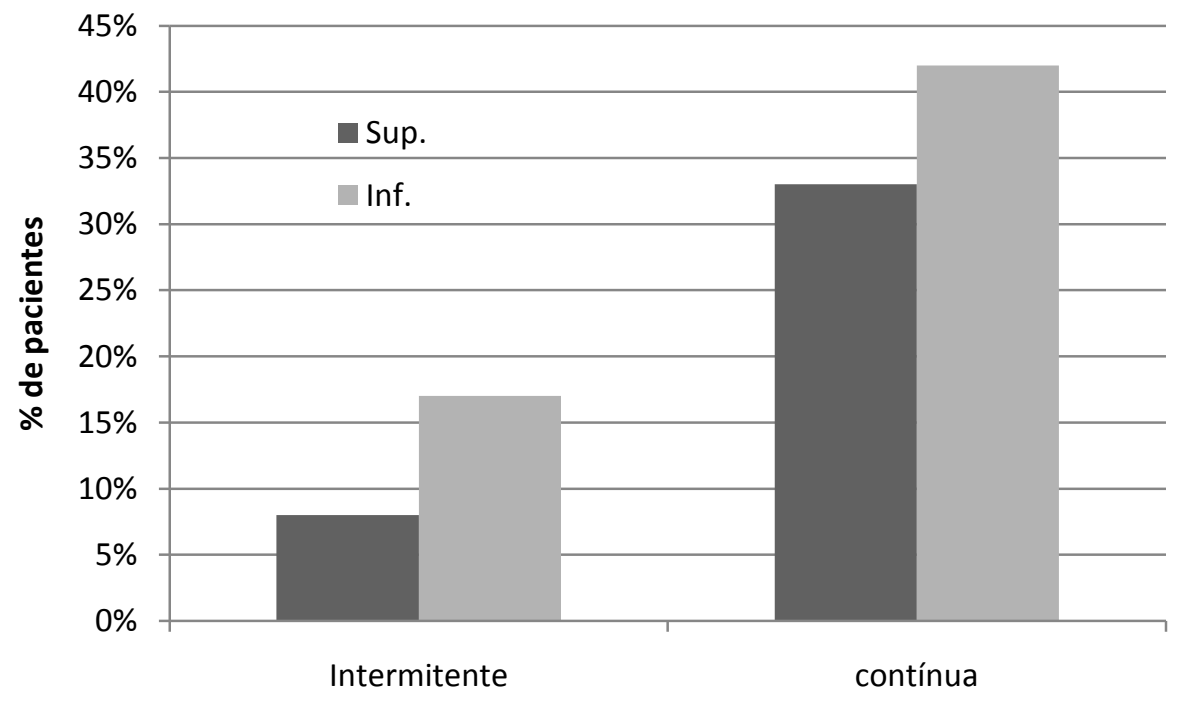

Figura 33: Localização do dente algógeno, superior (sup.) ou inferior (inf.) dividido em relação à duração da dor: dor intermitente e contínua.

\subsubsection{Intensidade da dor vs Duração da dor}

Finalmente relacionamos a duração da dor com sua intensidade (Tabela 25 e Figura 34).

Tabela 25: Duração da dor versus sua intensidade, dividida em: de fraca a moderada (1 a 5 na escala numérica); de moderada a intensa (6 a 10 na escala numérica).

\begin{tabular}{c|c|c}
\cline { 2 - 3 } & $1-5$ & $6-10$ \\
\hline Intermitente & $7(12 \%)$ & $8(13 \%)$ \\
\hline Contínua & $4(7 \%)$ & $41(68 \%)$ \\
\hline Total: & $11(19 \%)$ & $49(81 \%)$ \\
\hline
\end{tabular}




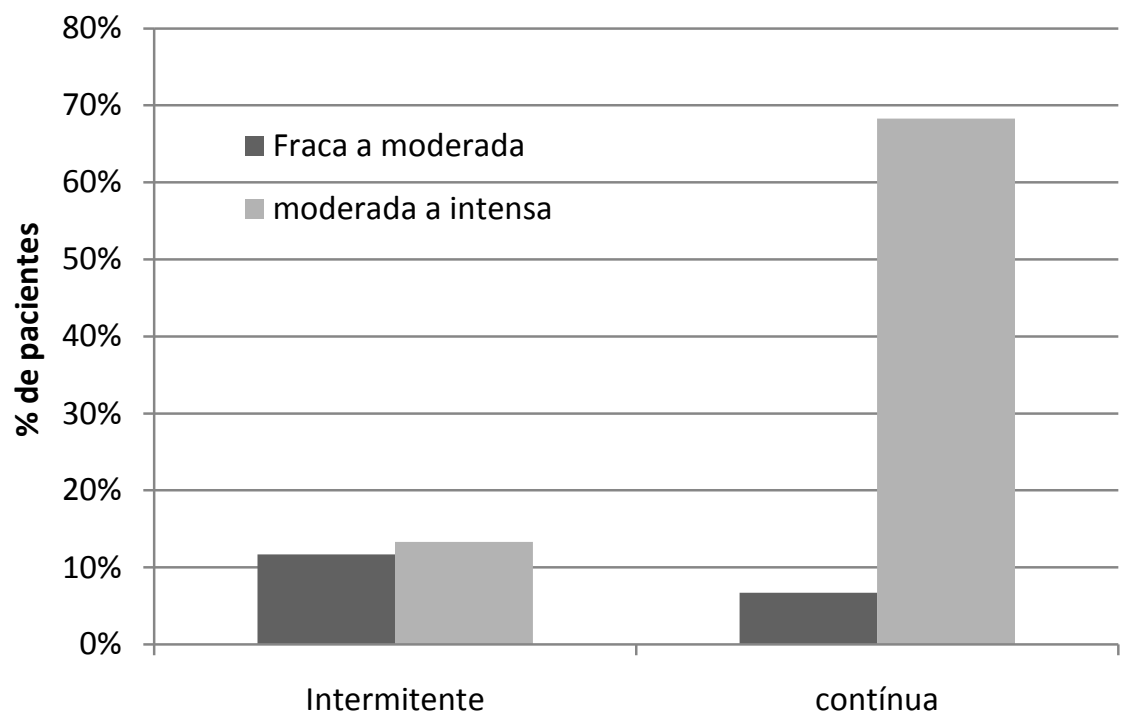

Figura 34: Distribuição dos pacientes quanto a duração da dor pela intensidade da dor dividida em dois grupos: com dor de fraca a moderada (1 a 5 na escala numérica) e moderada a intensa (6 a 10 na escala numérica).

Observamos que quando a dor era contínua, na maioria dos casos, os pacientes relatavam dor moderada a intensa (teste exato de Fisher, bicaudal, $\mathrm{p}=0,0031$ ), indicando que uma maior duração da dor propicia uma maior intensidade da mesma.

\subsection{Resolução Espacial de Estímulos Somestésicos}

Comparamos, em um segundo momento, a capacidade destes pacientes e de dois grupos controles de localizar e distinguir diferentes estímulos somestésicos. Acredita-se que a polpa dentária, quando estimulada, cause predominantemente a sensação de dor, pois possui majoritariamente fibras nervosas aferentes dos tipos: A-delta e C (nociceptores). Por isso, investigamos qual a sensação relatada pelos participantes do projeto de pesquisa quando estimulamos a polpa dentária com o teste térmico (teste que estimula os aferentes da polpa dentária que penetram nos túbulos dentinários). Os resultados podem ser observados na Figura 35 que indica que a dor foi a sensação significativamente mais sentida do que outras, porém não foi a única observada em todos os grupos estudados. 


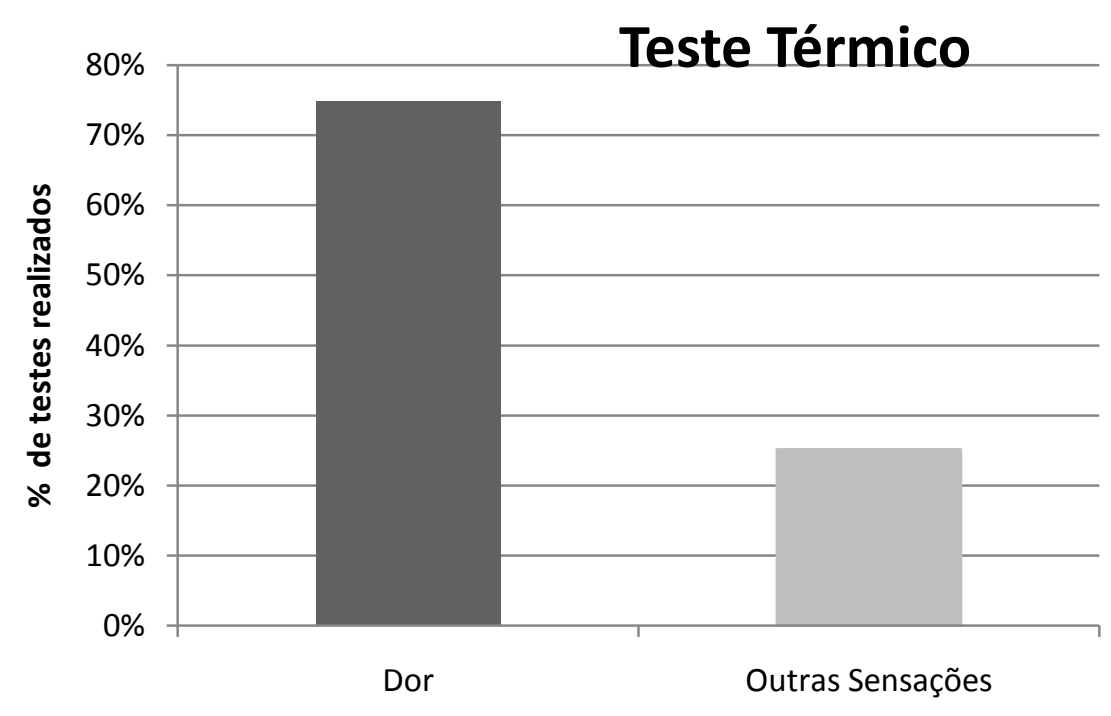

Figura 35: A dor foi a sensação mais sentida pelos participantes da pesquisa, porém não foi a única sensação percebida quando realizado teste térmico.

A dor dental aguda é citada na literatura como sendo de localização pobre, gostaríamos de comparar a resolução da dor que fez o paciente procurar o Serviço Odontológico (dor espontânea) com outros estímulos somestésicos (teste térmico de baixa temperatura, teste mecânico e pressórico) e com a dor induzida por nós, na maioria das vezes que realizamos o teste térmico. Também comparamos a resolução espacial dos diferentes grupos dentais.

\subsubsection{Testes somestésicos vs Dor}

Investigamos a capacidade dos pacientes de localizar e distinguir diferentes estímulos - mecânicos e térmicos - nos elementos dentários, permitindo uma comparação entre a resolução espacial destes estímulos somestésicos com a resolução espacial da dor de dente que fez o paciente buscar o serviço odontológico. Para esta análise, consideramos um dente de cada paciente em cada teste, o dente de mesmo grupo dental do dente que estava com dor. Podemos observar estes resultados na Tabela 26 e Figura 36 abaixo. 
Tabela 26: Distribuição dos acertos e erros cometidos pelos pacientes na tarefa de localizar o dente estimulado nos diferentes testes. Foi considerado para análise apenas um dente (de mesmo grupo dental que o dente com dor) em cada teste para cada paciente.

\begin{tabular}{c|c|c|c}
\cline { 2 - 4 } & Acertos & Erros & Total \\
\hline Dor & $53(88 \%)$ & $7(12 \%)$ & $60(100 \%)$ \\
\hline Teste Térmico & $37(62 \%)$ & $23(38 \%)$ & $60(100 \%)$ \\
\hline Teste Mecânico & $33(55 \%)$ & $27(45 \%)$ & $60(100 \%)$ \\
\hline Percussão Vertical & $30(50 \%)$ & $30(50 \%)$ & $60(100 \%)$ \\
\hline Total: & $153(64 \%)$ & $87(36 \%)$ & $240(100 \%)$ \\
\hline
\end{tabular}

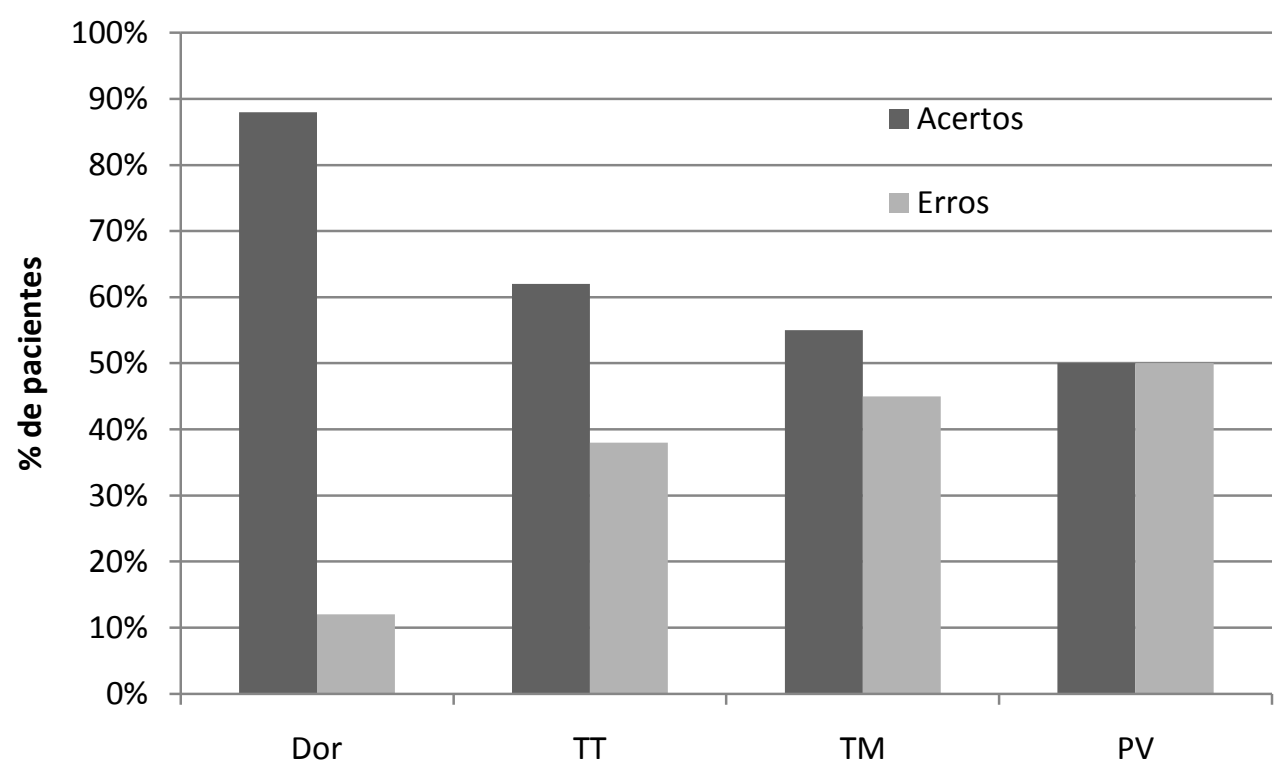

Figura 36: Acertos e erros cometidos pelos pacientes na tarefa de localizar o dente doloroso e três diferentes estímulos somestésicos no elemento dentário: teste térmico (TT), teste mecânico (TM) e percussão vertical (PV).

A acurácia da localização da dor foi significativamente maior que todos os outros testes realizados (teste de máxima verossimilhança, sendo dor versus TT $\mathrm{p}<0,001$; dor versus TM $\mathrm{p}<0,001 ;$ dor versus TM $\mathrm{p}<0,001)$. 
Comparamos esta dor de dente que sediava fez com que o paciente procurasse um serviço odontológico - dor espontânea - com a dor induzida experimentalmente pelo teste térmico (fato que aconteceu na maioria dos casos) nos elementos dentários sadios destes pacientes (aqui chamado de dor induzida). O resultado aparece no gráfico abaixo (Figura 37), indicando uma maior porcentagem de acertos na localização da dor espontânea, provocada pelo processo patológico que se instalou naquele dente (teste de máxima verossimilhança, $\mathrm{p}<0,001)$.

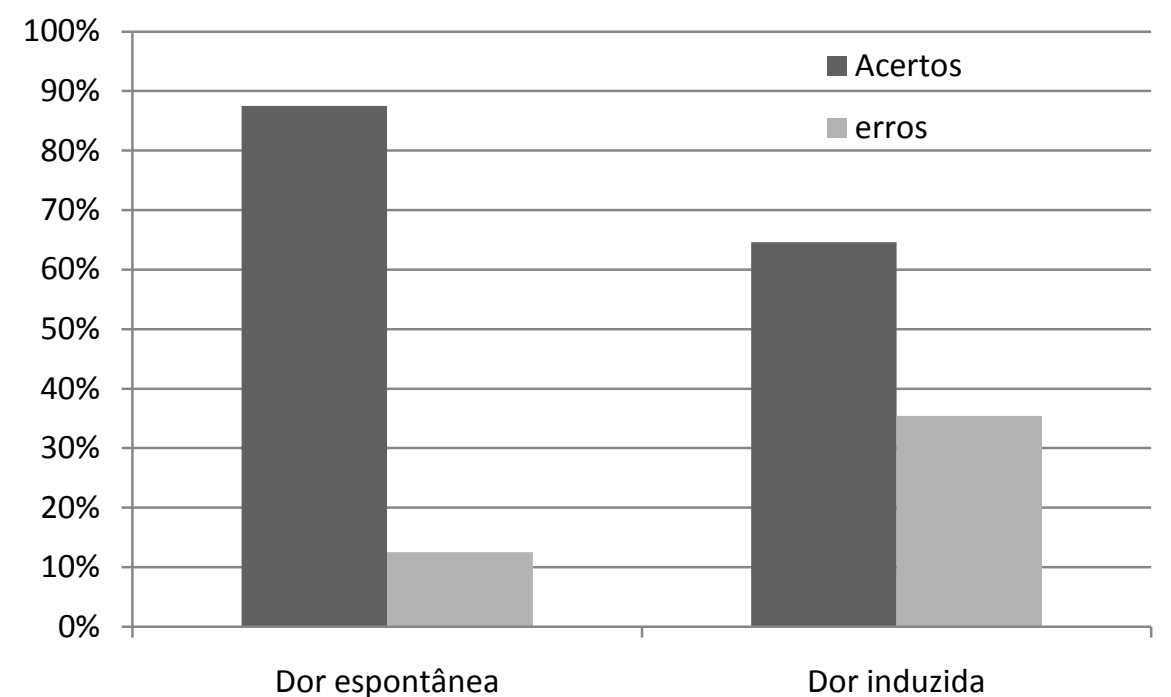

Figura 37: Acertos e erros cometidos pelos pacientes na tarefa de localizar o dente doloroso (dor espontânea que levou o paciente ao dentista) e o dente que foi estimulado com gás refrigerante e o paciente relatou que a sensação provocada foi dor (dor induzida).

\subsubsection{Comparação entre grupos}

Aplicamos os mesmos testes somestésicos (mecânicos e térmico) realizados nos pacientes em dois diferentes grupos controles no intuito de flagrar possíveis interferências que a experiência dolorosa poderia ocasionar na coleta dos testes somestésicos (pacientes submetidos ao estresse causado tanto pelo processo doloroso quanto pela iminência de uma intervenção odontológica). Utilizamos dois diferentes grupos controles. O primeiro, 
composto por voluntários não dentistas sem dor dental, seguindo os mesmos protocolos experimentais dos pacientes. O segundo grupo era de voluntários dentistas ou estudantes de odontologia que possuíssem o conhecimento sobre a anatomia, nomenclatura e notação dental. Estes foram instruídos a responder ao teste apenas citando verbalmente qual o elemento dentário que ele acreditava ter sido estimulado, isto é, sem apontar ou tocar no dente como os outros grupos. Investigamos se esta conduta facilita a correta localização do dente estimulado. Realizamos os testes somestésicos em 30 voluntários não dentistas e em 30 voluntários dentistas ou estudantes de odontologia, todos sem dor dental. Em cada participante, para cada um dos testes experimentais, testamos 4 elementos dentários hígidos que foram todos considerados na análise. Todos os dados colhidos referentes aos testes somestésicos realizados nos 3 grupos estão representados no ANEXO 11.

Comparamos os acertos na localização do dente estimulado dos diferentes grupos de voluntários estudados - pacientes, não dentistas e dentistas - somando todos os testes realizados (mecânicos e térmico) e obtivemos uma diferença significativa (teste de máxima verossimilhança, $\mathrm{p}=0,039)$. A Tabela 27 e Figura 38 mostram a porcentagem de acertos e erros dos 3 grupos. Na comparação pareada, observamos que o grupo dos não dentistas foi significativamente diferente do grupo dos pacientes $(\mathrm{p}=0,020)$ e dos dentistas $(\mathrm{p}=0,025)$.

Tabela 27: Distribuição dos acertos e erros cometidos por pelos três diferentes grupos na tarefa de localizar o dente estimulado nos três diferentes testes.

\begin{tabular}{c|c|c|c}
\cline { 2 - 4 } & Acertos & Erros & Total \\
\hline Pacientes & $517(69 \%)$ & $239(31 \%)$ & $756(100 \%)$ \\
\hline Não dentistas & $277(77 \%)$ & $83(23 \%)$ & $360(100 \%)$ \\
\hline Dentistas & $242(67 \%)$ & $118(33 \%)$ & $360(100 \%)$ \\
\hline Total: & $1036(70 \%)$ & $440(30 \%)$ & $1476(100 \%)$ \\
\hline
\end{tabular}




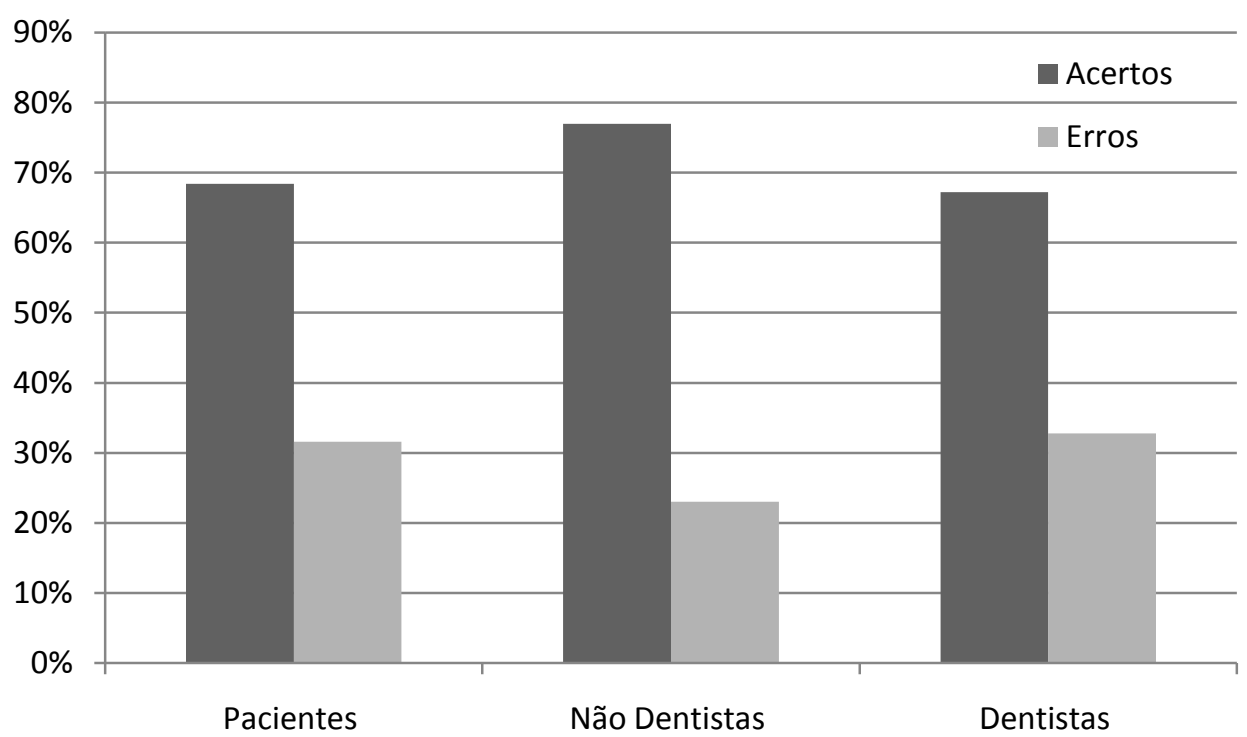

Figura 38: Gráfico do desempenho dos 3 diferentes grupos na tarefa de localização do dente estimulado nos 3 diferentes testes somados (testes térmico e mecânicos). $O$ grupo dos não dentistas obteve um melhor desempenho significativo em relação aos outros 2 grupos.

\subsubsection{Comparação entre testes}

Analisamos também os acertos cometidos por todos os sujeitos que participaram do projeto de pesquisa (pacientes, não dentistas e dentistas) nos diferentes testes realizados teste térmico, teste mecânico e percussão vertical - e obtivemos uma diferença significativa marginal neste fator estudado (teste de máxima verossimilhança, $p=0,071$ ). Nas comparações pareadas, observamos uma menor acurácia significativa do teste de percussão vertical quando comparado com o teste térmico $(\mathrm{p}=0,022)$ - Tabela 28 e Figura 39.

Tabela 28: Distribuição dos acertos e erros cometidos por todos os voluntários na tarefa de localizar o dente estimulado nos três diferentes testes.

\begin{tabular}{c|c|c|c}
\cline { 2 - 4 } & Acertos & Erros & Total \\
\hline Teste Térmico & $360(73 \%)$ & $132(27 \%)$ & $492(100 \%)$ \\
\hline Teste Mecânico & $346(70 \%)$ & $146(30 \%)$ & $492(100 \%)$ \\
\hline Percussão Vertical & $330(67 \%)$ & $162(33 \%)$ & $492(100 \%)$ \\
\hline Total: & $1036(70 \%)$ & $87(30 \%)$ & $1476(100 \%)$ \\
\hline
\end{tabular}




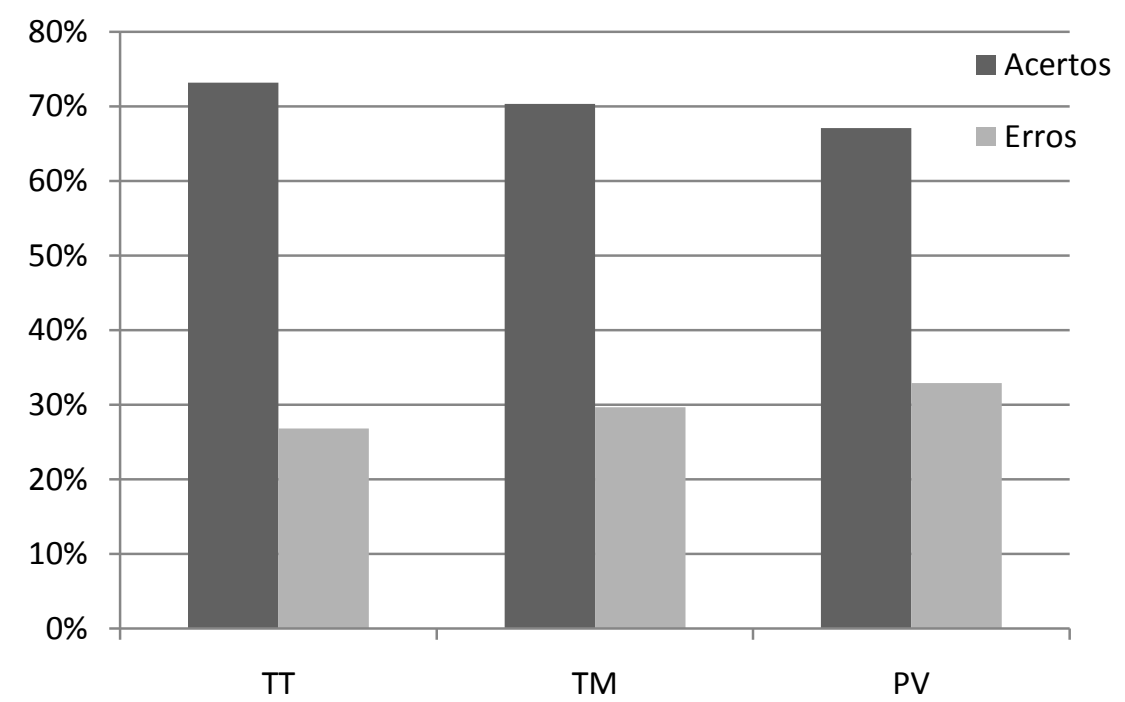

Figura 39: Comparando os acertos e erros cometidos pelos 3 grupos nos 3 testes, (TT=teste térmico; TM=teste mecânico; $P V=$ =percussão vertical), observamos que o teste de percussão vertical obteve uma menor acurácia significativa quando comparado com o teste térmico.

\subsubsection{Comparação entre grupos dentais}

Realizamos análise da resolução dos estímulos somestésicos levando em consideração o grupo dental estudado: incisivos, caninos, pré-molares e molares. Encontramos uma diferença significativa quando estudada esta variável (teste de máxima verossimilhança, p<0,0001). A tabela e gráfico abaixo (Tabela 29 e Figura 40) foram realizados somando-se todos os testes realizados em todos os grupos experimentais. Nas comparações pareadas, obtivemos uma diferença significativa para quase todas as comparações 2 a 2. A única comparação não significativa foi entre incisivos e caninos $(\mathrm{p}=0,343)$; todas as outras comparações pareadas entre grupos dentais foi significativa com $\mathrm{p}<0,0001$. 
Tabela 29: Distribuição dos acertos e erros cometidos por todos os voluntários na tarefa de localizar o dente estimulado nos três testes, nos quatro grupos dentais.

\begin{tabular}{c|c|c|c}
\cline { 2 - 4 } & Acertos & Erros & Total \\
\hline Incisivos & $317(83 \%)$ & $67(17 \%)$ & $384(100 \%)$ \\
\hline Caninos & $278(80 \%)$ & $69(20 \%)$ & $347(100 \%)$ \\
\hline Pré-molares & $258(67 \%)$ & $125(33 \%)$ & $383(100 \%)$ \\
\hline Molares & $183(51 \%)$ & $179(49 \%)$ & $362(100 \%)$ \\
\hline Total: & $1036(70 \%)$ & $440(30 \%)$ & $1476(100 \%)$ \\
\hline
\end{tabular}

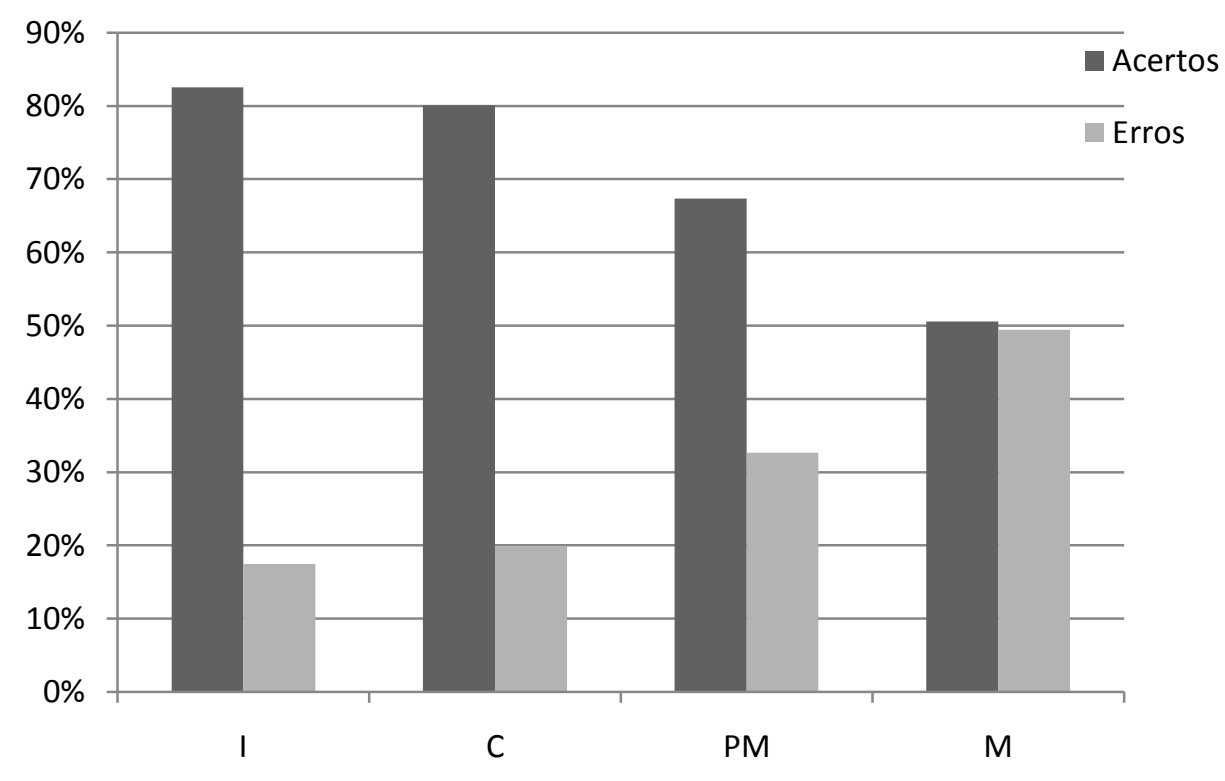

Figura 40: Porcentagem de acertos e erros cometidos somados todos os participantes da pesquisa em todos os testes somestésicos realizados para os diferentes grupos dentais: $\mathrm{I}=$ incisivos; $\mathrm{C}=$ caninos; $\mathbf{P M}=$ pré-molares; $\mathbf{M = m o l a r e s ) .}$ 


\subsubsection{Dispersão dos erros cometidos nos testes somestésicos}

$\mathrm{Na}$ Figura 41 podemos observar uma matriz com os resultados dos testes somestésicos realizados em todos os grupos, sendo que na vertical temos os dentes estimulados e na horizontal os dentes que foram localizados pelos voluntários. A diagonal principal representa os acertos na tarefa de localização do dente estimulado, onde está a maioria dos resultados; os números fora da diagonal principal são os erros de localização realizados pelos voluntários. Destes números que estão fora da diagonal, observamos uma maior quantidade de números abaixo da diagonal, indicando que os erros cometidos foram, em sua maioria, em dentes anteriores aos estimulados. Fazendo um teste de assimetria em torno da mediana, usando adaptação do teste não paramétrico de Wilcoxon (ZAR, 2009, pág. 127), pudemos confirmar estatisticamente esta observação ( $\mathrm{p}<0,0001$ ). Os erros não são simétricos. Os voluntários tendem a indicar, com maior probabilidade, um dente anterior ao realmente estimulado (Tabela 30 e Figura 42). Esta assimetria também foi observada quando analisamos os testes (teste térmico, mecânico e pressórico) separadamente, com $\mathrm{p}<0,0001$.

Tabela 29: Distribuição dos erros, em porcentagem, cometidos por todos os participantes da pesquisa em todos os testes.

\begin{tabular}{r|c|c}
\cline { 2 - 3 } & Posição & \% \\
\hline Erros (5 dentes anteriores) & $-\mathbf{5}$ & $\mathbf{0 , 0 7 \%}$ \\
\hline Erros (4 dentes anteriores) & -4 & $\mathbf{0 , 0 7 \%}$ \\
\hline Erros (3 dentes anteriores) & $-\mathbf{3}$ & $\mathbf{0 , 1 4 \%}$ \\
\hline Erros (2 dentes anteriores) & -2 & $\mathbf{1 , 8 3 \%}$ \\
\hline Erros (1 dente anterior) & -1 & $\mathbf{1 7 , 7 3 \%}$ \\
\hline Acertos & $\mathbf{0}$ & $\mathbf{7 2 , 7 0 \%}$ \\
\hline Erros (1 dente posterior) & $\mathbf{1}$ & $\mathbf{6 , 6 2 \%}$ \\
\hline Erros (2 dentes posteriores) & $\mathbf{2}$ & $\mathbf{0 , 6 3 \%}$ \\
\hline Erros (3 dentes posteriores) & $\mathbf{3}$ & $\mathbf{0 , 1 4 \%}$ \\
\hline Erros (4 dentes posteriores) & $\mathbf{4}$ & $\mathbf{0 , 0 7 \%}$ \\
\hline Erros (5 dentes posteriores) & $\mathbf{5}$ & $\mathbf{0 , 0 0 \%}$ \\
\hline
\end{tabular}




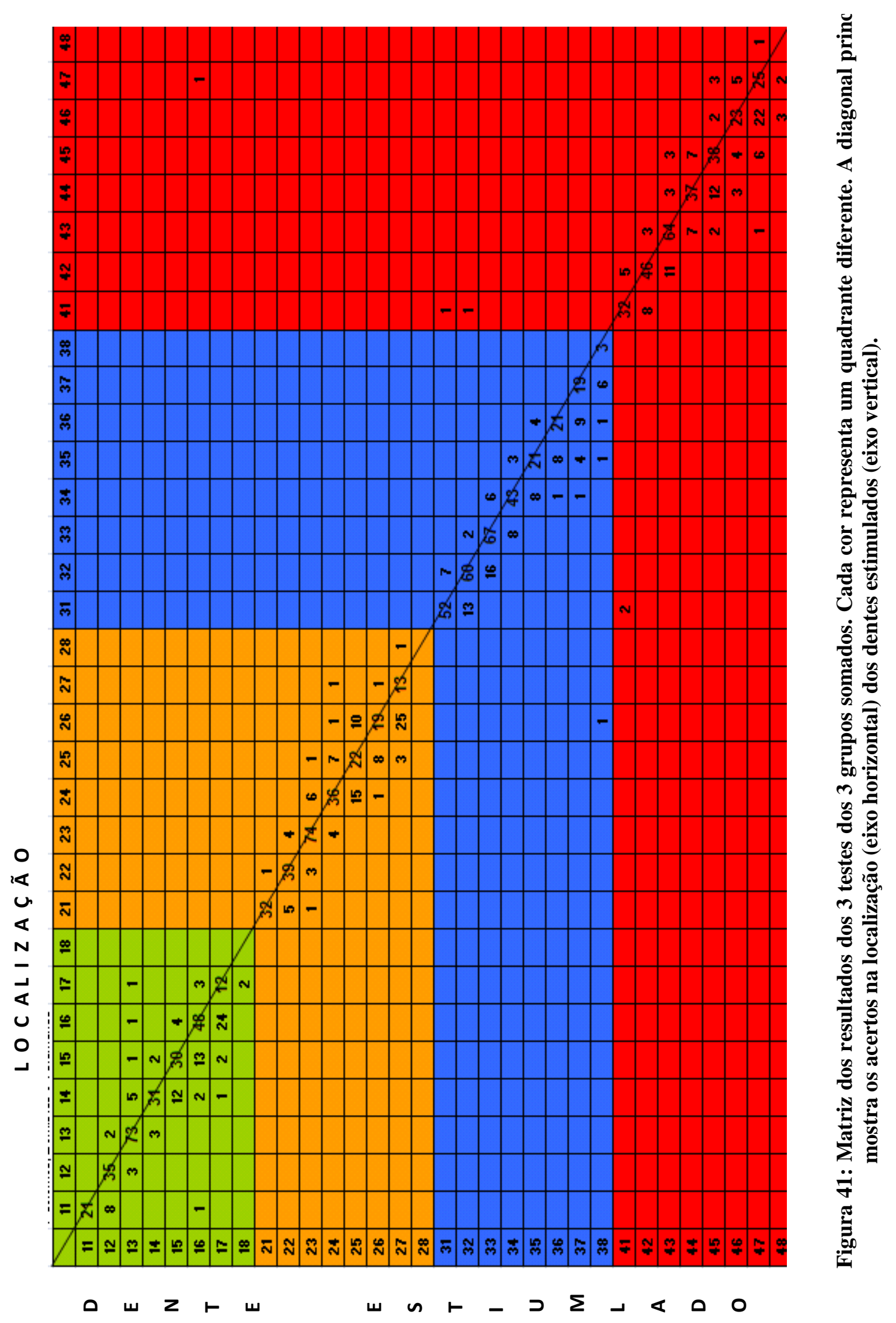




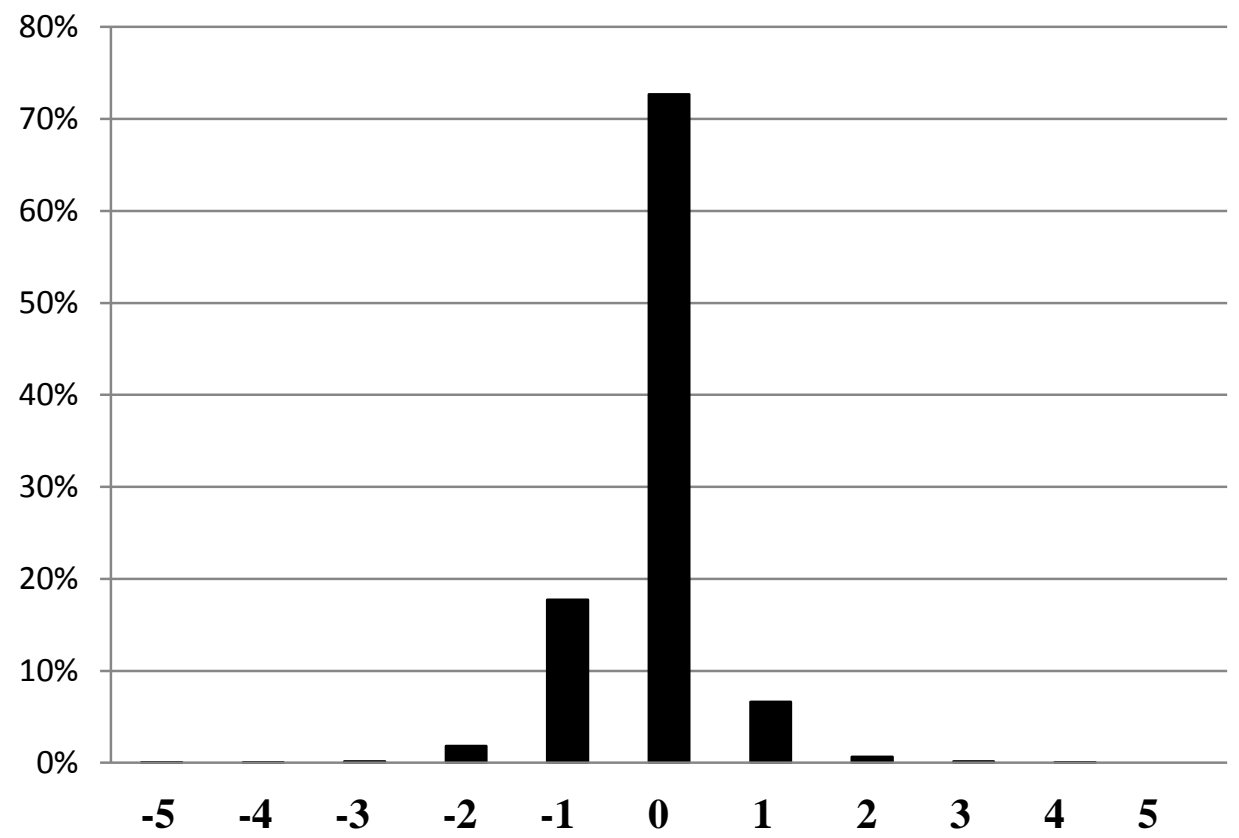

Figura 42: Porcentagem de acertos (na posição 0) e erros (em todas as outras posições), cometidos somados todos os participantes da pesquisa em todos os testes, sendo valores negativos para erros cometidos em dentes anteriores ao estimulado e valores positivos para erros indicando dentes posteriores ao estimulado. 


\section{Discussão}

Na primeira etapa do nosso projeto obtivemos uma amostra de 60 pessoas, sendo 45 mulheres e 15 homens, com idades que variavam de 15 a 60 anos. Estes resultados indicam que nossa amostra era possivelmente heterogênea e que as eventuais diferenças intra-grupo poderiam interferir na interpretação dos resultados obtidos. Prevendo esta situação, realizamos testes estatísticos que poderiam flagrar esta heterogeneidade, mas não encontramos diferenças significativas que comprometeriam a interpretação dos resultados se analisados em um único grupo amostral representativo da população estudada. Entre gêneros, uma única diferença significativa foi encontrada na correlação entre o número de áreas com dor referida e a intensidade da dor, observada no grupo das mulheres e não no dos homens.

Esta única diferença encontrada entre os gêneros, dentre todas as outras análises realizadas neste trabalho, evidencia a homogeneidade existente entre os grupos de homens e mulheres. Essa diferença deve-se, provavelmente, ao efeito de uma menor proporção de homens em nossa amostra, reduzindo o poder estatístico na análise de correlação que se mostrou discrepante. De fato, o número de participantes do sexo masculino foi menor quando comparado ao feminino. $\mathrm{O}$ fato de haver um maior número de mulheres $(75 \%)$ do que homens $(25 \%)$ em nossa amostra é coerente com o dia-a-dia do Serviço de Urgência da FOUSP. Este Serviço tem uma predominância do gênero feminino em seus atendimentos, que pode ser explicado por um maior interesse dessas mulheres em cuidarem de sua saúde e estética. Além disso, pouco mais de $70 \%$ das mulheres que procuram freqüentemente este Serviço alegam não possuírem uma renda pessoal, podendo, assim, simplesmente disporem de mais tempo livre para procurar o atendimento odontológico (TORTAMANO, et al., 2007).

A faixa etária estudada (15 a 60 anos, com média de 32 e desvio padrão de 11 anos) também foi bastante heterogênea, porém, ao analisarmos as possíveis diferenças que poderiam existir dentro da amostra, separando-a em dois grupos divididos pela mediana das idades, encontramos diferença significativa em apenas uma única variável: a maior proporção de dentes algógenos com polpa mortificada no grupo de maior idade. Esta 
diferença pode ser explicada pelo fato de que pacientes mais velhos possuem o elemento dentário há mais tempo na boca e sofreram mais intervenções bucais, o que aumentaria a probabilidade de uma mortificação pulpar (BOUCHER et al.,2006).

Não foi objetivo de nossa pesquisa e, portanto, não nos preocupamos em colher mais informações pessoais dos voluntários, como sua etnia, escolaridade ou classe social, que também poderiam ser relevantes no estudo da dor. Algumas diferenças na percepção da dor, por exemplo, são bastante conhecidas e estudadas em indivíduos de diferentes etnias (LE BRETON, 2006). Porém, não foi o foco deste projeto uma análise do eventual papel desses fatores sobrea percepção da dor, e sim buscar características comuns a diferentes tipos de pessoas que sofrem com dor de origem dentária.

\subsection{Mensuração da Dor}

As escalas de mensuração de dor utilizadas nesta pesquisa se mostraram instrumentos válidos de aquisição da magnitude da dor sentida. Observamos, porém, que essas escalas são quantitativamente diferentes entre si, embora mantenham uma correlação positiva significativa. Examinando as duas escalas, vemos que a intensidade máxima de dor foi, muitas vezes, citada pelos pacientes na escala numérica, fato que não ocorreu freqüentemente na escala analógica visual (EAV) para a mesma situação dolorosa. Portanto, a escala numérica alcançou efeito-teto mais rapidamente. A EAV, mesmo sendo limitada em seus extremos como a numérica, parece ter um intervalo maior, talvez por não apresentar categorias numéricas que restringem a quantidade de respostas possíveis como na escala numérica. No entanto, não podemos ignorar o fato de que nem todos os pacientes compreendem o conceito da escala como sendo uma representação gráfica da dor (FALEIROS SOUSA e DA SILVA, 2002; PRICE e HARKINS, 1992). Alguns pacientes afirmaram estar com uma dor muito forte, assinalando na escala numérica a posição 9 ou 10, porém não apontaram a porção final da EAV. Sendo assim, torna-se difícil distinguir a situação em que estes pacientes não consideravam sua dor como máxima daquela em que não compreenderam com clareza o conceito dessa última escala. Apesar da escala numérica apresentar categorias que limitam as respostas dos pacientes, ela é prática e de fácil 
compreensão para todos, podendo ser utilizada como um válido instrumento de medida de dor para avaliação de procedimentos terapêuticos.

A metodologia psicofísica é amplamente empregada na mensuração da dor, tanto em ambiente de laboratório quanto na prática clínica. Podemos destacar algumas vantagens na utilização da psicofísica como fornecedora de métodos para avaliação e mensuração da percepção de dor: os procedimentos são simples, realizados com baixo custo, facilmente aplicados pelos observadores, contribuem significativamente com os métodos de diagnóstico e a avaliação de condutas terapêuticas (ROWBOTHAM, 2001). No entanto, encontramos dificuldades inerentes ao próprio procedimento psicofísico que devem ser consideradas quando analisamos uma metodologia de mensuração de dor. Não sabemos se, quando um paciente descreve a intensidade da dor que sente, está se referindo exclusivamente à intensidade sensorial decorrente da estimulação nociceptiva ou também ao seu sofrimento, desprazer ou outros aspectos afetivos que caracterizam a sensação de dor, em contraste à simples nocicepção (NAKAMURA e CHAPMAN, 2002). A natureza subjetiva e multifacetada do fenômeno doloroso nos impede de realizar uma mensuração totalmente objetiva e precisa da percepção da dor. Não dispomos de uma medida absoluta e objetiva, o que torna impossível comparar a dor sentida por diferentes pessoas.

\subsection{Dor Referida}

Nossos resultados confirmam dados da literatura que indicam que a maioria dos pacientes que têm dor de origem dentária pulpar ou periapical relata dores em outras regiões da cabeça e pescoço, isto é, manifestam dor referida (FALACE et al, 1996; SESSLE et al, 2000; REGATÃO, CALDEIRA e BALDO, 2002; OKESON, 2006). As características anátomo-fisiológicas dos aferentes dentários ao longo do seu trajeto propiciam a dispersão da dor para áreas próximas ou mesmo distantes do local da origem da dor.

O dente dói quando há estimulação capaz de excitar receptores presentes nos túbulos dentinários ou na polpa. Estímulos frios, quentes e elétricos podem provocar dor, mas a dor espontânea está, geralmente, associada a processos patológicos inflamatórios. Não foi o objetivo deste trabalho mensurar o grau de inflamação pulpar, sendo que apenas 
observamos e registramos se a polpa estava viva (com seu componente vascular preservado) ou morta. De fato, parece não existir uma relação direta entre o grau de inflamação pulpar e a dor sentida pelos pacientes (TROWBRIDGE, 1986). Ainda assim, todos pacientes da nossa amostra necessitaram de tratamento endodôntico, indicando alguma gravidade da patologia pulpar e da dor que os acometiam. A estimulação dentinária normalmente excita os nociceptores de fibras A-delta que têm, como característica, a indução de dor aguda, rápida e bem localizada. Quando há um processo inflamatório pulpar, o tipo de fibra ativada é a $\mathrm{C}$ amielínica, que tem a capacidade de sobreviver em tecidos pobres em oxigênio, limiar de ativação mais alto que as fibras A-delta, e causa dor persistente, difusa e de localização pobre. (BENDER, 2000; TROWBRIDGE, 1986; OLGART, 1986; NÄRHI, 1985).

A face, a maxila, a mandíbula e os dentes são ricamente inervados e os aferentes periféricos advindos destas regiões convergem aos núcleos trigeminais para transmitir a informação sensorial a centros neurais superiores. Esta grande convergência de aferentes, particularmente os aferentes nociceptivos que inervam diversas regiões da cavidade oral, ao núcleo espinal (especialmente sua porção caudal) também favorece a dor referida (Figura 43). Estes aferentes nociceptivos convergem para um neurônio de projeção específico (ou um neurônio de amplitude dinâmica ampla ou um neurônio nociceptivo específico). Quando este neurônio de segunda ordem é ativado, por exemplo, por um aferente que inerva uma polpa dentária, percebemos a dor em todas as regiões inervadas por outros aferentes nociceptivos que chegam até este mesmo neurônio de projeção, e não apenas no local onde a dor se origina. Este mecanismo é, assim, denominado de teoria da convergência da dor referida (SESSLE, 2000, SESSLE, 1986). Esta não é a única teoria sobre a dor referida, mas é a mais aceita atualmente, enfatizando a primeira estação sináptica como sendo a principal responsável pela confusão perceptual na localização da dor. Adotando a teoria da convergência da dor referida como hipótese de nosso trabalho, não iremos aqui discutir os detalhes do processamento da dor em níveis superiores do sistema nervoso central, onde reconhecemos que também poderia ocorrer uma perda progressiva da informação sobre a origem exata do processo algógeno. 


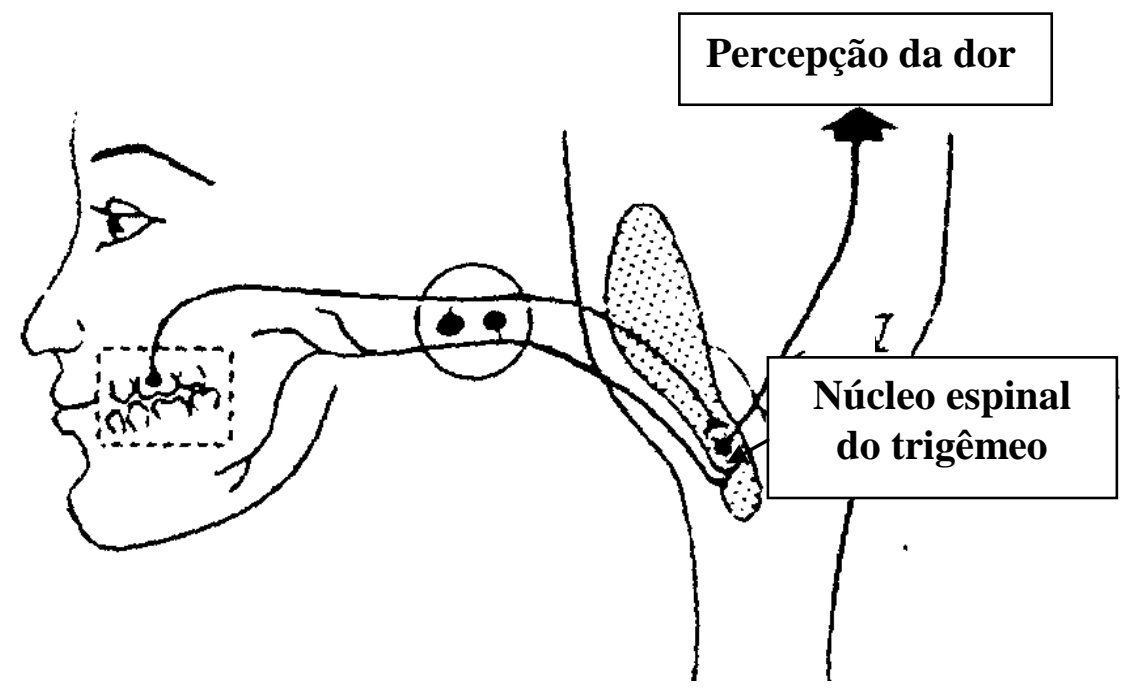

Figura 43: Esquema representando a convergência de aferentes primários para o núcleo espinal do trigêmeo. Um aferente nociceptivo que inerva a polpa dentária com uma inflamação irreversível faz sua primeira sinapse com um neurônio de projeção que normalmente recebe informações nociceptivas advindas de outras regiões da face. Este neurônio de projeção conduz a informação para centros superiores, onde a dor é percebida nas regiões inervadas pelos dois aferentes primários, e não só da polpa dentária que originou a dor.

Os aferentes pulpares se projetam para o núcleo principal do trigêmeo e para todos os níveis do núcleo espinal do trigêmeo (WAITE, 2004; SHINEGAGA et al, 1986b). Cada núcleo é responsável pelo processamento de diferentes aspectos da informação sensorial que chega até ele. Aparentemente, existe uma redundância funcional e topográfica na informação que chega aos núcleos trigeminais: as informações nociceptiva e térmica são, inicialmente, processadas nos subnúcleos oral e, principalmente, caudal do núcleo espinal do trigêmeo, enquanto o núcleo principal e subnúcleo interpolar são considerados rêles da informação tátil e proprioceptiva. (DALLEL et al, 2003; VOISIN, et al 2002). A porção caudal do núcleo espinal é, assim, o principal local de chegada das fibras nociceptivas $\mathrm{C}$ amielínicas e, portanto, onde a dor começa a ser processada. Dele partem projeções para outras regiões dos núcleos trigeminais, inclusive o subnúcleo oral que também é responsável pela transmissão da informação nociceptiva (CHIANG et al, 2002; WAITE, 2004; WODA, 2001; PAJOT et al., 2000). Este subnúcleo possui uma organização das fibras aferentes primárias que chegam até ele na direção rostro-caudal, proporcionando um 
padrão de representação facial em "casca de cebola", isto é, o campo receptivo dos neurônios de $2^{\mathrm{a}}$ ordem deste subnúcleo está organizado na direção ântero-posterior na face, produzindo áreas que se dispõem verticalmente no segmento cefálico (Figura 2B da Introdução). De acordo com teoria de convergência, a dor referida deveria seguir este padrão de áreas de referência de dor. Em nossa amostra, observamos uma maior dispersão no sentido vertical $(61 \%)$ na face humana, indicando que a as áreas de referência de dor se distribuem, preferencialmente, de acordo com o arranjo das fibras aferentes no núcleo espinal do trigêmeo, subnúcleo caudal, e não com a inervação dos diferentes ramos trigeminais. Entretanto, pudemos perceber uma extensa superposição destas áreas, principalmente quando a dor foi de forte intensidade (assim como FALACE et al., 1996) e quando a polpa dentária estava com vitalidade.

O fenômeno da dor referida está relacionado com a intensidade da dor, isto é, a manifestação da dor referida ocorre, preferencialmente, quando o indivíduo sente uma dor de forte intensidade (HARGREAVES, 2002; BENDER, 2000; FALACE et al, 1996; SESSLE, 1986). Observamos em nossos resultados referentes à intensidade da dor que, quanto maior é a intensidade da dor, maior é a probabilidade do paciente ter áreas de dor referida e, além disso, maior é a chance dele reportar mais áreas dolorosas inervadas por dois ou mesmo todos os três ramos trigeminais. A percepção do aumento na intensidade de um estímulo sensorial está associada, do ponto de vista neurofisiológico, a um aumento na freqüência de disparos das fibras aferentes primárias, a um aumento no número de aferentes primários recrutados, ou a ambos os processos simultaneamente. Em nossos resultados, observamos que um maior número de áreas de dor referida também parece estar associado à presença de polpa viva em dentes algógenos. Este fato pode ser explicado pela maior vascularização, maior densidade de nociceptores ainda ativos e maior concentração de mediadores químicos que, em conjunto, caracterizam o ambiente apresentados pelos tecidos vivos da polpa. O aumento da freqüência de disparos das fibras aferentes, por meio da facilitação temporal e espacial e convergência neural, também pode contribuir para a ampliação da dor referida para regiões mais distantes, não só aquelas que se projetam a regiões vizinhas no interior do núcleo espinal do trigêmeo. A dispersão da dor na região orofacial é bastante extensa nos casos de polpa viva e de dor de forte intensidade, tanto no sentido vertical quanto horizontal da face, extrapolando os locais preferenciais de referência 
de dor previstos somente a partir do padrão "casca de cebola". Uma interpretação fisiológica inicial para estes dados está na convergência de aferentes nociceptivos primários aos núcleos trigeminais (SESSLE, 1986), somada a uma maior atividade algógena, sobretudo em dentes com polpa viva, causando tanto uma maior intensidade da dor percebida como também uma maior probabilidade de somações espaciais e temporais nos microcircuitos trigeminais. Essa somação espaço-temporal, por sua vez, tenderia a aumentar não só o número potencial de áreas de dor referida como também sua dispersão sobre outras regiões que ultrapassam os limites dos campos receptivos do conjunto original de neurônios de $2^{a}$ ordem. Assim, a organização hodológica do núcleo espinal - subnúcleo caudal - do trigêmeo (em "casca de cebola") e mecanismos fisiológicos básicos de integração neural, tais como a somação espacial e temporal, podem explicar, de maneira bastante satisfatória, várias características da dor referida de origem dentária - Figuras 44 e 45.

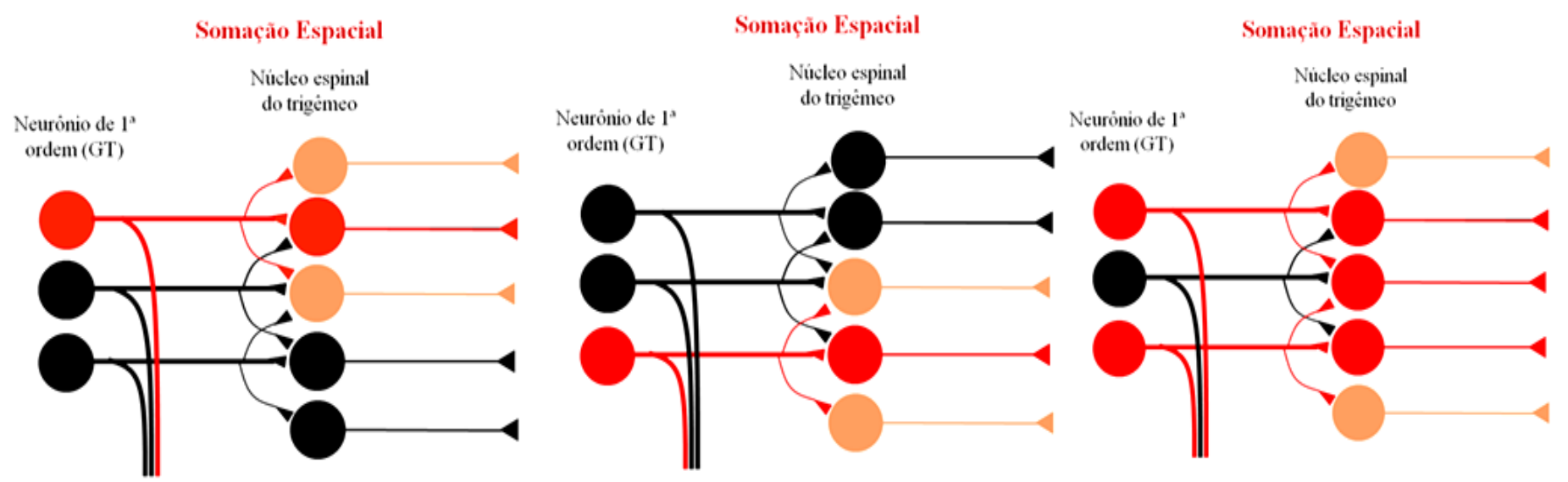

Figura 44: Somação Espacial: várias fibras trigeminais estimulam fibras de segunda ordem no núcleo espinal do trigêmeo. Por meio da convergência neural neste núcleo, outras fibras de segunda ordem também são estimuladas, ocasionando uma ampliação perceptiva da área dolorosa (dor referida em estruturas próximas ou distantes da área afetada). 

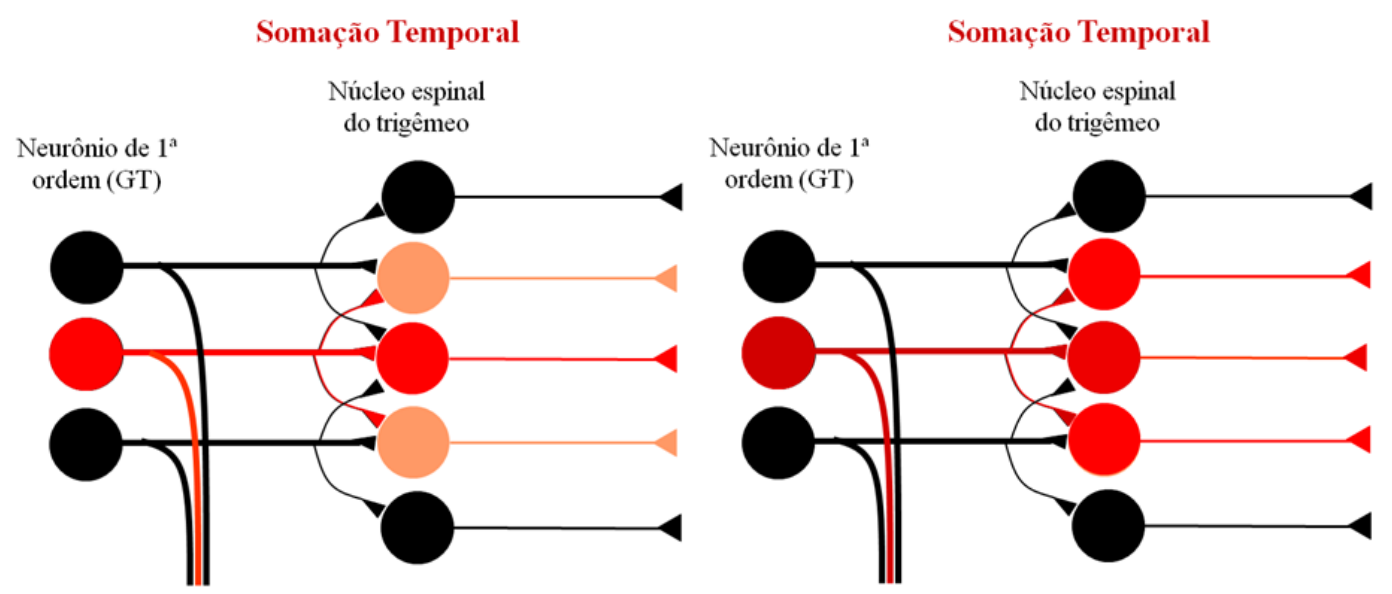

Figura 45: Somação Temporal: uma fibra trigeminal estimula uma fibra de segunda ordem no núcleo espinal do trigêmeo. Aumentando a freqüência de disparos desta fibra (maior intensidade da dor) e através da convergência neural no núcleo espinal do trigêmeo, há uma sensibilização de outras fibras de segunda ordem neste núcleo. Esta situação é interpretada como um aumento de áreas dolorosas - dor referida.

Como vimos, a porção caudal do núcleo espinal do trigêmeo é um importante local de entrada da informação dolorosa orofacial (porém não a única), onde há convergência de aferentes nociceptivos, neurônios de projeção, projeções descendentes e uma complexa rede de interneurônios, (HARGREAVES, 2002). A atividade dos aferentes nociceptivos pode sofrer modulação, já na sua entrada no sistema nervoso central, por meio de projeções descendentes implicadas nos mecanismos analgésicos endógenos, como a substância cinzenta periaqueductal, o núcleo magno da rafe e regiões corticais. Alterações provocadas por processos inflamatórios ou lesões dos tecidos periféricos podem interferir na eficácia desta modulação (SESSLE, 2003). Não podemos também ignorar a plasticidade existente no processo de transmissão neuronal. A dor não é um sintoma passivo, sendo o resultado de um processo agressivo que produz alterações fisiológicas, morfológicas e neuroquímicas nos neurônios que compõem as vias nociceptivas, podendo conduzir à dor persistente e aumentada (DUBNER, 2003). A partir do momento em que um processo inflamatório se instala, uma série de alterações, tais como aumento na expressão de receptores de membrana e diminuição no limiar de ativação do neurônio, pode ocorrer nos neurônios do núcleo espinal do trigêmeo, do tálamo e córtex somatossensorial, ocasionando uma sensibilização central que pode durar semanas ou meses (DUBNER, 2005; BYERS, 
SUZUKI e MAEDA, 2003). Estas alterações parecem acontecer, preferencialmente, com fibras C e estão relacionadas com o aumento de sensibilidade e hiperalgesia da região orofacial, modificando, assim, a percepção da dor (SESSLE, 2003; DUBNER e RUDA, 1992). Portanto, fatores ligados à modulação da dor e sensibilização central também influenciam a dor referida, porque podem favorecer o aumento da quantidade e freqüência de ativação dos aferentes nociceptivos (SESSLE, 2006; DUBNER, 2005; DALLEL, et al 2003).

Outro fator estudado no presente trabalho foi a influência do tempo de instalação da dor sobre a dor referida. Durante a anamnese, dentre outras questões, caracterizava-se a duração e eventual periodicidade da dor que o paciente reportava. Enquanto alguns pacientes relatavam que o dente sinálgico doía de maneira intermitente (iniciando espontaneamente ou após alguma estimulação), outros relatavam que a dor era contínua, apenas melhorando ou cessando com o uso de medicamentos (p. ex., analgésicos, antiinflamatórios ou antibióticos). Portanto, embora alguns pacientes que participaram da pesquisa $(22 \%)$ encontravam-se sob influência destes medicamentos, insistíamos para que descrevessem a dor que sentiam previamente à medicação. A duração da dor, se intermitente ou contínua, não pareceu favorecer diretamente o aparecimento da dor referida, assim como no trabalho de FALACE et al. (1996), que também não conseguiram encontrar esta relação. No entanto, quando analisamos a influência da duração da dor na intensidade da mesma, pudemos observar que, quanto mais a dor perdurava, apresentava a tendência de aumentar sua intensidade. Portanto, a duração da dor parece ter um efeito indireto sobre a dor referida: quanto mais tempo a dor permanece, maior é a intensidade da dor, com isso favorecendo-se o surgimento da dor referida e sua dispersão em um maior número de ramos trigeminais afetados, como também no sentido vertical e, principalmente, horizontal da face. Não podemos esquecer que o aumento do tempo de ativação de nociceptores favorece uma sensibilização da via de dor, por meio dos mecanismos de neuroplasticidade já citados e, conseqüientemente, a manifestação da dor referida (OKESON, 2005; SESSLE, 2003; DUBNER, 2005).

A localização do dente algógeno, se superior ou inferior, não influencia o aparecimento da dor referida, sua intensidade, duração e sua distribuição topográfica, 
indicando que não existem, aparentemente, grandes diferenças na inervação dos dentes provenientes do ramo maxilar e mandibular do nervo trigêmeo. Aliás, dentes algógenos superiores, inervados pelo ramo maxilar, podem proporcionar dor referida nos outros dois ramos trigeminais, assim como os dentes inferiores, inervados pelo ramo mandibular, podem propiciar dor referida na região inervada por quaisquer ramos trigeminais. Observamos também uma grande dispersão da dor referida independentemente do grupo dental estudado (molares e pré-molares), tanto no sentido vertical como horizontal da face dos pacientes. Muitas vezes o paciente não consegue definir corretamente o dente algógeno, ou aponta com segurança um dente sinálgico que não possui vestígios de patologias, nos obrigando a investigar outros dentes não sintomáticos. Um dado padrão topográfico de distribuição dor referida para algumas áreas específicas da face poderia, eventualmente, dar indícios semiológicos valiosos sobre qual dente estaria provocando a dor. Porém, notamos que molares e pré-molares não diferem significativamente entre si quanto à provável distribuição, na face, de referência da dor. Deste modo, devido a essa importante sobreposição de áreas de dor encontradas por nós e também citados por outros na literatura (FALACE et al, 1996, INGLE et al, 1979b), não podemos nos basear apenas neste padrão de referência da dor na região orofacial como indicativo seguro do grupo dental ao qual pertence o dente algógeno.

\subsection{Resolução Espacial de Estímulos Somestésicos}

Nos humanos, a estimulação dos dentes pode causar basicamente três diferentes sensações: dor, tato e pressão (LINDEN, 1990). A dor de origem dentária é citada normalmente como sendo de localização difícil (OKESON, 2006; SESSLE, 1987) por ser considerada dor somática profunda (BELL, 1991). No nosso trabalho efetivamente encontramos pacientes com dificuldade em definir corretamente o dente algógeno, embora tenham sido minoria (12\%). E quando realizamos outros testes somestésicos nos dentes sadios desses pacientes, observamos que a acurácia da localização dos dentes nestes testes foi menor do que quando comparada com a acurácia da localização da dor. Pudemos observar esta diferença mesmo quando comparamos a dor espontânea (a que fez com que o paciente procurasse o serviço odontológico) com a dor induzida por nós durante o teste 
térmico com gás refrigerante. Cabe ressaltar que nem todos os indivíduos relataram dor quando estimulados com um estímulo térmico pulpar de baixa temperatura. Uma variedade de sensações parece depender do tipo e número de fibras ativadas e também da quantidade e intensidade do estímulo aplicado na superfície dental (NARHI,1995). Evidentemente, os resultados foram influenciados pelo fato do paciente, no caso de um processo doloroso espontâneo, ter mais tempo para localizar o dente algógeno, além da maior motivação oriunda da importância biológica da dor patológica em comparação aos testes experimentais realizados rapidamente durante o atendimento. Os receptores ligados às fibras $\mathrm{C}$ são os mais afetados e ativados em casos de inflamação, até mesmo em condições de hipoxia pulpar, e são conhecidos por sua associação com uma localização mais pobre da estimulação nociceptiva (BYERS e NÄRHI, 2002; BENDER, 2000; OLGART, 1986; JOHNSEN, 1985). No entanto, o paciente pode utilizar outras pistas para localizar o dente algógeno, como a mastigação, a ingestão de alimentos frios ou quentes que podem estimular receptores ligados a fibras A-delta, que são conhecidas por sua melhor localização (BYERS e NÄRHI, 2002; BENDER, 2000). Aliás, em situações de inflamação pulpar, as fibras A-delta são ativadas com mais facilidade, mesmo com estímulos que normalmente não causariam dor (hiperalgesia) (OLGART, 1986; BENDER, 2000; BYERS e NÄRHI, 2002). Quando induzíamos a dor com estímulo térmico, eram excitados receptores ligados às fibras A-delta, que têm bom poder de resolução espacial. Mesmo assim, os pacientes apresentaram maior acurácia na localização do dente com dor espontânea em relação aos dentes em que a dor foi induzida, ressaltando, como já discutida, a importância funcional da dor de origem dentária.

O grupo controle composto por dentistas ou estudantes de odontologia obteve um pior desempenho que os outros grupos, mostrando que as reaferentações somestésica e proprioceptiva fornecidas pela mão e pelo braço ajudaram os outros grupos a localizarem corretamente, em um referencial egocêntrico, o elemento dentário que havia sido estimulado. Os pacientes também não obtiveram um bom desempenho, provavelmente pela ação do estresse ao qual estavam submetidos, causado tanto pelo processo doloroso quanto pela iminência de uma intervenção odontológica, circunstância usual em serviços de saúde (MAGGIRIAS e LOCKER, 2002). 
O teste somestésico com pior desempenho dos participantes foi o de percussão vertical, que provavelmente estimula majoritariamente os mecanoceptores da região apical que parecem estar envolvidos com a sensibilidade proprioceptiva e não com a sensibilidade tátil, pressórica e nociceptiva, e, por isso, de difícil localização (LINDEN, 1990). Os corpos celulares desses mecanorreceptores estão localizados no núcleo mesencefálico do nervo trigêmeo e são responsáveis pela detecção de pressão na superfície dental, importante para controlar o padrão funcional da mordida e deglutição (VAN DER BILT, et al., 2006), já que a sensação do tato dos dentes está envolvida em várias funções, como a mastigação e a fala (MIYAMOTO et al, 2006). Outras características dos receptores periodontais e periapicais também não facilitam a acurácia na localização dentária: eles não estão distribuídos de maneira uniforme por todos os dentes, sendo que um único receptor pode inervar mais de um dente, além de parecer ter uma direção de ativação preferencial (LINDEN, 1990; TRULSSON, 2006).

Os dentes posteriores apresentam um menor número de mecanoceptores quando comparados com os dentes anteriores (TRULSSON, 2006; LINDEN, 1990), o que pode justificar um maior número de erros nos testes somestésicos encontrados em dentes localizados mais posteriormente na cavidade oral. A acurácia na localização dos dentes foi diminuindo significativamente conforme partíamos da região anterior para a posterior. A região anterior da boca, incluindo os dentes, por terem um primeiro contato com o meio exterior, tem grande capacidade perceptiva, sendo considerada como a "terceira mão", tamanho é o seu refinamento sensorial e motor (TRULSSON, 2006; LINDEN, 1990). A porcentagem de acertos e erros cometidos pelos participantes da pesquisa, quando estimulados os diferentes grupos dentais, sugere a distribuição dos mecanorreceptores presentes no periodonto dos diferentes grupos dentais. Em outra análise realizada os resultados apontam esta mesma característica fisiológica dos aferentes sensoriais periodontais. Ao observamos a matriz apresentada na Figura 41, podemos perceber que os erros cometidos pelos participantes não tão distribuídos uniformemente em torno da sua diagonal principal. Existe uma assimetria na distribuição dos erros dos participantes. Quando estes cometiam um erro, com maior probabilidade eles indicavam como estimulado 
um dente anterior ao realmente estimulado. Estes resultados corroboram o fato de que a região bucal posterior, por ser menos inervada, tem menor resolução espacial, induzindo o participante, que está habituado a reconhecer um maior número de estímulos em áreas mais anteriores, a reportar mais erros de localização neste sentido.

\subsection{Considerações Finais}

Nossos resultados sobre dor referida são compatíveis com dados na literatura e sugerem a existência da organização topográfica das fibras aferentes no núcleo espinal do trigêmeo, subnúcleo caudal, no sentido rostro-caudal com importantes implicações clínicas. A maioria das pessoas estudadas tinha dor referida e apontava áreas doloridas dentro deste “dermátomo funcional” do padrão de "casca de cebola". Porém, em condições de dor de maior intensidade e com atividade de uma polpa ainda viva, nos deparamos com a dispersão da dor além dessas áreas preferenciais da dor referida. Isso pode ser explicado pela grande convergência de aferentes nociceptivos da região de cabeça e pescoço aos núcleos trigeminais, pelo arranjo das fibras aferentes no subnúcleo caudal e pelos mecanismos fisiológicos de facilitação espacial e temporal. Mecanismos de somação espaço-temporal fariam com que mais neurônios de $2^{\mathrm{a}}$ ordem no subnúcleo caudal fossem recrutados, aumentando assim o tamanho da área identificada pelo sistema nervoso como supostamente afetada. Acreditamos também que outros mecanismos estão envolvidos com este fenômeno. O sistema trigeminal, quando recebe estímulos constantes, elétricos ou inflamatórios, sofre modificações fisiológicas que alteram a percepção da dor (SESSLE, 2006). Podemos citar, como exemplo, a sensibilização periférica e central (no subnúcleo caudal, oral e áreas talâmicas) e uma série de modificações envolvendo receptores celulares e neurotransmissores que atuam na região. Deste modo, a dor referida parece ser consequiência tanto da arquitetura quanto da organização funcional do sistema nervoso e, no presente estudo, particularmente do sistema trigeminal: grande convergência de aferentes nociceptivos, somação temporal e espacial, sensibilização central (SESSLE, 2005; WODA, 2003; CHIANG et al, 2003; FALACE et al, 1996). Sendo assim, não podemos sempre direcionar procedimentos diagnósticos de acordo com áreas prováveis de dor referida. Estes

achados clínicos indicam que, dependendo da gravidade da dor sentida pelo paciente, 
devemos avaliar minuciosamente o máximo de informações relevantes sobre a dor e a condição dentária, nunca subestimando as causas e diferentes origens da dor dentária, procedimento este essencial para realizar a terapêutica apropriada em cada caso.

Finalmente, a dor dental, que é considerada como mal localizada, aparentemente é a sensação somestésica melhor localizada em comparação a outras também produzidas por estimulação dental. Isso porque a dor tem um grande significado biológico para quem a sente e, em situações normais, não nos habituamos a localizar espacialmente estímulos que são aplicados rotineiramente nos elementos dentários, quando falamos ou comemos. Em geral, não aprendemos a localizar estímulos nos dentes, a menos que estejam doendo, o que é compatível com o valor adaptativo de sua função no indivíduo. 


\section{Conclusões}

As principais conclusões do nosso projeto de pesquisa serão apresentadas a seguir. Elas estão separadas por assunto e apresentadas em tópicos, assim como descrito no decorrer de todo trabalho.

\subsection{Mensuração da Dor}

- As escalas numérica e analógica visual (EAV), utilizadas na mensuração da dor, diferem entre si, porém se correlacionam positiva e significativamente.

- Tanto a escala numérica quanto a EAV são instrumentos válidos para mensuração da dor. A escala numérica se mostrou mais prática e de melhor compreensão para os pacientes que participaram da pesquisa.

\subsection{Dor Referida}

- A maioria dos pacientes que tem dor de origem dentária e periapical manifesta dor referida.

- A intensidade da dor favorece o aparecimento do fenômeno da dor referida dental e interfere na sua distribuição topográfica (tanto número de áreas quanto ramos trigeminais envolvidos).

- A distribuição da dor referida dental na região de cabeça e pescoço depende do estágio do estado pulpar do dente algógeno (se polpa viva ou morta).

- A duração da dor favorece o aumento de intensidade da dor, influenciando, assim, indiretamente a dor referida e sua dispersão.

- O padrão de dispersão vertical da dor referida é o mais encontrado (compatível com a organização em "casca de cebola" do subnúcleo caudal do núcleo espinal trigeminal), porém fatores como a intensidade da dor e o diagnóstico de polpa viva parecem influenciar no sentido de um padrão horizontal da dor referida. 
- A localização do dente algógeno, superior ou inferior, não influencia a duração e intensidade da dor e não interfere na distribuição topográfica da dor referida.

- A dor referida parece ser consequiência tanto da arquitetura quanto da organização funcional do sistema trigeminal: grande convergência de aferentes nociceptivos, somação temporal e espacial, sensibilização central e modulação da dor.

\subsection{Resolução Espacial de Estímulos Somestésicos}

- Há uma maior resolução espacial na localização do estímulo nociceptivo em relação à localização de outros estímulos somestésicos, como térmico, dor induzida e mecânicos, nos elementos dentários.

- O maior número de erros realizados na localização dos dentes estimulados foi no teste de percussão vertical, onde a maioria dos mecanoceptores ativados é responsável pela condução da informação propriocetiva.

- O grupo dos dentistas, que não podia tocar nos dentes que haviam sido estimulados, e o grupo dos pacientes, submetidos ao estresse causado pela dor e intervenção odontológica que iriam sofrer, obtiveram piores desempenhos nos testes somestésicos.

- A localização de estímulos somestésicos realizados nos dentes é mais difícil na região posterior (molares e pré-molares).

- Os erros cometidos pelos participantes não são simétricos: há uma tendência a referir o dente anterior ao estimulado.

- Dor não é a única sensação relatada pelos sujeitos quando realizados testes somestésicos nos elementos dentários. 


\section{Referências Bibliográficas}

ABD-ELMEGUID, A.; YU, D. Dental pulp neurophysiology: part 1, clinical and diagnostic implications. J. Can. Dent. Assoc., v.75, n.1, p.55-59, 2009.

ABDEL WAHAB, M. H.; KENNEDY, J. G. Accuracy of localization of pulpal pain on cold stimulation. J. Dent. Res., v.64, n.9, p. 1155-1158, 1985.

AGRESTI, A. An introduction to categorical data analysis. $2^{a}$ ed., Hoboken: Wiley InterScience, 2007. p.89.

ARANA-CHAVEZ, V. E. Histologia dentária aplicada a clínica. In: SIQUEIRA, J.T.T.; TEIXEIRA, M.J. Dor Orofacial - diagnóstico, terapêutica e qualidade de vida. Curitiba, Editora Maio, 2001. p.47-58.

BATES JR., R. E.; STEWART, C. M. Atypical odontalgia: phantom tooth pain. Oral Surg. Oral Med. Oral Pathol, v.72, n.4, p. 479-483, 1991.

BEAR, M. F.; CONNORS, B. W.; PARADISO, M. A. Neurociências. $2^{a}$ Ed. Porto Alegre: Artmed editora, 2002. p.397-435.

BELL, W. E. Dores orofaciais, classificação, diagnóstico e tratamento. $3^{\text {a }}$ ed. Rio de Janeiro: Quintessence, 1991. 426p.

BENDER, I. B. Pulp pain diagnosis: a review. J. Endod., v.26, n.3, p.175-179, 2000.

BENDER, I. B. Pain conference summary. J. Endod., v.12, n.10, p.509-517, 1986.

BOUCHER Y.; BERTERETCHE M. V.; FARHANG F.; ARVY M. P.; AZE'RAD J.; FAURION A. Taste deficits related to dental deafferentation: an electrogustometric study in humans. Eur. J. Oral Sci., v. 114, p.456-464, 2006.

BRADLEY, R. M. Fisiologia oral básica. $2^{\mathrm{a}}$ ed. São Paulo: Panamericana, 1986. p.112. 
BRÄNNSTRÖM, M. Dentinal and pulpal response: IV. Int. Dent. J., v. 22, p.219-227, 1972.

BRÄNNSTRÖM, M.; ÅSTRÖM, A. The hidrodynamics of the dentine; its possiblerelationship to dentinal pain. Int. Dent. J., v. 22, p.219-227, 1972.

BRODAL, A. The cranial nerves. In: Neurological anatomy in relation to clinical medicine. New York: Oxford University Press, 1981. p.508-530.

BYERS, M. R.; NARHI, M. V. O. Nerve supply of the pulpodentin complex and responses to injury. In: HARGREAVES, K. M. ; GOODIS, H. E. (Eds). Seltzer and Bender's dental pulp. Chicago: Quintessence, 2002. p.151-180.

BYERS, M. R.; SUZUKI, H.; MAEDA, T. Dental neuroplasticity, neuro-pulpal interactions, and nerve regeneration. Microsc. Res. Tech., v.60, p.503-515, 2003.

CALDEIRA, C. L.; PROKOPOWITSCH, I.; ANDRADE, W. B. Como identificar as odontalgias dentárias típicas e atípicas mais comuns. Inf. APCD de São Caetano do Sul, v.16, p. 10-13, 1999.

CHAMBERS, I. G. The role and methods of pulp teting in oral diagnosis: a review. Int. Endod. J., v.15, n.1, p. 1-15, 1982.

CHAPMAN, C. R.; STILLMAN, M. Pathological pain. In: KRUGER, L. Pain and touch. San Diego: Academic Press, 1996. p.315-342.

CHIANG, C. Y; HU, B.; HU, J. W.; DOSTROVSKY, J. O.; SESSLE, B. J. Central sensitization of nociceptive neurons in trigeminal subnucleus oralis depends on integrity of subnucleus caudalis. J. Neurophysiol., v. 88, p.256-264, 2002.

CODERRE, T. J.; KATZ, J. Peripheral and central hyperexcitability: differential signs and symptoms in persistent pain. Behav. Brain Sci., v.20, p. 404-419, 1997.

CONTI, P. C. R.; AZEVEDO, L. R.; SOUZA, N. V. W.; FERREIRA, F. V. Pain measurement in TMD patients: evaluation of precision and sensitivity of different scales. $\mathbf{J}$. Oral Rehabil., v. 28, p. 534-539, 2001. 
DALLEL, R.; VILLANUEVA, L.; WODA, A.; VOISIN, D. Neurobiologie de la douleur trigéminale. Med/Sci., v.19, p. 567-74, 2003.

DASILVA, A. F. M.; BECERRA, L.; MAKRIS, N.; STRASSMAN, A.M.; GONZALEZ, R.G.; GEATRAKIS, N.; BORSSOK, D. Somatotopic activation in the human trigeminal pain pathway. J. Neurosci., v. 22, n.18, p.8183-8192, 2002.

DUBNER, R.; RUDA, M. A. Activity-dependent neuronal plasticity following tissue injury and inflammation. TINS, v.15, p. 96-103, 1992.

DUBNER, R. Hiperalgesia na resposta à lesão aos tecidos cutâneos e profundos. In: FRICTON, J. R.; DUBNER, R. Dor orofacial e desordens tenporomandibulares. São Paulo: Editora Santos, 2003. p.61-71.

DUBNER, R. Plasticity in central nociceptive pathways. In: MERSKEY, H.; LOESER, J.; DUBNER, R. The paths of pain 1975-2005. Seattle, IASP Press, 2005. 101-115 p.

EDWALL, L. Sensory nerve recordings in human teeth. J. Endod., v.12, n.10, p.462-463, 1986.

FALACE, D.; REID, K.; RAYENS, M. The influence of deep (odontogenic) pain intensity, quality and duration on the incidence and characteristics of referred orofacial pain. $\mathbf{J}$. Orofac. Pain, v. 10, n.3, p. 232 - 239, 1996.

FIELDS, H. L. Pain modulation: expectation, opioid analgesia and virtual pain. Prog. Brain Res., v.122, p.245-253, 2000.

FIELDS, H. L. State-dependent opioid control of pain. Nat. Rev., v. 5, p.565-575, 2004.

GEBHART, G. F. Descending modulation of pain. Neurosci. Biobehav. Rev., v.27, p.729737, 2004.

GRACELY, R. H.; NALIBOFF, B. D. Measurement of Pain Sensation. In: KRUGER, L. pain and touch. San Diego: Academic Press, 1996. p. 243-314. 
GRACELY, R. H. Pain measurement. Acta Anaesthesiol. Scand., v. 43, p.897-908. 1999.

HAGENACKER, T.; LEDWIG, D.; BÜSSELBERG, D. Feedback mechanisms in the regulation of intracellular calcium $([\mathrm{Ca} 2+] \mathrm{i})$ in the peripheral nociceptive system: role of TRPV-1 and pain related receptors. Cell Calcium, v. 43; p. 215-227, 2008.

HANSSON, P.; EKBLOM, A.; LINDBLOM, U.; MARCHETTINI, P. Does acute intraoral pain alter cutaneous sensibility? J. Neurol., Neurosurg. Psychiatry, v.. 51, p. 1032 1036, 1988.

HARGREAVES, K. M. Pain mechanisms of the pulpodentin complex. In: Seltzer and Bender's dental pulp. Chicago: Quintessence, 2002. p. 181-204.

HARGREAVES, K. M.; SELTZER, S. Pharmacologic control of dental pain. In: Seltzer and Bender's dental pulp. Chicago: Quintessence, 2002. p.205-226.

HAYS, W. L. The principles of Maximum likelihood. In: Statistics. $5^{\circ}$ ed. Fort Worth: Harcourt Brace College Publisher, 1994, p. 209-211.

HILDEBRAND, C.; FRIED, K.; TUISKU, F.; JOHANSSON, C.S. Teeth and Tooth Nerves. Prog. Neurobiol., v. 45, p. 165 - 222, 1995.

INGLE, J. I.; BEVERIDGE, E. E.; GAUN, C.; SLOWEY, R. R. Métodos de Diagnóstico. In:__Endodontia. $2^{a}$ ed. Rio de Janeiro: Interamericana, 1979. p. 404-449.

INGLE, J. I; BEVERIDGE, E. E. Diagnóstico diferencial e tratamento das dores oral e perioral. In: Endodontia. $2^{a}$ ed. Rio de Janeiro: Interamericana, 1979. p. 450-517.

JACOBS, R.; VAN STEENBERGHE, D. From osseoperception to implant-mediated sensory-motor interactions and related clinical implications. J. Oral Rehabil., v.33, p. 282-292, 2006.

JAEGER, B. Differential diagnosis and management of craniofacial pain. In: INGLE, J.I.; BAKLAND, L. K. Endodontics. $4^{2}$ ed. Baltimore: Williams \& Wilkins, 1994. p.550-607. 
JULIUS, D.; BASBAUM, A. I. Molecular mechanisms of nociception. Nature, v.413, p.203-210, 2001.

KANDEL, E. R.; SCHWARTZ, J. H.; JESSEL, T. M. The perception of pain. In: p.472-500.

Essentials of neural science and behavior. 4 ed. Chicago: Prentice Hall, 2000.

LE BRETON, D. Anthropologie de la douleur. Paris: Métaillié, 2006. 227p.

LEFFINGWELL, C. S.; MEINBERG, T. A.; WAGNER, J. G.; GOUND, T. G.; MARX, D.B.; REINHARDT, R. A. Pulp responses to precise thermal stimuli in dentin-sensitive teeth. J. Endod., v.30, n.6, p. 384-387, 2004.

LILLY, J. P.; LAW, A. S. Atypical odontalgia misdiagnosed as odontogenic pain: a case report and discussion of treatment. J. Endod., v.23, n.5, p. 337-339, 1997.

LYNN, B.; PERL, E. R. Afferent mechanisms of pain. In: KRUGER, L. Pain and touch. San Diego: Academic Press, 1996.p.213-243.

MAGGIRIAS, J.; LOCKER, D. Psychological factors and perceptions of pain associated with dental treatment. Commun. Dentist. Oral Epidemiol., v. 30, p. 151-59, 2002.

MARTYN, S. On the physiological meaning of inframammary pain. Br. Med. J., v.2, p.296-98, 1864.

MELZACK, R. Phantom limbs and the concept of a neuromatrix. Trends Neurosci., v.13, n.3, p.89-92, 1990.

MELZACK, R. Pain: an overview. Acta Anaesthesiol. Scand., v.43, p.880-884. 1999.

MELZACK, R.; WALL, P. D. Pain mechanisms: a new theory. Science, v.150, n.3699, 1965.

MERSKEY, H.; BOGDUK, N. Classification of chronic pain. $2^{\circ}$ ed., Seattle: IASP Press, 1994. 
NÄRHI, M. V. O. The characteristics of intradental sensory units and their responses to stimulation. J. Dent. Res., v. 64, p. 564-571, 1985.

OKESON, J. P. Dores Bucofaciais de Bell. 5ª ed. São Paulo: Quintessence, 1998. 500 p.

OKESON, J. P.; FALACE, D. A. Monodontogenic toothache. Orofac. Pain and Other Disorders, v.41, n.2, p. $367-383,1997$.

PAJOT, J.; PELISSIER, T; SIERRALTA, F.; RABOISSON, P.; DALLEL, R. Differential effects of trigeminal tractotomy on $\mathrm{A}-\delta$ and $\mathrm{C}$-fiber-mediated nociceptive responses. Brain Res., v. 863, p.289-292, 2000.

PARENT, A. Pons. In:_Carpenter's human neuroanatomy. $9^{\text {a }}$ ed. Baltimore: Willims \& Wilkins, 1996. p.469-526.

PRICE, D. D. Psychophysical and neural mechanisms of the affective dimension of pain. Science, n 288, n.5472, p.1769-1772, 2000.

PRICE, D. D.; HARKINS, S.W. Psychophysical approaches to pain measurement and assessment. In: TURK, D.C.; MELZACK, R. (Eds.) Handbook of pain. New York: Guilford Press, 1992.p.229-243.

RAMACHANDRAN NAIR, P. N. Neural elements in dental pulp and dentin. Oral Surg. Oral Med. Oral Pathol, v.80, n. 6, p. $710-719,1995$.

REGATÃO, M. C.; CALDEIRA, C. L.; BALDO, M. V. C. Análise topográfica da dor referida de origem dentária. In: $17^{\mathrm{a}}$ REUNIÃO ANUAL DA FEDERAÇÃO DE SOCIEDADES DE BIOLOGIA EXPERIMENTAL (FeSBE). São Paulo: FeSBE, 2002. 01.320 .

REECH, E. S.; ELDEEB, M. E. Referred pain of muscular origin resembling endodontic involvement. Oral Surg. Oral Med. Oral Pathol, v.71, n.2, p. 223 - 2227, 1991.

REY, R. Histoire de la douleur. 2a ed. Paris: La Découverte et Syros, 2000. 420p. 
RICKOFF, B.; TROWBRIDGE, H.; BAKER, J.; FUSS, Z.; BENDER, I.B. Effects of thermal vitality tests on human dental pulp. J. Endod., v.14, n. 10, p. 482-485, 1988.

SCHIFFMAN, H. R. Psychophysics. In: Sensation and Perception. $5^{\mathrm{a}}$ ed. New York, Wiley, 2001. p. 23-45.

SESSLE, B. J. Central sensitization in thalamic nociceptive neurons induce by mustard oil application to rat molar tooth pulp. Neuroscience., v.142, p. 833-842, 2006.

SESSLE, B. J. Orofacial pain. In: MERSKEY, H., LOESER, J.D. e DUBNER, R. The paths of pain 1975-2005. Seattle: IASP Press, 2005.p.131-150.

SESSLE, B. J. Mecanismos da dor orofacial no tronco cerebral. In: FRICTON, J.R. e DUBNER, R. Dor orofacial e desordens tenporomandibulares, São Paulo: Editora Santos, 2003. p.43-60.

SESSLE, B. J.; HU, J. W.; AMANO, N.; ZHONG, G. Convergence of cutaneous, tooth pulp, visceral, neck and muscle afferents onto nociceptive and non-nociceptive neurons in trigeminal subnucleus caudalis (medullary dorsal horn) and its implications for referred pain. Pain, v.27, p.219-235, 1986.

SESSLE, B. J. Acute and chronic craniofacial pain: brainstem mechanisms of nociceptive transmission and neuroplasticity, and their clinical correlates. Crit Rev Oral Biol Med, v.11, n.1, p. 57-91, 2000.

SESSLE, B. J. The neurobiology of facial and dental pain: present knowledge, future directions. J. Dent. Res, v.66, p. 962-981, 1987.

SESSLE, B. J. Recent developments in pain research: central mechanisms of orofacial pain and its control. J. Endod., v.12, n.10, p. 435-461, 1986.

SHINENAGA, Y.; CHEN, I. C.; SUEMUNE, S.; NISHIMORI, T. ; NASUTION, I. D. ; YOSHIDA, A.; SATO,H.; OKAMOTO, T.; SERA, M.; HOSOI, M. Oral and facial representation within the medullary and upper cervical dorsal horns in the cat. J. Comp. Neurol., v. 243, p. 388-408, 1986a. 
SHINENAGA, Y., I.C.; SUEMUNE, S.; NISHIMURA, M.; NISHIMORI, T. ; SATO,H.; ISHIDORI, A.; YOSHIDA, A.; TSURU, K.; TSUIKI, Y.; DATEOKA, I. D.; NASUTION, I. D.; HOSOI, M. Topographic representation of lower and upper teeth within the trigeminal sensory nuclei of adult cat as demonstrated by the transganglionic transport of horseradish peroxidade. J. Comp Neurol., v. 251, p. 299-316, 1986 b.

SICHER, H.; JANDLER, J. Anatomia para Dentistas. São Paulo: Atheneu Editora, 1981. p.143.

SIQUEIRA, J. T. T. Dores dentárias difusas/odontalgia atípica. In: Dor Orofacial: diagnóstico, terapêutica e qualidade de vida. $1^{\text {a }}$ ed. Curitiba: Editora Maio, 2001.p.243-254.

SIQUEIRA, J. T. T.; CHING, L. H. Odontalgia e neuralgias - diagnóstico diferencial. In: Dor dor orofacial/ ATM: bases para o diagnóstico clínico. $1^{\mathrm{a}}$ ed. Curitiba: Editora Maio, 2001. p.251-266.

SINCLAIR, D. C.; WEDDELL, G.; FEINDEL, W. H. Referred pain and associated phenomena. Brain, v. 71, p. 184-211, 1948.

SUDA, H.; IKEDA, T. The circulation of the pulp. In: HARGREAVES, K. M.; GOODIS, H.E. (Eds) Seltzer and Bender's dental pulp. Chicago: Quintessence, 2002. p.123-145.

SVENSSON, P.; BAKKE, M.; MICHLER, L., ARENDT-NIELSEN, L.; MOLLER, E. Trigeminal responses evoked by painful electrical stimulation. J. Oral Rehabil., v. 25, p. $128-134,1998$.

SVENSSON, P.; ARENDT-NIELSEN, L.; BJERRING, P. BAK, P.; HJORTH, T.; TROEST, T. Human mastication modulated by experimental trigeminal and estratrigeminal painful stimuli. J. Oral Rehabil., v. 23, p. 838 - 848, 1996.

TRACEY, I. Nociceptive processing in the human brain. Curr. Opin Neurobiol, v.15, p.478-487, 2005.

TROWBRIDGE, H. O. Review of dental pain: histology and physiology. J. Endod., v.12, n.10, p. 445-452, 1986. 
TRULSSON, M. Sensory-motor function of human periodontal mechanoreceptors. J. Oral Rehabil., v. 33, p. $262-273,2006$.

USUNOFF, K. G.; MARANI, E.; SCHOEN, J. H. R. The trigeminal system in man. New York: Springer, 1997.p.1-118.

VOISIN, D. L.; DOMÉJEAN-ORLIAGUET, S.;CHALUS, M.; DALLEL, R.; WODA, A. Ascending connections from the caudal part to the oral part of the spinal trigeminal nucleus in the rat. Neuroscience., v. 109, n.1, p. 183-193, 2002.

WAITE, P. M. E. Trigeminal sensory system. In: PAXINOS, G. The rat nervous system. $3^{\mathrm{a}}$ ed. Amsterdam: Elsever, 2004. p. 817-851.

WILliS, W. D.; WESTLUND, K. N.; CARLTON, S. M. Pain system. In: PAXINOS, G. The rat nervous system. $3^{\mathrm{a}}$ ed. Amsterdam: Elsever, 2004. p. 853-890.

WODA, A. Pain in the trigeminal system: from orofacial nociception to neural network modeling. J. Dent. Res., v.82, n.10, p. 764-768, 2003.

WRIGHT, E.T. Referred craniofacial pain patterns in patients - with temporomandibular disorder. J. Dent. Assoc., v.131, n.9, p. 1307-1315, 2000.

ZAR, J. H. Two sample hypotheses In: Biostatistical Analysis. 5a ed. New Jersey: Prentice-Hall/Pearson, 2009.p.127. 
ANEXO 
NOME:

SEXO: M F IDADE:

DENTE SINÁLGICO :

$\begin{array}{lllllllllllllllllll}18 & 17 & 16 & 15 & 14 & 13 & 12 & 11 & 21 & 22 & 23 & 24 & 25 & 26 & 27 & 28\end{array}$

$\begin{array}{llllllllllllllll}48 & 47 & 46 & 45 & 44 & 43 & 42 & 41 & 31 & 32 & 33 & 34 & 35 & 36 & 37 & 38\end{array}$

DURAÇÃO DA DOR: segundos minutos ocontínua

HÁ QUANTO TEMPO DÓI? dias meses

INTENSIDADE DA DOR :

0 1 2 $4+5$ 6 7 9 10

FATORES DE MELHORA E PIORA:

Melhora: Piora:

\section{ÁREAS OROFACIAS SINÁLGICAS:}

\section{LADO : DIREITO o ESQUERDO o}

DENTE ALGÓGENO :
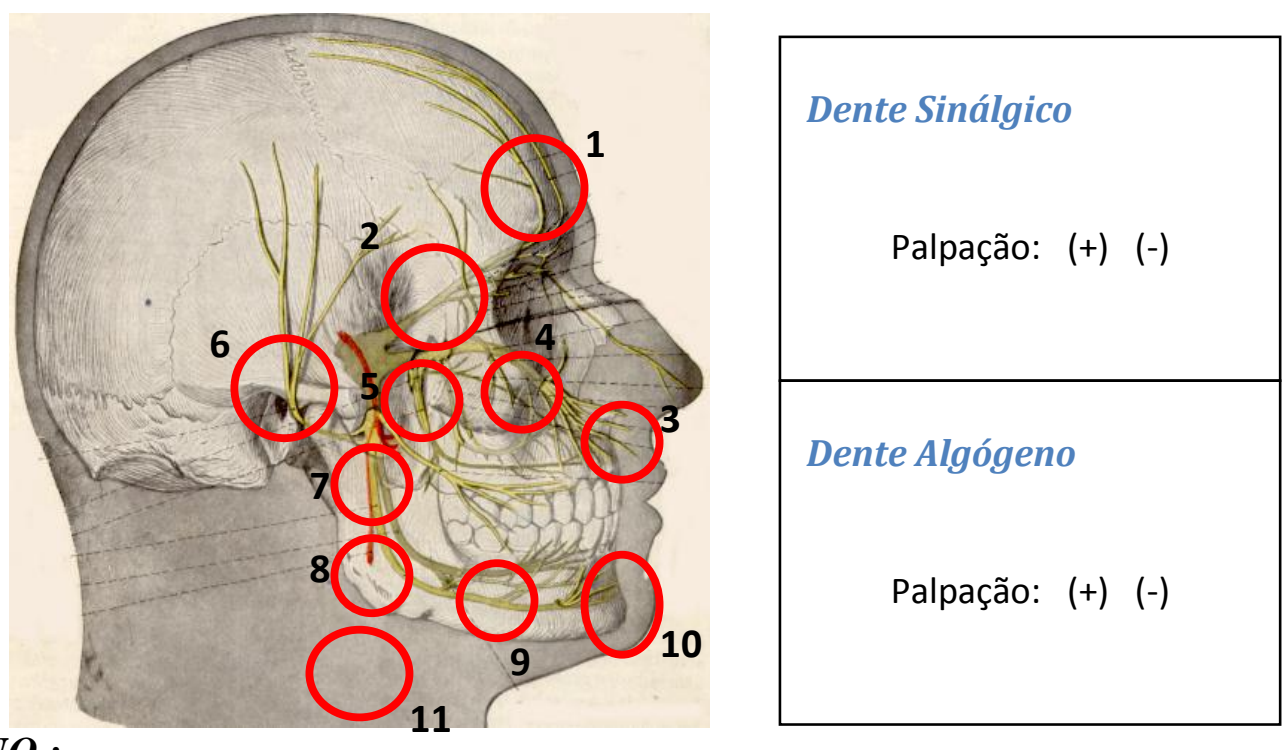

$\begin{array}{llllllllllllllll}18 & 17 & 16 & 15 & 14 & 13 & 12 & 11 & 21 & 22 & 23 & 24 & 25 & 26 & 27 & 28\end{array}$

$\begin{array}{lllllllllllllllll}48 & 47 & 46 & 45 & 44 & 43 & 42 & 41 & 31 & 32 & 33 & 34 & 35 & 36 & 37 & 38\end{array}$

\section{DIAGNÓSTICO CLIINICO PROVÁVEL:}

POLPA VIVA LESÃO REVERSÍVELo TRANSIÇÃOo IRREVERSÍVELo POLPA MORTA SEM LESÃO O COM LESÃO o

OBSERVAÇÕES: 
Instituto de Ciências Biomédicas - USP

\section{Termo de Consentimento Livre e Esclarecido}

Este termo visa esclarecer e obter autorização para participação voluntária na pesquisa "Estudo Topográfico da Dor de Origem Dentária", desenvolvida pela mestranda Milene Camargo Regatão sob orientação do Prof. Marcus Vinicius C. Baldo.

O objetivo do trabalho é conhecer mais detalhadamente alguns tipos, manifestações e características de dores faciais de origem dentária.

Paciente:

A participação consiste em responder um questionário, sendo que não haverá prejuízo de tempo com relação ao atendimento ao qual vim me submeter e que posso me recusar a participar sem perder o direito ao atendimento emergencial. Fui informado que todos os dados obtidos a meu respeito serão sigilosos e poderão ser utilizados em possíveis publicações científicas.

Data: Assinatura do paciente: 
Instituto de Ciências Biomédicas - USP

NOME:

SEXO: M F IDADE:

\section{Parte A: Estímulo Térmico (Frio)}

1) Dente testado:

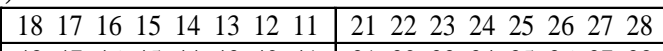
\begin{tabular}{|lllllllll|llllllll|}
\hline 48 & 47 & 46 & 45 & 44 & 43 & 42 & 41 & 31 & 32 & 33 & 34 & 35 & 36 & 37 & 38 \\
\hline
\end{tabular}

Sensação:

$$
1 \_2 \_3 \_4-5 \_6 \_7 \_8 \_9 \_10
$$

Localização:

\begin{tabular}{|llllllll|llllllll|}
\hline 18 & 17 & 16 & 15 & 14 & 13 & 12 & 11 & 21 & 22 & 23 & 24 & 25 & 26 & 27 & 28 \\
\hline 48 & 47 & 46 & 45 & 44 & 43 & 42 & 41 & 31 & 32 & 33 & 34 & 35 & 36 & 37 & 38 \\
\hline
\end{tabular}

Dificuldade de localização: fácil - difícil

Obs:
3) Dente testado:

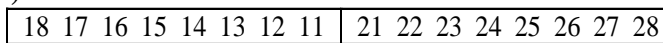
\begin{tabular}{llllllllll|lllllllll}
48 & 47 & 46 & 45 & 44 & 43 & 42 & 41 & 31 & 32 & 33 & 34 & 35 & 36 & 37 & 38 \\
\hline
\end{tabular}

Sensação: $1+2 \_3+4-5+6 \_7-8+9+10$

Localização:

\begin{tabular}{|llllllll|llllllll|}
\hline 18 & 17 & 16 & 15 & 14 & 13 & 12 & 11 & 21 & 22 & 23 & 24 & 25 & 26 & 27 & 28 \\
\hline 48 & 4 & 46 & 45 & 44 & 43 & 42 & 41 & 31 & 32 & 33 & 34 & 35 & 36 & 37 & 88 \\
\hline
\end{tabular} \begin{tabular}{lllllllll|llllllll}
48 & 47 & 46 & 45 & 44 & 43 & 42 & 41 & 31 & 32 & 33 & 34 & 35 & 36 & 37 & 38
\end{tabular}

Dificuldade de localização: fácil - difícil Obs:
2) Dente testado:

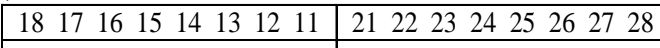

\begin{tabular}{|llllllll|llllllll|}
48 & 47 & 46 & 45 & 44 & 43 & 42 & 41 & 31 & 32 & 33 & 34 & 35 & 36 & 37 & 38 \\
\hline
\end{tabular}

Sensação:

$$
1 \_2 \_3 \_4-5 \_6 \_7 \_8 \_9 \_10
$$

Localização:

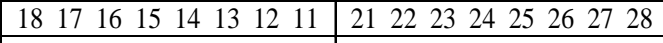

\begin{tabular}{|lllllllllllllllll}
48 & 47 & 46 & 45 & 44 & 43 & 42 & 41 & 31 & 32 & 33 & 34 & 35 & 36 & 37 & 38 \\
\hline
\end{tabular}

Dificuldade de localização: fácil - difícil Obs:
4) Dente testado:

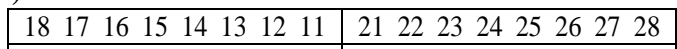
\begin{tabular}{|llllllll|llllllll|}
\hline 48 & 47 & 46 & 45 & 44 & 43 & 42 & 41 & 31 & 32 & 33 & 34 & 35 & 36 & 37 & 38 \\
\hline
\end{tabular}

Sensação: $1 \_2 \_3 \_4-5 \_6 \_7 \_8 \_9 \_10$ Localização:

\begin{tabular}{|llllllll|llllllll|}
\hline 18 & 17 & 16 & 15 & 14 & 13 & 12 & 11 & 21 & 22 & 23 & 24 & 25 & 26 & 27 & 28 \\
\hline 48 & 47 & 46 & 45 & 44 & 43 & 42 & 41 & 31 & 32 & 33 & 34 & 35 & 36 & 37 & 38 \\
\hline
\end{tabular}

Dificuldade de localização: fácil - difícil Obs: 
Instituto de Ciências Biomédicas - USP

Departamento de Fisiologia e Biofísica

Estudo Topográfico da Dor de Origem Dentária

NOME:

SEXO: M F IDADE:

\section{Parte B: Estímulo Mecânico (Controle)}

1) Dente testado:

\begin{tabular}{|llllllll|llllllll|}
\hline 18 & 17 & 16 & 15 & 14 & 13 & 12 & 11 & 21 & 22 & 23 & 24 & 25 & 26 & 27 & 28 \\
\hline 48 & 47 & 46 & 45 & 44 & 43 & 42 & 41 & 31 & 32 & 33 & 34 & 35 & 36 & 37 & 38 \\
\hline
\end{tabular}

Sensação:

Localização:

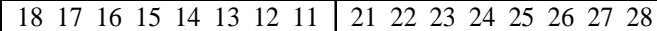
\begin{tabular}{|lllllllll|lllllll|}
\hline 48 & 47 & 46 & 45 & 44 & 43 & 42 & 41 & 31 & 32 & 33 & 34 & 35 & 36 & 37 & 38 \\
\hline
\end{tabular}

Dificuldade de localização: fácil - difícil

Obs:
3) Dente testado:

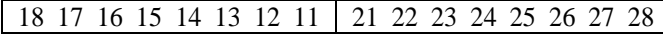
\begin{tabular}{|llllllll|lllllllll}
48 & 47 & 46 & 45 & 44 & 43 & 42 & 41 & 31 & 32 & 33 & 34 & 35 & 36 & 37 & 38 \\
\hline
\end{tabular}

Sensação:

Localização:

\begin{tabular}{|llllllll|llllllll|}
\hline 18 & 17 & 16 & 15 & 14 & 13 & 12 & 11 & 21 & 22 & 23 & 24 & 25 & 26 & 27 & 28 \\
\hline 48 & 47 & 46 & 5 & 44 & 43 & 42 & 4 & 3 & 32 & 33 & 34 & 35 & 36 & 37 & 38 \\
\hline
\end{tabular}

\begin{tabular}{llllllllllllllllllll}
18 & 17 & 16 & 15 & 14 & 13 & 12 & 11 & 21 & 22 & 23 & 24 & 25 & 26 & 27 & 28 \\
\hline 48 & 47 & 46 & 45 & 44 & 43 & 42 & 41 & 31 & 32 & 33 & 34 & 35 & 36 & 37 & 38
\end{tabular}

Dificuldade de localização: fácil - difícil

Obs:
2) Dente testado:

\begin{tabular}{|llllllll|llllllll|}
\hline 18 & 17 & 16 & 15 & 14 & 13 & 12 & 11 & 21 & 22 & 23 & 24 & 25 & 26 & 27 & 28 \\
\hline 48 & 47 & 46 & 45 & 44 & 43 & 42 & 41 & 31 & 32 & 33 & 34 & 35 & 36 & 37 & 38 \\
\hline
\end{tabular}

Sensação:

Localização:

\begin{tabular}{|llllllll|llllllll|}
18 & 17 & 16 & 15 & 14 & 13 & 12 & 11 & 21 & 22 & 23 & 24 & 25 & 26 & 27 & 28 \\
\hline 48 & 4 & 46 & 45 & 44 & 43 & 4 & 41 & 31 & 32 & 33 & 34 & 35 & 36 & 37 & 38 \\
\hline
\end{tabular} \begin{tabular}{|llllllllllllllll|}
48 & 47 & 46 & 45 & 44 & 43 & 42 & 41 & 31 & 32 & 33 & 34 & 35 & 36 & 37 & 38 \\
\hline
\end{tabular}

Dificuldade de localização: fácil - difícil Obs:
4) Dente testado:

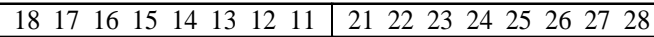

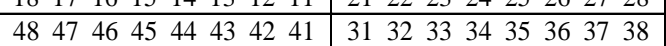

Sensação:

Localização:

\begin{tabular}{|llllllll|llllllll|}
18 & 17 & 16 & 15 & 14 & 13 & 12 & 11 & 21 & 22 & 23 & 24 & 25 & 26 & 27 & 28 \\
\hline 48 & 4 & 46 & 45 & 44 & 4 & 42 & 41 & 31 & 32 & 33 & 34 & 35 & 36 & 37 & 38 \\
\hline
\end{tabular} \begin{tabular}{llllllll|llllllll}
48 & 47 & 46 & 45 & 44 & 43 & 42 & 41 & 31 & 32 & 33 & 34 & 35 & 36 & 37 & 38
\end{tabular}

Dificuldade de localização: fácil - difícil Obs: 
Instituto de Ciências Biomédicas - USP

Departamento de Fisiologia e Biofísica

Estudo Topográfico da Dor de Origem Dentária

NOME:

SEXO: M F IDADE:

\section{Parte C: Percussão Vertical}

1) Dente testado:

\begin{tabular}{|llllllll|llllllll|}
\hline 18 & 17 & 16 & 15 & 14 & 13 & 12 & 11 & 21 & 22 & 23 & 24 & 25 & 26 & 27 & 28 \\
\hline
\end{tabular}

\begin{tabular}{|llllllll|lllllllll}
48 & 47 & 46 & 45 & 44 & 43 & 42 & 41 & 31 & 32 & 33 & 34 & 35 & 36 & 37 & 38 \\
\hline
\end{tabular}

Sensação:

Localização:

\begin{tabular}{|llllllll|llllllll|}
\hline 18 & 17 & 16 & 15 & 14 & 13 & 12 & 11 & 21 & 22 & 23 & 24 & 25 & 26 & 27 & 28 \\
\hline
\end{tabular}

\begin{tabular}{|llllllll|llllllll|}
\hline 48 & 47 & 46 & 45 & 44 & 43 & 42 & 41 & 31 & 32 & 33 & 34 & 35 & 36 & 37 & 38 \\
\hline
\end{tabular}

Dificuldade de localização: fácil - difícil

Obs:
3) Dente testado:

\begin{tabular}{|llllllll|llllllll|}
\hline 18 & 17 & 16 & 15 & 14 & 13 & 12 & 11 & 21 & 22 & 23 & 24 & 25 & 26 & 27 & 28 \\
\hline 48 & 4 & 46 & 4 & 44 & 43 & 42 & 41 & 3 & 32 & 33 & 34 & 35 & 36 & 37 & 38 \\
\hline
\end{tabular}

\begin{tabular}{|llllllllllllllll}
\hline 48 & 47 & 46 & 45 & 44 & 43 & 42 & 41 & 31 & 32 & 33 & 34 & 35 & 36 & 37 & 38
\end{tabular}

Sensação:

Localização:

\begin{tabular}{|llllllll|llllllll|}
\hline 18 & 17 & 16 & 15 & 14 & 13 & 12 & 11 & 21 & 22 & 23 & 24 & 25 & 26 & 27 & 28 \\
\hline 48 & 47 & 46 & 45 & 44 & 43 & 42 & 41 & 31 & 32 & 33 & 34 & 35 & 36 & 37 & 38 \\
\hline
\end{tabular}

Dificuldade de localização: fácil - difícil

Obs:
2) Dente testado:

\begin{tabular}{|llllllll|llllllll|}
\hline 18 & 17 & 16 & 15 & 14 & 13 & 12 & 11 & 21 & 22 & 23 & 24 & 25 & 26 & 27 & 28 \\
\hline 4 & 47 & 46 & 5 & 44 & 43 & 2 & 41 & 31 & 32 & 3 & 34 & 35 & 36 & 37 & 38 \\
\hline
\end{tabular}

\begin{tabular}{|llllllllllllllllll}
48 & 47 & 46 & 45 & 44 & 43 & 42 & 41 & 31 & 32 & 33 & 34 & 35 & 36 & 37 & 38 \\
\hline
\end{tabular}

Sensação:

Localização:

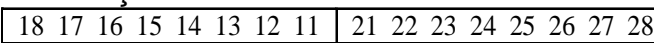

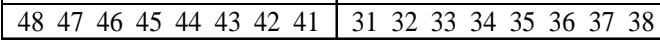

Dificuldade de localização: fácil - difícil

Obs:
4) Dente testado:

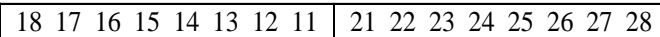

\begin{tabular}{|llllllll|llllllll|}
\hline 48 & 47 & 46 & 45 & 44 & 43 & 42 & 41 & 31 & 32 & 33 & 34 & 35 & 36 & 37 & 38 \\
\hline
\end{tabular}

Sensação:

Localização:

\begin{tabular}{|llllllll|llllllll|}
\hline 18 & 17 & 16 & 15 & 14 & 13 & 12 & 11 & 21 & 22 & 23 & 24 & 25 & 26 & 27 & 28 \\
\hline 48 & 47 & 46 & 45 & 44 & 43 & 42 & 41 & 31 & 32 & 33 & 34 & 35 & 36 & 37 & 38 \\
\hline
\end{tabular}

Dificuldade de localização: fácil - difícil

Obs: 
Instituto de Ciências Biomédicas - USP

Departamento de Fisiologia e Biofísica

Estudo Topográfico da Dor de Origem Dentária

\section{Termo de Consentimento Livre e Esclarecido}

Este termo visa esclarecer e obter autorização para participação voluntária na pesquisa "Estudo Topográfico da Dor de Origem Dentária", desenvolvida pela mestranda Milene Camargo Regatão sob orientação do Prof. Dr. Marcus Vinicius C. Baldo.

O objetivo deste trabalho é conhecer mais detalhadamente a percepção de diferentes estímulos somestésicos pelo elemento dentário.

Paciente:

A participação consiste em responder um questionário depois de me submeter a um teste de sensibilidade dental por estímulos térmico e mecânico. Fui informado que nenhum dos testes executados pode provocar danos ao elemento dentário; que todos os dados obtidos a meu respeito serão sigilosos e poderão ser utilizados em possíveis publicações científicas. As informações aqui contidas são verdadeiras e estou ciente que posso me recusar a participar, em qualquer momento, do projeto de pesquisa.

Data: Assinatura do paciente: 
Instituto de Ciências Biomédicas - USP

Departamento de Fisiologia e Biofísica

Estudo Topográfico da Dor de Origem Dentária

SEXO: $\underline{\mathbf{M}} / \underline{\mathbf{F}} \quad$ IDADE: $\underline{\mathbf{N}}^{\mathbf{0}}$

DENTE SINÁLGICO : pelo $\mathbf{N}^{\circ}$

\begin{tabular}{|llllllllllllllll|l|}
\hline 18 & 17 & 16 & 15 & 14 & 13 & 12 & 11 & 21 & 22 & 23 & 24 & 25 & 26 & 27 & 28 \\
\hline 48 & 47 & 46 & 45 & 44 & 43 & 42 & 41 & 31 & 32 & 33 & 34 & 35 & 36 & 37 & 38 \\
\hline
\end{tabular}

A: $>23$

DURAÇÃO DA DOR: $\underline{\mathbf{N}^{\mathbf{0}} \text { Segundos }}$

$\underline{\mathbf{N}^{0} \text { minutos }} \quad \underline{\text { Contínua }}$

B: $19-23$

C: $9-18$

HÁ QUANTO TEMPO DÓI? $\underline{\mathbf{N}}^{\mathbf{0}} \mathbf{d i a s}$

D: $<8$

INTENSIDADE DA DOR : pelo $\underline{\mathbf{N}}^{\mathbf{0}}$

$0 \_1 \_2 \_3 \_4 \_5 \_6 \_7 \_8 \_9+10$

Fatores de Melhora e Piora (M ou P nestas condições: Frio; Quente; Mastigação;

Outros: escrever)

ÁREAS OROFACIAS SINÁLGICAS:

LADO : DIREITO (D) ESQUERDO (E)

Área pelo №

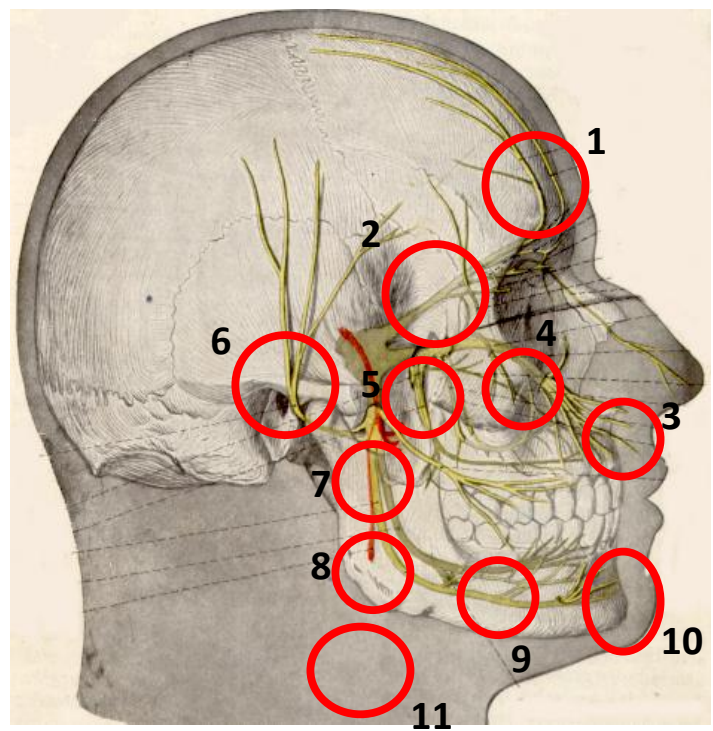

Dente Sinálgico Positivo $S$

$\uparrow$ Negativo $\mathbf{N}$

pelo $n \underline{-}$

Palpação: (+S) (- N)

Dente Algógeno Positivo $S$

$\uparrow$ Negativo $\mathbf{N}$

pelo $n \underline{\text { 은 }}$

Palpação: (+S) (- N)

DENTE ALGÓGENO : pelo $\underline{\mathrm{N}}^{\circ}$

$\begin{array}{lllllllllllllllll}18 & 17 & 16 & 15 & 14 & 13 & 12 & 11 & 21 & 22 & 23 & 24 & 25 & 26 & 27 & 28\end{array}$

$\begin{array}{llllllllllllllll}48 & 47 & 46 & 45 & 44 & 43 & 42 & 41 & 31 & 32 & 33 & 34 & 35 & 36 & 37 & 38\end{array}$

\section{DIAGNÓSTICO CLIINICO PROVÁVEL:}

POLPA VIVA LESÃO REVERSÍVEL(PVR) TRANSIÇÃO(PVT) IRREVERSÍVEL (PVI) POLPA MORTA SEM LESÃO (PMSL) COM LESÃO (PMCL)

OBSERVAÇÕES: se tiver....

Ou simplesmente PV e PM

\begin{tabular}{|c|c|c|}
\hline $0 \mathbf{~ m m}$ & 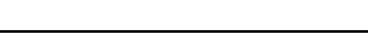 & $-100 \mathrm{~mm}$ \\
\hline nenhuma dor & em milímetros (mm) & dor insuportável \\
\hline
\end{tabular}




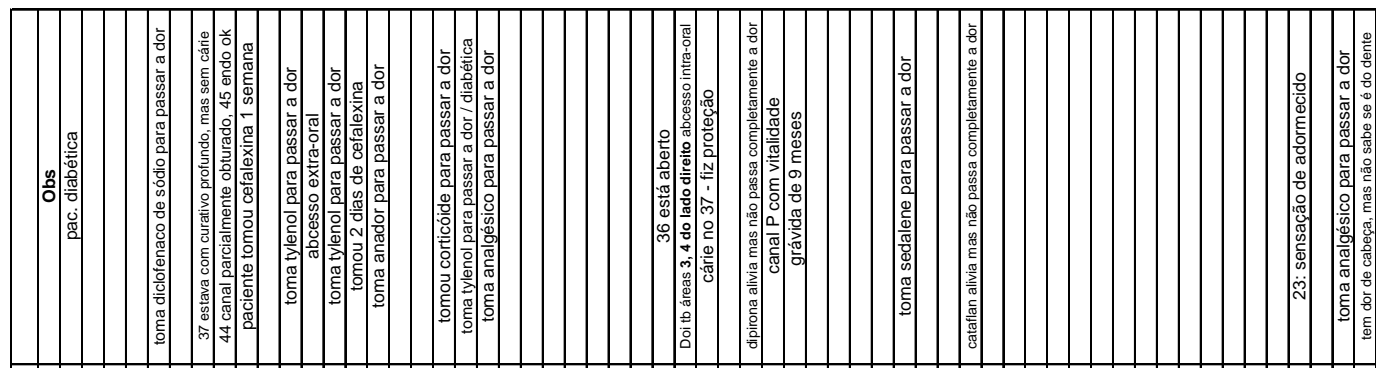

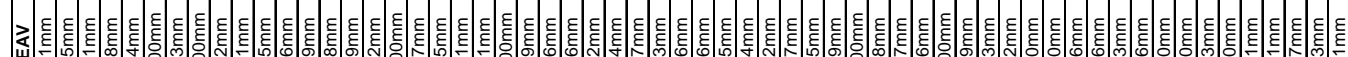

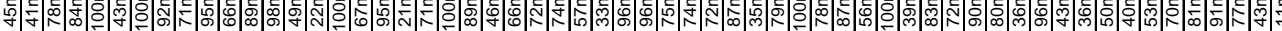

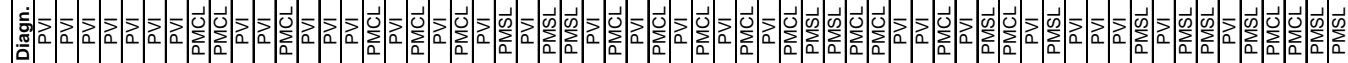

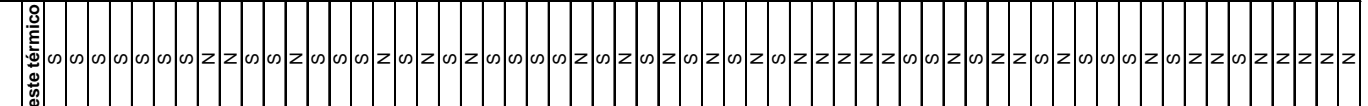

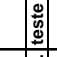

-

:

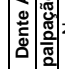

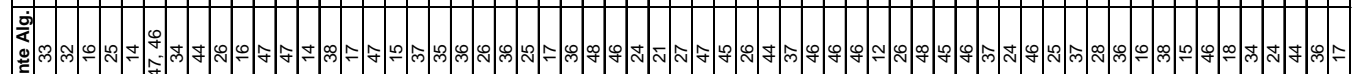

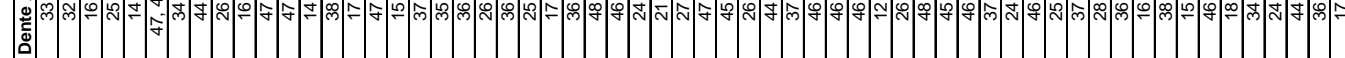

$F \cos \cos \cos \cos z z \cos \cos \cos \cos z \cos z \cos z \cos \cos \cos z \cos z \cos z \cos z \cos z \cos z z z z z \cos z \cos z z \cos z \cos \cos z \cos z z \cos z z z z$

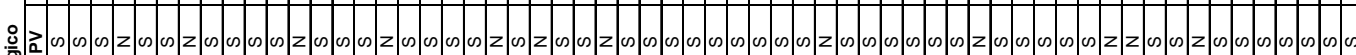

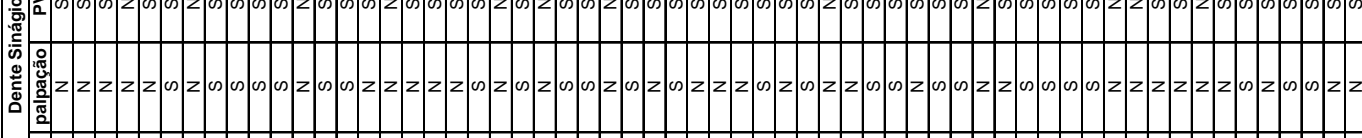

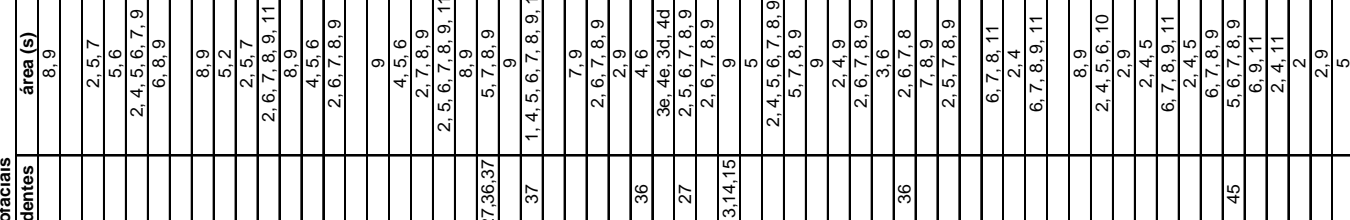

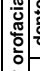

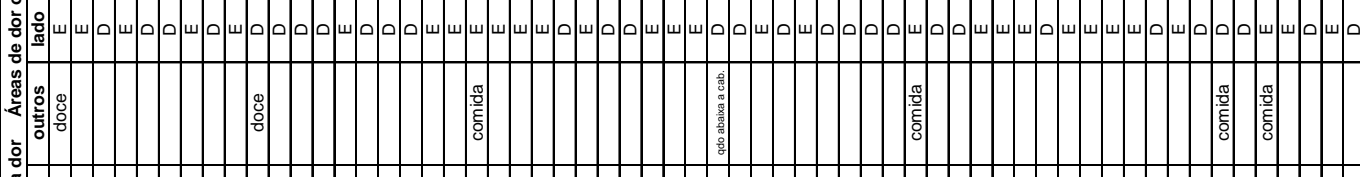

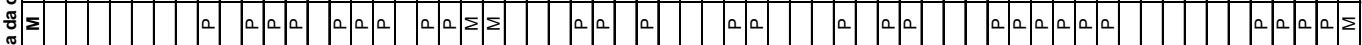

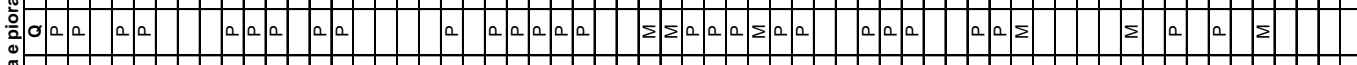

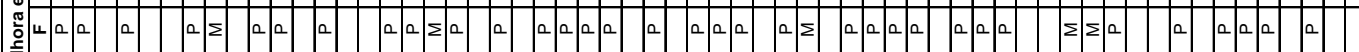

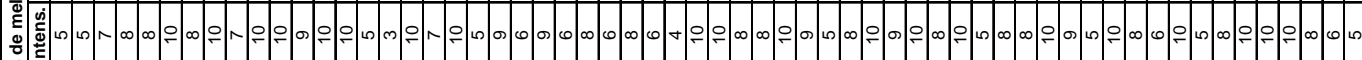

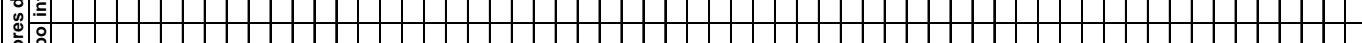

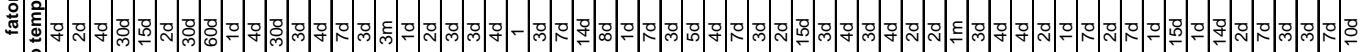

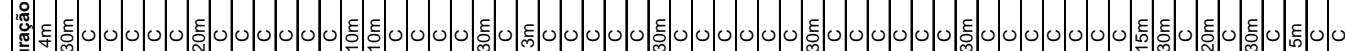
跑

$\frac{2}{2}$

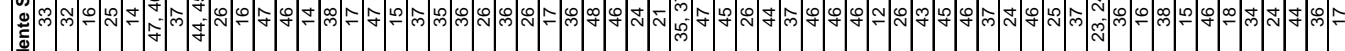

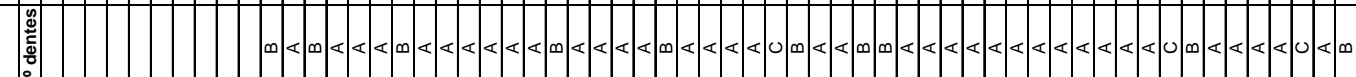

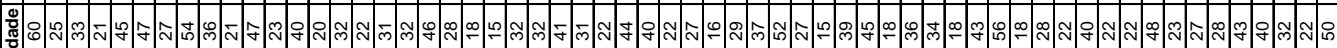

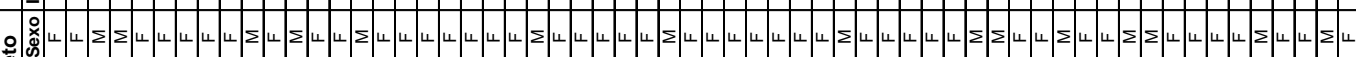

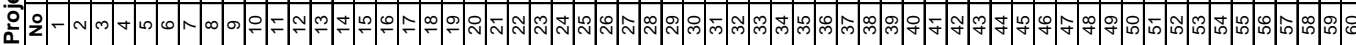




\section{Anexo 9 - Análise por gênero}

Realizamos testes estatísticos para todas as variáveis que foram analisadas para toda a amostra e não encontramos grandes diferenças significativas entre homens e mulheres. Isto é, independentemente do sexo estudado, os resultados obtidos foram os mesmos do que quando analisados juntos homens e mulheres. A seguir, o resumo desta análise:

- Comparando as escalas de dor utilizadas para mensuração da dor, obtivemos uma correlação positiva significativa $(r=0,8 ; \mathrm{p}<0,001$ - coeficiente de correlação de Spearman) tanto no grupo dos homens quanto nos das mulheres;

- Com relação à presença de dor referida (DR), não encontramos diferenças significativas entre homens e mulheres (teste exato de Fisher, bicaudal, $\mathrm{p}=0,1588$;

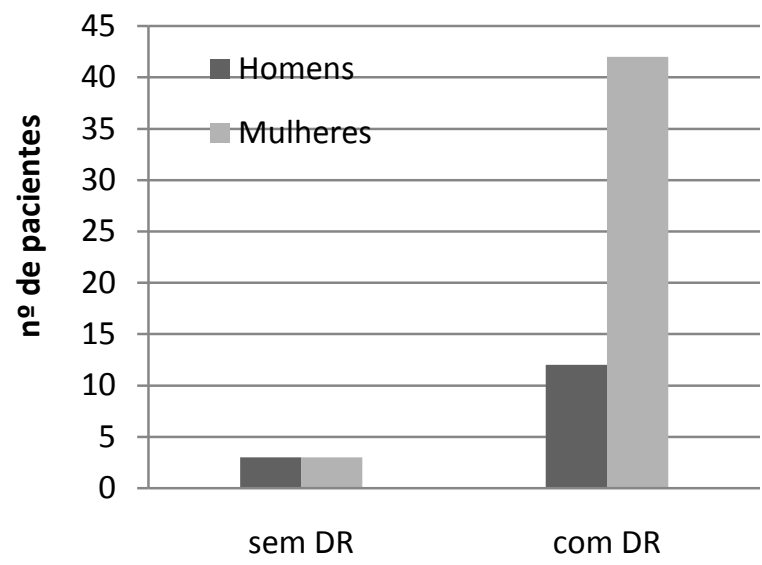

- Quando comparado à intensidade da dor (dividida em dor de "fraca a moderada" e de "moderada a intensa") sentida pelos dois grupos, também não encontramos diferenças significativas entre os sexos (teste exato de Fisher bicaudal $p=0,9969$ ), indicando que homens e mulheres tiveram a mesma proporção de dor "fraca a moderada" e de "moderada a intensa"; 


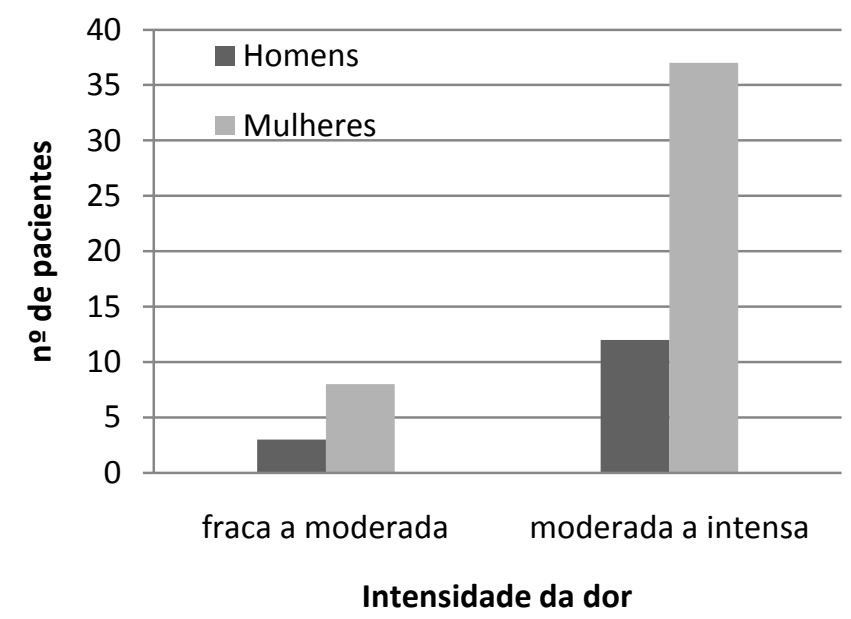

- Também não encontramos diferenças significativas quando comparamos os dois grupos com relação ao número de áreas com dor referida (teste exato de Fisher bicaudal $\mathrm{p}=0,1448)$. Homens e mulheres foram separados em: nenhuma área de dor referida, poucas áreas com dor e muitas áreas com dor e se distribuíram nestas situações em proporções estatisticamente iguais;

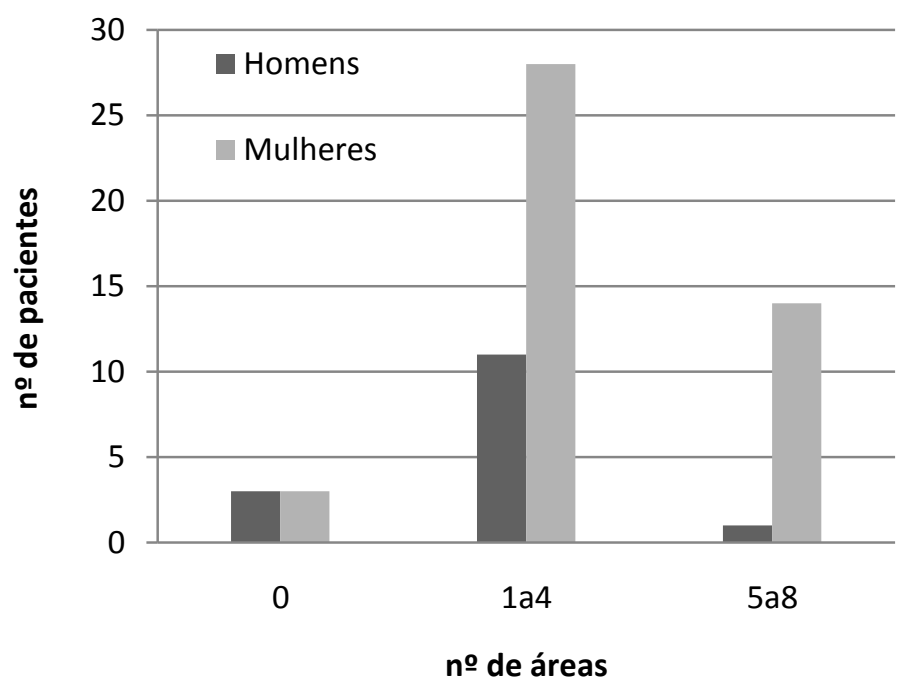

- $\quad$ Obtivemos a mesma proporção de mulheres e homens com diagnóstico de polpa viva (PV) e também de polpa mortificada (PM) (teste exato de Fisher bicaudal $\mathrm{p}=1)$; 


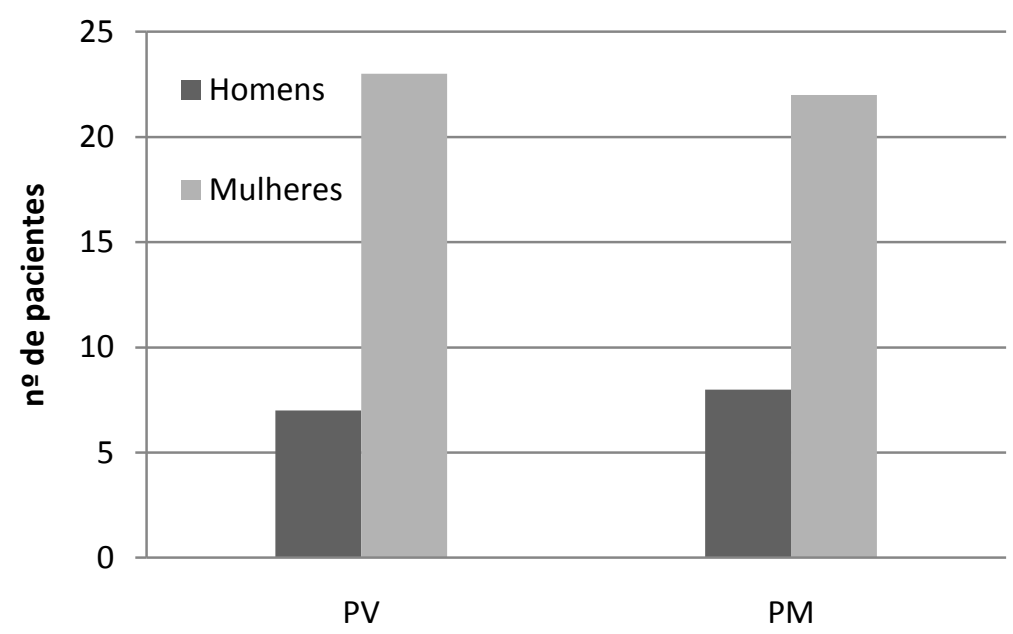

- Apenas encontramos diferenças entre sexos quando analisamos a correlação entre intensidade da dor e número de áreas com dor referida. As mulheres apresentaram uma correlação positiva entre o número de áreas com dor referida e a intensidade da dor ( $\mathrm{r}=$ 0,63 - coeficiente de correlação de Spearman). Quanto maior a intensidade da dor, um maior número de áreas de dor referida era reportado pelas mulheres, resultado este não encontrado no grupo dos homens $(r=0,26-$ coeficiente de correlação de Spearman). 


\section{Anexo 10- Análise por faixa etária}

Não encontramos grandes diferenças significativas entre jovens e adultos quando fizemos as comparações estatísticas realizadas para toda a amostra. Isto é, independentemente da idade, os resultados obtidos foram os mesmos do que quando analisadas todas as faixas etárias em conjunto. A seguir, o resumo desta análise:

- Comparando as escalas de dor utilizadas para mensuração da dor, obtivemos uma correlação positiva significativa $(r=0,8 ; \mathrm{p}<0,001$ - coeficiente de correlação de Spearman) tanto no grupo dos jovens quanto no dos adultos;

- Com relação à presença de dor referida (DR), não encontramos diferenças significativas entre jovens e adultos (teste exato de Fisher, bicaudal, $\mathrm{p}=0,6707$ );

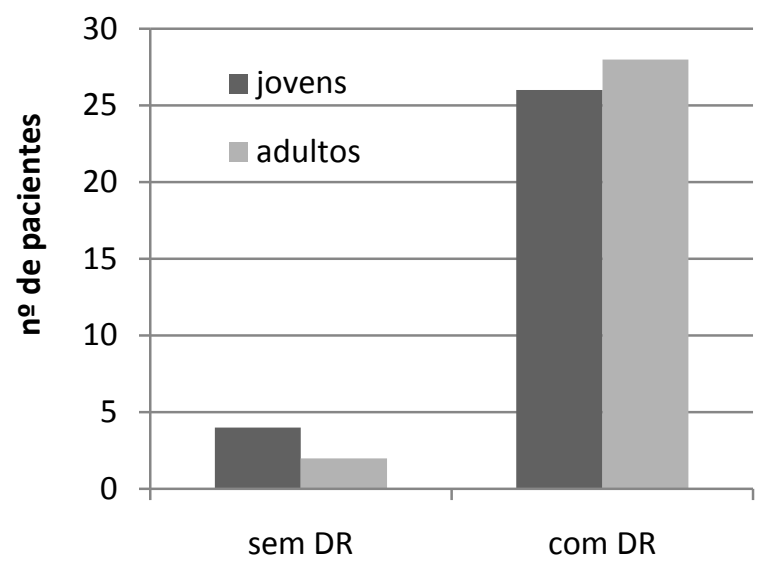

- Quando comparado à intensidade da dor (dividida em dor de "fraca a moderada" e de "moderada a intensa") sentida pelos dois grupos, também não encontramos diferenças significativas entre as faixas etárias (teste exato de Fisher, bicaudal $\mathrm{p}=0,5062$ ), indicando que jovens e adultos tiveram a mesma proporção de dor "fraca a moderada" e de "moderada a intensa"; 


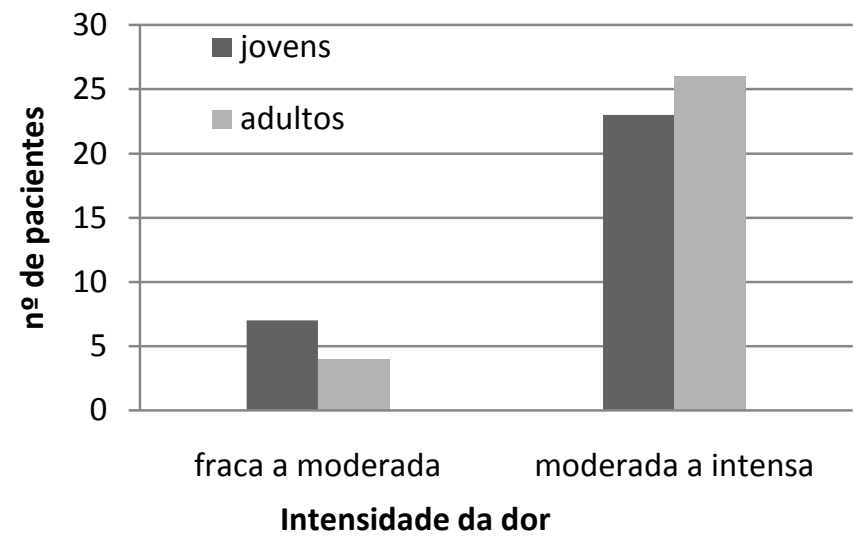

- Também não encontramos diferenças significativas quando comparamos os dois grupos com relação ao número de áreas com dor referida (teste exato de Fisher, bicaudal, $\mathrm{p}=0,5500$ ). Jovens e adultos foram separados em: nenhuma área de dor referida, poucas áreas com dor e muitas áreas com dor e se distribuíram nestas situações em proporções estatisticamente iguais;

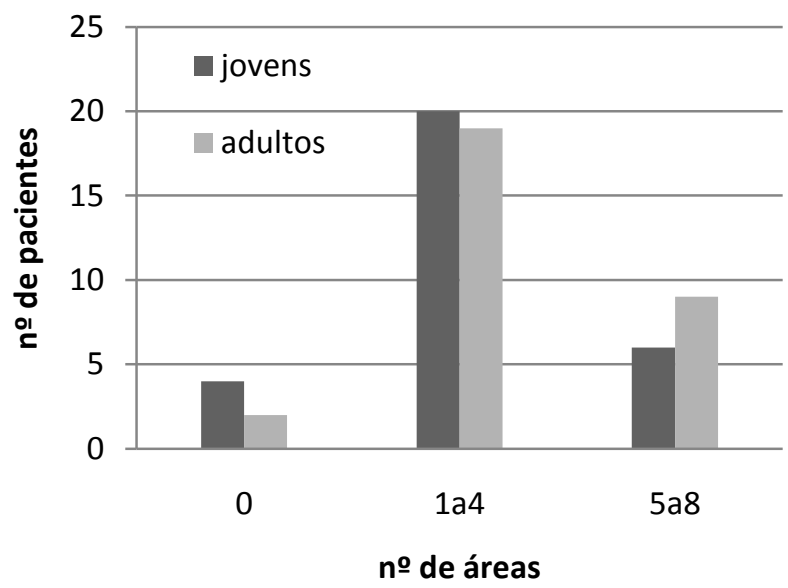

- Não encontramos diferenças entre as faixas etárias quando analisamos a correlação entre intensidade da dor e número de áreas com dor referida. Os jovens apresentaram uma correlação positiva entre o número de áreas com dor referida e a intensidade da dor ( $\mathrm{r}=0,55$ - coeficiente de correlação de Spearman) assim como o grupo dos adultos $(r=0,60$ - coeficiente de correlação de Spearman). Quanto maior a intensidade da dor, um maior número de áreas de dor referida era reportado por ambos os grupos (assim como a análise global dos dados); 
Apenas obtivemos diferença significativa quando analisamos a proporção de diagnóstico de polpa viva e de polpa mortificada entre as faixas etárias estudadas (teste exato de Fisher, bicaudal, p=0,0061). Os jovens apresentaram dentes algógenos com diagnóstico de polpa viva em maior proporção do que os adultos; e os adultos apresentaram dentes algógenos com diagnóstico de polpa morta em maior proporção que os jovens. Este resultado é esperado porque dentes mais velhos têm maior probabilidade de terem sofrido lesões cariosas e traumas que levassem a necrose pulpar.

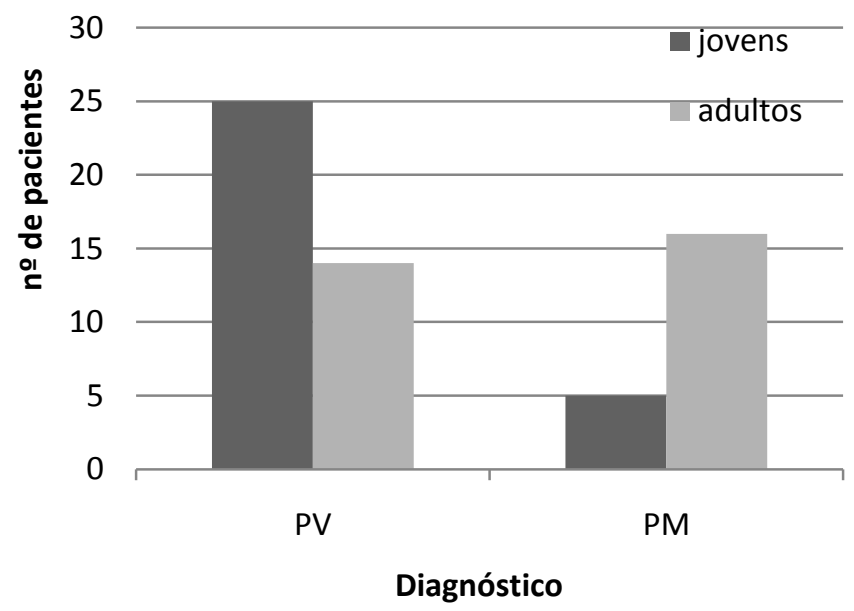

